Universidade de Brasília

Instituto de Ciências Exatas

Departamento de Matemática

Aplicações do Estudo da Derivada no Nível Básico de Ensino Associado à Resolução de Questões de Máximos e Mínimos

\author{
por \\ Maryna de Oliveira Paiva
}




\title{
Aplicações do Estudo da Derivada no Nível Básico de Ensino Associado à Resolução de Questões de Máximos e Mínimos
}

por

\author{
Maryna de Oliveira Paiva *
}

Dissertação apresentada ao Departamento de Matemática da Universidade de Brasília, como parte dos requisitos do "Programa" de Mestrado Profissional em Matemática em Rede Nacional - PROFMAT, para obtenção do grau de

\section{MESTRE}

Brasília, 13 de Março de 2015

Comissão Examinadora:

Dr. Ricardo Ruviaro - UnB - Orientador

Dr. Jhone Caldeira Silva - UFG - Examinador

Dr. Rui Seimetz - UnB - Examinador

*O autor foi bolsista do CAPES durante a elaboração deste trabalho. 
"Mas a educação, com o cultivo da inteligência e com o aperfeiçoamento do campo intimo, em exaltação de conhecimento e bondade, saber $e$ virtude, não será conseguida tão só à força de instrução, que se imponha de fora para dentro, mas sim com a consciente adesão da vontade que, em se consagrando ao bem por si própria, sem constrangimento de qualquer natureza, pode libertar e polir o coração, nele plasmando a face cristalina da alma, capaz de refletir a vida gloriosa e transformar, consequentemente, o cérebro em preciosa usina de energia superior." 


\section{Agradecimentos}

Diante da grandiosidade de Deus e grata à Sua bondade, devo mais esta conquista da minha vida a Ele. Agradeço pela oportunidade de ter obtido esse crescimento intelectual e pela chance de ter acrescentado um pouco mais de conhecimento à minha bagagem espiritual. Também fico feliz em ter a chance de elaborar um trabalho que pode ajudar o próximo no sentido dessa evolução.

Seguido de Deus, agradeço àqueles que nesta vida se fizeram meus parentes mais próximos: minha mãe, Marli Paiva, meu pai, Gilton Paiva, minha irmã, Carolyna Paiva, minha prima, Larissa Mazépas e tantos outros que com muito carinho e alegria me incentivaram a sempre permanecer no caminho dos estudos.

Agradeço também aos meus amigos da MERT e demais grupos espíritas que sempre estiveram ao meu lado. Nesses dois anos se mostraram compreensivos nas minhas ausências quando associadas ao mestrado.

Não posso deixar de citar, nesta sessão, meus companheiros de curso aos quais criei um carinho especial. Amigos que durante esse tempo me acompanharam em dias e noites de estudo, orientações, conversas e cumplicidade. Queria agradecer especialmente ao Douglas Nunes e à Ana Paula Vilarinho, que se mostraram pessoas muito especiais nessa caminhada. Além do Gustavo Candeia, Daniel Klug, Frederico Torres e Marco Dias, pela paciência e disponibilidade em todos os momentos. Guardo os demais em meus pensamentos. Sou grata a todos.

Compartilho também está alegria com os demais amigos, parte dos meus dias, e que por várias vezes me incentivaram ao estudo contínuo. Pessoas como Paula Lins, Daniela Lopes, Guilherme Amaral, Vinícius Pires, entre outros que sempre me apoiaram em todas as minhas decisões. Com o mestrado não seria diferente.

Registro também meu agradecimento a todos os metres que me transmitiram conhecimento nesse período, em especial ao Lineu Neto a se mostrar, além de professor, tantas vezes humano, dando-nos conselhos, estando ao nosso lado e nos incentivando a continuar firme em todos os momentos. Principalmente perto do período do exame de qualificação.

Não poderia deixar de agradecer ao melhor orientador que eu poderia ter: Ricardo Ruviaro. Além 
de ter sido prestativo desde o primeiro momento estruturando minhas ideias, ele também se mostrou preocupado e me ajudou diretamente na confecção desta dissertação. Não teria conseguido sem ele. Digo ser quase um coautor deste trabalho. Muito obrigada.

Por fim, agradeço à CAPES, pelo apoio financeiro, e a todos ao meu redor, minha sincera gratidão. Este trabalho também é de vocês. 


\section{Resumo}

Este trabalho tem como foco o estudo de questões de otimização que podem ser resolvidas tanto pelo método aprendido na Educação Básica (até o Ensino Médio) quanto através de uma nova ferramenta, apresentada e explicada no decorrer da dissertação, chamada derivada.

Ao procurar seguir um encadeamento de raciocínio construtivo e didático, resolveu-se trazer conceitos necessários para fortalecer a base da Matemática. Foram também desenvolvidas várias questões de nível básico utilizando a teoria explorada até então. Assim, trabalhou-se o conceito de derivada seguida de resolução dos mesmos exercícios propostos anteriormente resolvidos agora com a utilização desse novo recurso.

Por fim, propus questões que mostraram de uma forma sutil, porém eficiente, a importância do conceito principal trazido no trabalho associando a necessidade dele ao desenvolvimento do raciocínio. Por meio de uma linguagem de fácil entendimento e acessível a muitos públicos diferentes.

Palavras-Chaves: Função; máximo; mínimo; derivada. 


\section{Abstract}

This work focuses on the study of optimization issues that can be resolved by the methods learned in basic education (through high school) and through a new tool, presented and explained along of the dissertation, called a derivative.

We try to follow a chain of constructive and didactic reasoning, we decided to bring concepts needed to strengthen the foundation of mathematics. Were also developed several basic level issues using the theory explored before. So we worked on the concept of derivative followed by resolution of the same exercises proposed previously solved now with the use of this new approach.

Finally, I suggested questions that showed a subtle but effective way, the importance of the main concept brought in work involving its need for the development of reasoning. Through a language easily understood and accessible to many different audiences.

Key-Words: Function; maximum; minimum; derivative. 


\section{Sumário}

1 Um Breve Apanhado Sobre Algumas Funções Elementares 2

2 Um Estudo Teórico Sobre Pontos Máximos e Minimos de uma Função

3 Aprendendo na Prática Sobre Máximos e Mínimos

4 Outro Método de Resolução de Problemas de Máximos e Mínimos 29

4.1 Regras de Derivação . . . . . . . . . . . . . . . . . . . . . 37

4.2 Derivada como Taxa de Variação . . . . . . . . . . . . . . . . . . . . . . . 41

4.3 Derivadas de Ordem Superior . . . . . . . . . . . . . . . . . . . . . 45

4.4 Máximos e Mínimos . . . . . . . . . . . . . . . . . . . . . . . . . . 45

4.5 Teorema do Valor Médio . . . . . . . . . . . . . . . . . . . . . . . . . . . . 49

4.6 O Teste da Derivada Primeira . . . . . . . . . . . . . . . . . . . 52

4.7 Concavidade e Pontos de Inflexão . . . . . . . . . . . . . . . . . . . . 55

5 Problemas do Ensino Médio sob uma Nova Ótica $\quad 61$

6 A Derivada na Prática $r$

$\begin{array}{lr}\text { Bibliografia } & 83\end{array}$ 


\section{Introdução}

Como docentes, muitas vezes, nos deparamos com o seguinte questionamento "Professor, será que eu posso fazer de outro jeito?". Essa pergunta pode gerar reações diferentes em cada profissional. Em mim, particularmente, desperta uma mistura de curiosidade e emoção ao pensar na gama de caminhos que podem ser desenvolvidos a partir de outros raciocínios.

Resolvi unir essa motivação com um assunto muito recorrente no Ensino Médio e no Ensino Superior. Assim, surgiu a ideia de preparar um material com possibilidade de ser utilizado como base para estudantes de várias idades e níveis de escolaridade. Um conteúdo de fácil contextualização e agradável de ser estudado.

O foco da pesquisa foi questões de otimização, em várias áreas diferentes, que abordam situações de máximos e mínimos. Com relações aos capítulos, para construir um encadeamento de ideias, no primeiro foram abordados conceitos estudados no início do Ensino Médio como função, injetividade, sobrejetividade, bijetividade e exemplos de outros conceitos mencionados.

No segundo, foi trabalhado o tema da dissertação com base no conteúdo visto no Ensino Médio, além de exemplos e outros assuntos necessários no decorrer do trabalho. O terceiro destinou-se à resolução de exercícios de máximos e mínimos utilizando apenas os conceitos estudados no nível básico de formação.

Os capítulos seguintes foram destinados à iniciação da ideia de uma nova ferramenta muito útil não só para a matemática, mas também para outras áreas da ciência. No entanto, esta necessita de um conhecimento mais avançado em relação ao obtido no Ensino Médio. O nome dessa ferramenta é derivada e ela foi cuidadosamente explicada, com muitos exemplos para tornar a construção agradável e simples de ser compreendida.

No quinto capítulo, foram resolvidos os mesmos exercícios do Capítulo 3, porém utilizando derivada. Para finalizar, foram propostas questões aparentemente simples, entretanto que exigem os conceitos recém ensinados.

O intuito deste material não é de defender a implementação da derivada no ensino médio e nem de utilizá-lo como justificativa para isso. Mas é sim de servir de base para o estudo não só daqueles que estiverem aprendendo o conteúdo deste, mas também para os que tiverem curiosidade no assunto. É acreditando em um ensino da Matemática mais agradável e motivador que cada teoria e cada questão foi selecionada para a elaboração desta dissertação. Aproveite. 


\section{Capítulo}

1

\section{Um Breve Apanhado Sobre Algumas Funções Elementares}

Antes de discorrer sobre o principal foco do estudo realizado, é necessária a definição de várias expressões que aparecerão no decorrer do trabalho.

Definição 1.1. Uma função $f: A \rightarrow B$, é uma relação que para cada $x \in A$, associa-se um único $y=f(x) \in B$.

Neste caso, $x$ é chamado variável independente e $y$, variável dependente. Diz-se também que $y$ é uma função de $x$. Note que existe uma "direção" (de $A$ para $B$ ) e que as exigências para que a relação entre os conjuntos $A$ e $B$ sejam uma função recaem sobre os elementos do "conjunto de partida" $A$, nada sendo exigido sobre os elementos do "conjunto de chegada" $B$ a não ser que seja não-vazio.

Plano Cartesiano: Criado por René Descartes, o plano cartesiano consiste em dois eixos perpendiculares, sendo o horizontal chamado de eixo das abscissas e o vertical de eixo das ordenadas. O encontro dos eixos é chamado origem. O plano cartesiano é utilizado no intuito de posicionar pontos e a disposição de seus eixos no plano forma quatro quadrantes. Cada ponto do plano cartesiano é formado por um par ordenado $(x, y)$, onde $x$ é sua abscissa e $y$ sua ordenada.

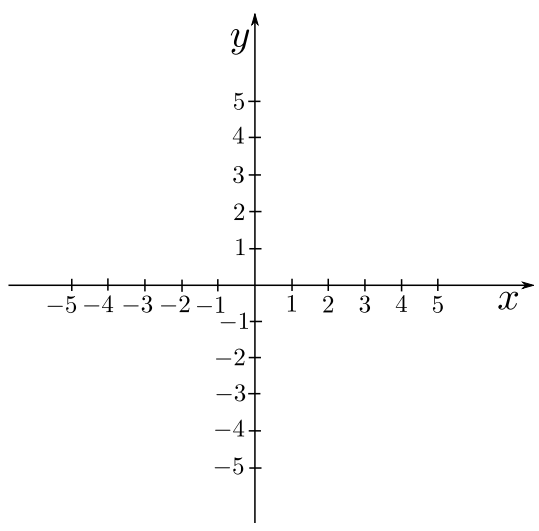

Figura 1.1: Plano Cartesiano 
O sistema de coordenadas cartesianas possui inúmeras aplicações, desde a construção de um simples gráfico, até os trabalhos relacionados à cartografia, localizações geográficas, pontos estratégicos de bases militares ou localização no espaço aéreo, terrestre e marítimo, por exemplo.

O gráfico de uma função $f: D \subset \mathbb{R} \rightarrow \mathbb{R}$ é o conjunto dos pares ordenados em $D \times \mathbb{R}$ da forma $(x, f(x))$, ou seja:

$$
\{(x, f(x)): x \in D\} .
$$

Observação 1.1. Para sabermos se o gráfico de uma curva representa uma função, basta traçarmos retas verticais e verificar se para todos os pontos do dominio elas intersectam o gráfico apenas uma vez. Se para algum valor ela não intersectar ou intersectar mais de uma vez, o gráfico não representa uma função.

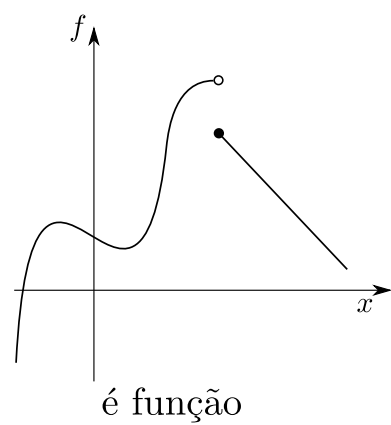

é função

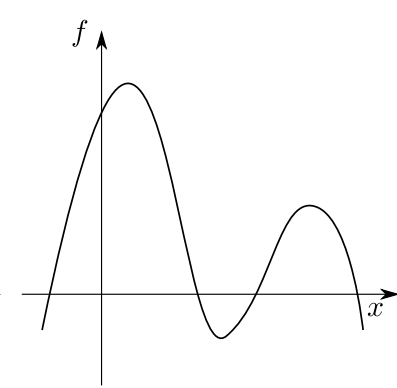

é função

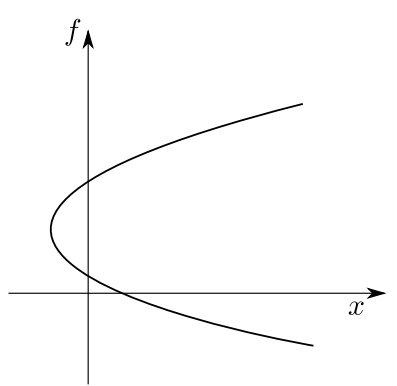

não é função

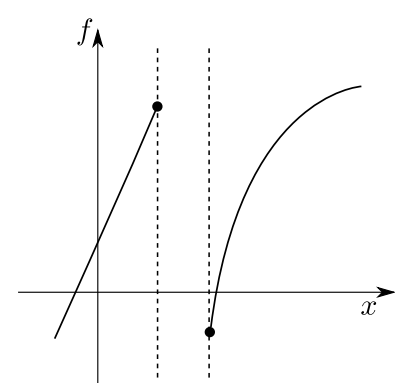

não é função

Figura 1.2: Exemplos de Curvas $f: \mathbb{R} \rightarrow \mathbb{R}$

O domínio de $f: A \rightarrow B$ é o conjunto formado pelos elementos que a variável independente da função pode assumir. Em geral, é representado no eixo $x$ do plano cartesiano e expresso por $D(f)$. Também é considerado o "conjunto de partida" da função.

A imagem de $f: A \rightarrow B$ é o conjunto formado pelos elementos que são correspondentes de um ou mais elementos do domínio, pela função em questão. Em geral, é representado no eixo $y$ do plano cartesiano e expresso por $\operatorname{Im}(f)$.

O contradomínio de $f: A \rightarrow B$ é o conjunto que contém o conjunto imagem de uma função, podendo ou não ser igual a ele. Em geral, é representado no eixo $y$ do plano cartesiano e expresso por $C D(f)$. Também é considerado o "conjunto de chegada" da função.

Em breve serão apresentados vários exemplos que facilitarão o entendimento dos conceitos que acabaram de ser definidos.

Definição 1.2. Uma função $f: A \rightarrow B$ é dita injetora quando para todo par $x_{1}$ e $x_{2}$ de elementos distintos do dominio A, tivermos $f\left(x_{1}\right) \neq f\left(x_{2}\right)$, isto é, se não há elementos distintos em A associados a um mesmo elemento em $B$.

Definição 1.3. Uma função $f: A \rightarrow B$ é dita sobrejetora quando seu conjunto imagem é igual seu contradominio, ou seja, todo elemento de $B$ é imagem de um ou mais elementos de $A$.

Definição 1.4. Uma função $f: A \rightarrow B$ é dita bijetora quando é injetora e sobrejetora simultaneamente.

A seguir, representaremos alguns exemplos de funções, assim como suas classificações com relação às definições abordadas acima. 
Função Constante: Uma função $f: \mathbb{R} \rightarrow \mathbb{R}$ é dita constante, se para todo par de elementos $x_{1}$ e $x_{2}$ do domínio, tivermos $f\left(x_{1}\right)=f\left(x_{2}\right)$. Sua representação gráfica é uma reta paralela ao eixo $x$.

Exemplo: Seja $f: \mathbb{R} \rightarrow \mathbb{R}$ tal que $f(x)=5$.

Dominio: $D(f)=\mathbb{R}$.

Contradomínio: $C D(f)=\mathbb{R}$.

Imagem: $\operatorname{Im}(f)=5$.

Injetora: Não é injetora, pois diferentes valores do domínio possuem a mesma imagem.

Sobrejetora: Não é sobrejetora, pois o contradomínio é diferente da imagem.

Bijetora: Não é bijetora, por não ser simultaneamente injetora e sobrejetora.

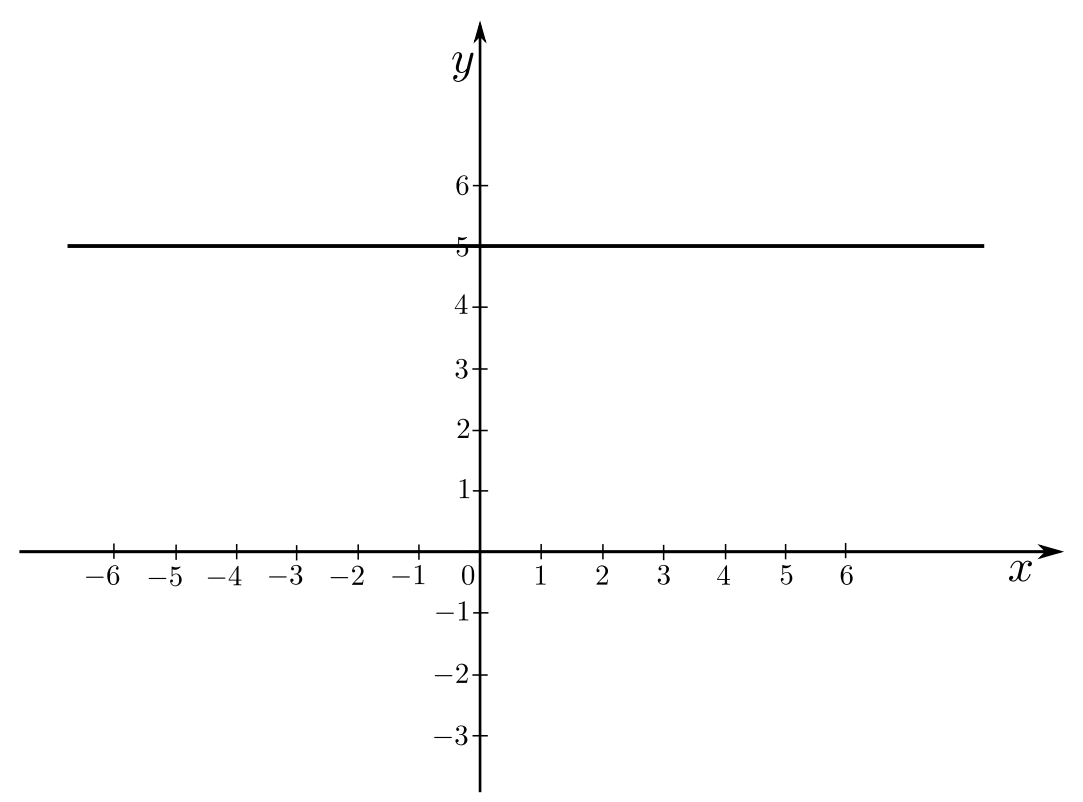

Figura 1.3: Função $f(x)=5$

Função Afim: Uma função $f: \mathbb{R} \rightarrow \mathbb{R}$ é dita afim se segue a lei $f(x)=a x+b$, onde $a$ e $b$ são constantes reais e $a \neq 0$. Sua representação gráfica é uma reta não perpendicular ao eixo $x$. Nesse tipo de função, $a$ é chamado de coeficiente angular e $b$ é chamado de coeficiente linear.

Exemplo: Seja $f: \mathbb{R} \rightarrow \mathbb{R}$ tal que $f(x)=2 x+3$.

Dominio: $D(f)=\mathbb{R}$.

Contradomínio: $C D(f)=\mathbb{R}$.

Imagem: $\operatorname{Im}(f)=\mathbb{R}$.

Injetora: É injetora, pois diferentes valores do domínio associam-se a diferentes imagens.

Sobrejetora: É sobrejetora, pois o contradomínio é igual a imagem.

Bijetora: É bijetora, pois a função é simultaneamente injetora e sobrejetora. 


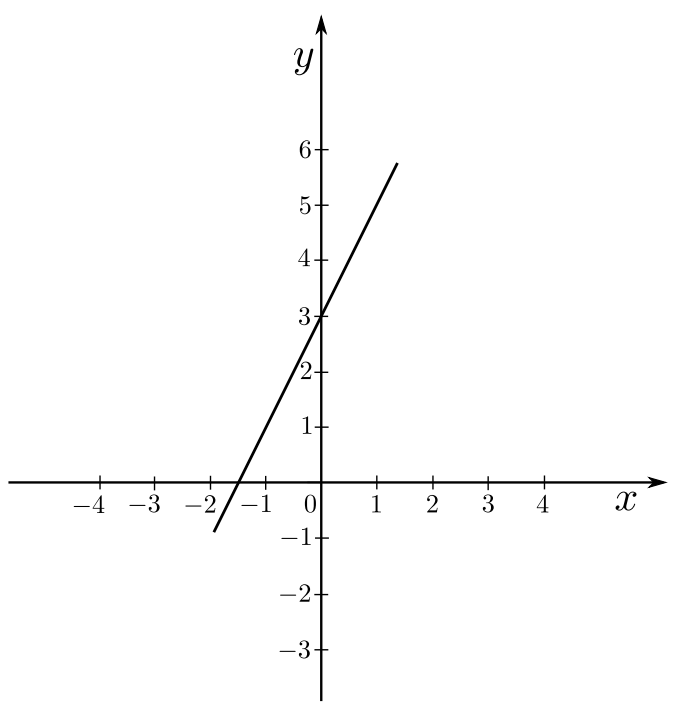

Figura 1.4: Função $f(x)=2 x+3$

Função Quadrática: Uma função $f: \mathbb{R} \rightarrow \mathbb{R}$ é dita quadrática se segue a lei $f(x)=a x^{2}+b x+c$, onde $a, b$ e $c$ são constantes reais e $a \neq 0$. Sua representação gráfica é uma parábola.

Exemplo: Seja $f: \mathbb{R} \rightarrow \mathbb{R}$ tal que $f(x)=x^{2}-5 x+4$.

Domínio: $D(f)=\mathbb{R}$.

Contradomínio: $C D(f)=\mathbb{R}$.

Imagem: $\operatorname{Im}(f)=\left[-\frac{9}{4},+\infty\right)$.

Injetora: Não é injetora, pois diferentes valores do domínio possuem a mesma imagem.

Sobrejetora: Não é sobrejetora, pois o contradomínio é diferente da imagem.

Bijetora: Não é bijetora, por não ser simultaneamente injetora e sobrejetora.

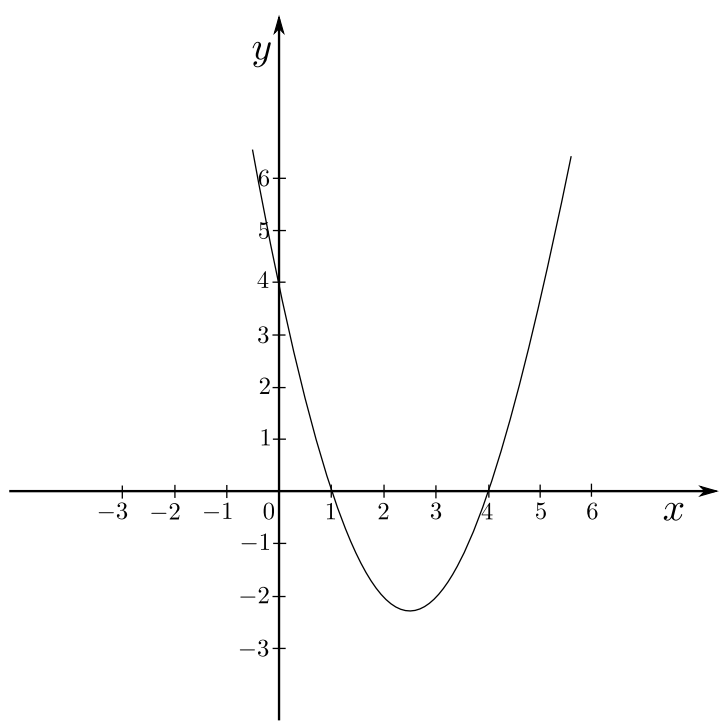

Figura 1.5: Função $f(x)=x^{2}-5 x+4$ 
Função Polinomial do Terceiro Grau: Uma função $f: \mathbb{R} \rightarrow \mathbb{R}$ é dita polinomial do terceiro grau se segue a lei $f(x)=a x^{3}+b x^{2}+c x+d$, onde $a, b, c$ e $d$ são constantes reais e $a \neq 0$.

Exemplo: Seja $f: \mathbb{R} \rightarrow \mathbb{R}$ tal que $f(x)=x^{3}-x^{2}-4 x+4$.

Domínio: $D(f)=\mathbb{R}$.

Contradominio: $C D(f)=\mathbb{R}$.

Imagem: $\operatorname{Im}(f)=\mathbb{R}$.

Injetora: Não é injetora, pois diferentes valores do domínio possuem a mesma imagem.

Sobrejetora: É sobrejetora, pois o contradomínio é igual da imagem.

Bijetora: Não é bijetora, por não ser simultaneamente injetora e sobrejetora.

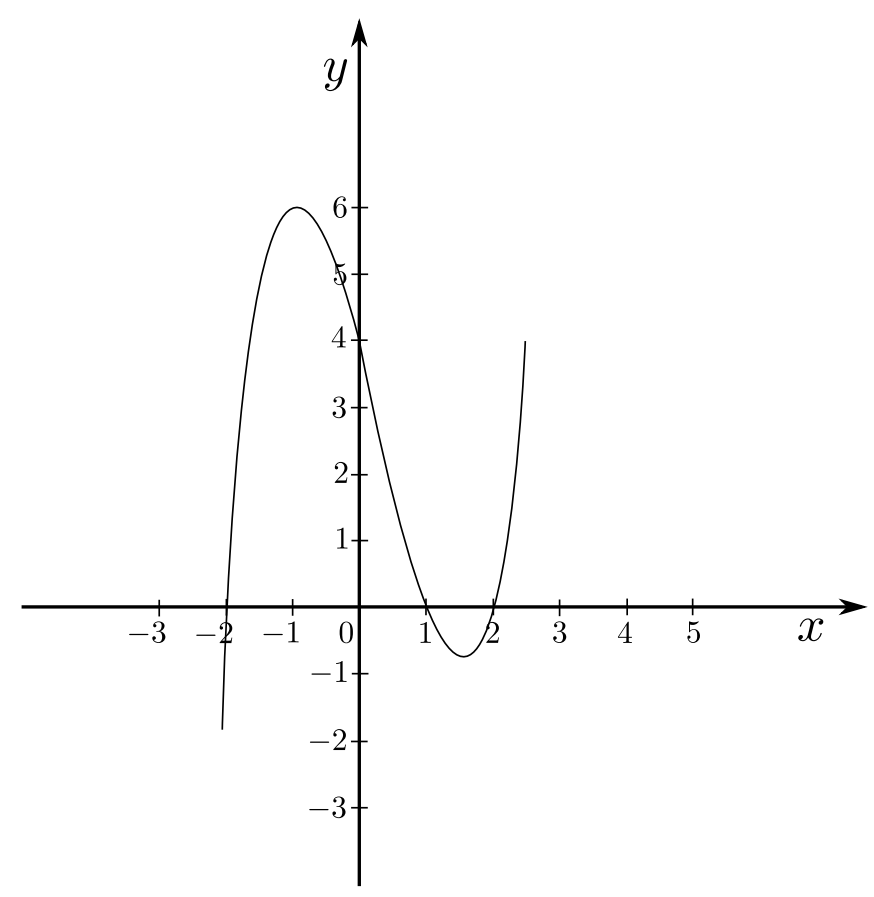

Figura 1.6: Função $f(x)=x^{3}-x^{2}-4 x+4$

Função Exponencial: Uma função $f: \mathbb{R} \rightarrow \mathbb{R}$ é dita exponencial se segue a lei $f(x)=a^{x}$, onde $a \in \mathbb{R}^{+}$e $a \neq 1$.

Exemplo: Seja $f: \mathbb{R} \rightarrow \mathbb{R}$ tal que $f(x)=2^{x}$.

Domínio: $D(f)=\mathbb{R}$.

Contradomínio: $C D(f)=\mathbb{R}$.

Imagem: $\operatorname{Im}(f)=(0,+\infty)$.

Injetora: É injetora, pois diferentes valores do domínio, associam-se a diferentes imagens.

Sobrejetora: Não é sobrejetora, pois o contradomínio é diferente da imagem.

Bijetora: Não é bijetora, por não ser simultaneamente injetora e sobrejetora. 


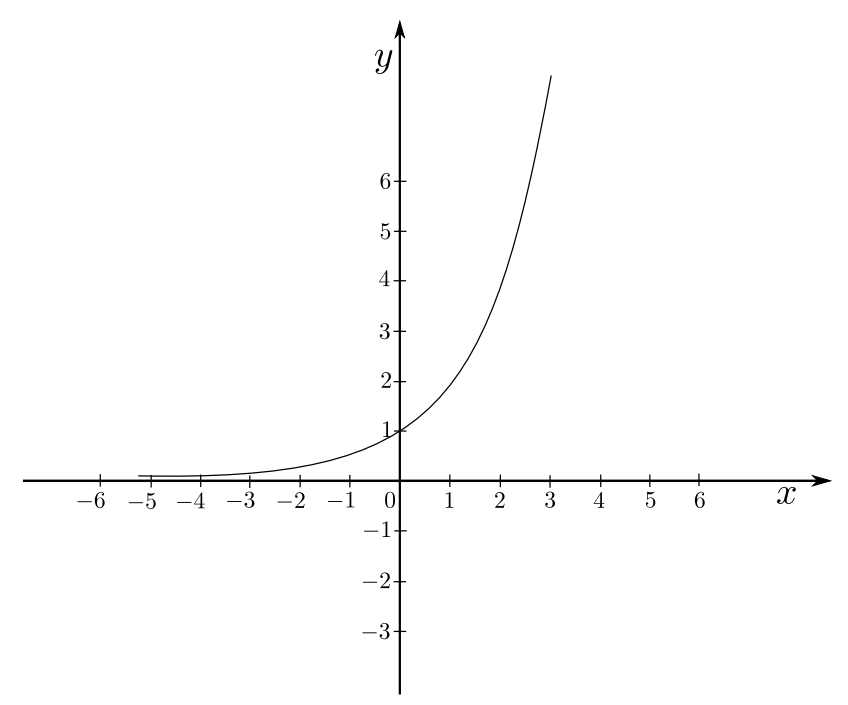

Figura 1.7: Função $f(x)=2^{x}$

\section{Funções Trigonométricas}

Consideraremos a circunferência de raio um e centro na origem do sistema ortogonal de coordenadas, dado como na figura abaixo.

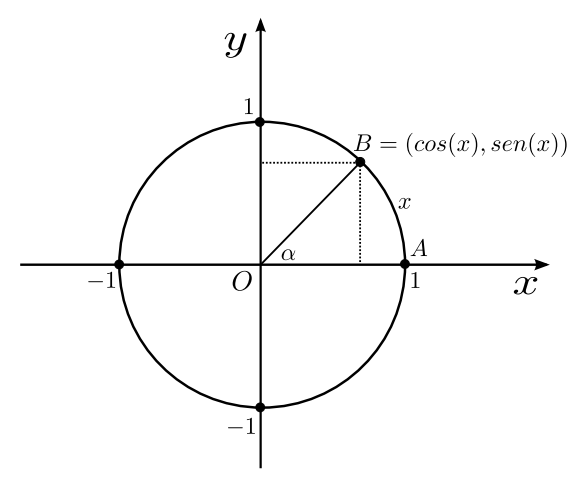

Figura 1.8: Círculo Trigonométrico

Vamos adotar o ponto $A$ como a origem dos arcos sobre a circunferência, e o comprimento x de um arco é positivo quando for obtido a partir de $A$, deslocando-se, no sentido anti-horário e, negativo, se no sentido horário.

Função Seno: Uma função $f: \mathbb{R} \rightarrow \mathbb{R}$ é dita seno se segue a lei $f(x)=a+b \operatorname{sen}(c x+d)$, onde $a, b, c, d \in \mathbb{R}$ e $b, c \neq 0$.

Exemplo: Seja $f: \mathbb{R} \rightarrow \mathbb{R}$ tal que $f(x)=1+3 \operatorname{sen}(x)$.

Domínio: $D(f)=\mathbb{R}$.

Contradomínio: $C D(f)=\mathbb{R}$.

Imagem: $\operatorname{Im}(f)=[-2,4]$.

Injetora: Não é injetora, pois diferentes valores do domínio possuem a mesma imagem.

Sobrejetora: Não é sobrejetora, pois o contradomínio é diferente da imagem. 
Bijetora: Não é bijetora, por não ser simultaneamente injetora e sobrejetora.

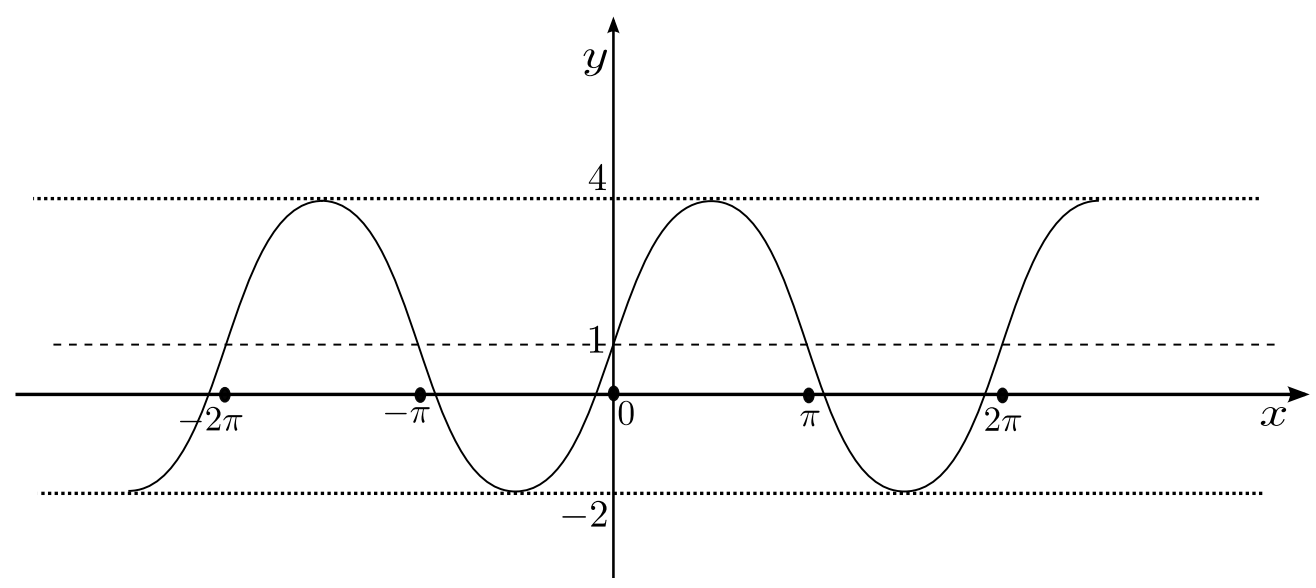

Figura 1.9: $f(x)=1+3 \operatorname{sen}(x)$

Função Cosseno: Uma função $f: \mathbb{R} \rightarrow \mathbb{R}$ é dita cosseno se segue a lei $f(x)=a+b \cos (c x+d)$, onde $a, b, c, d \in \mathbb{R}$ e $b, c \neq 0$.

Exemplo: Seja $f: \mathbb{R} \rightarrow \mathbb{R}$ tal que $f(x)=-2+\cos (2 x)$.

Domínio: $D(f)=\mathbb{R}$.

Contradominio: $C D(f)=\mathbb{R}$.

Imagem: $\operatorname{Im}(f)=[-3,-1]$.

Injetora: Não é injetora, pois diferentes valores do domínio possuem a mesma imagem.

Sobrejetora: Não é sobrejetora, pois o contradomínio é diferente da imagem.

Bijetora: Não é bijetora, por não ser simultaneamente injetora e sobrejetora.

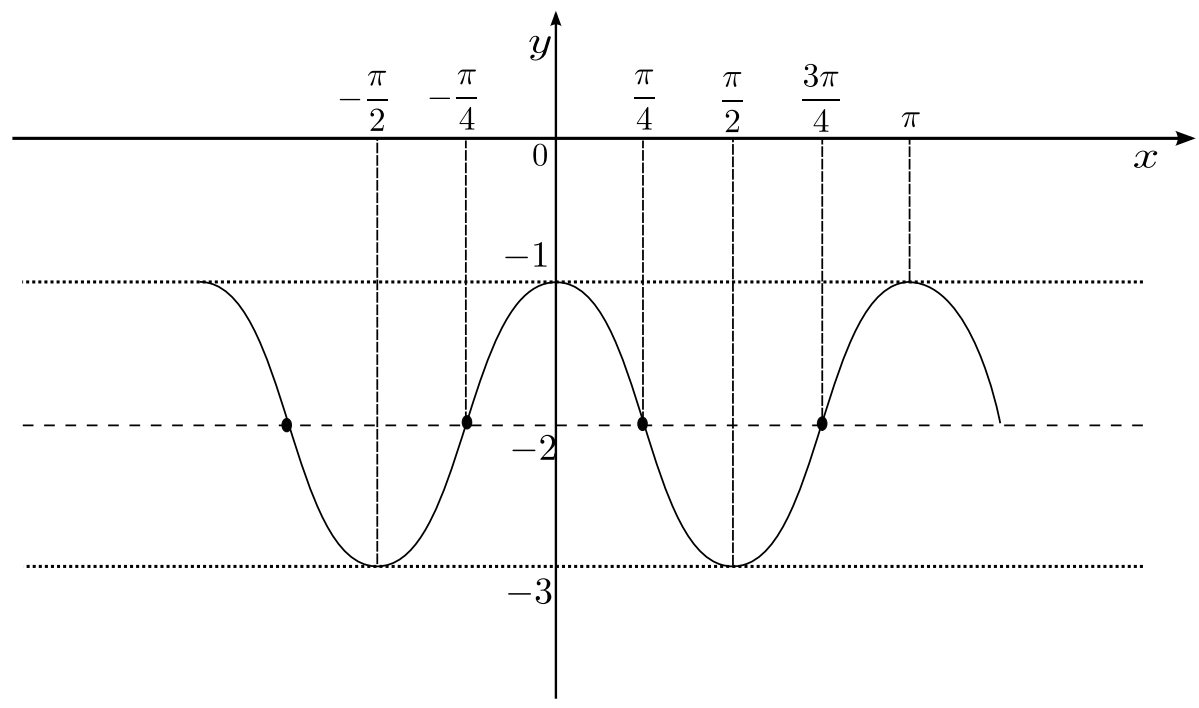

Figura 1.10: $f(x)=-2+\cos (2 x)$ 
Função Logarítmica: Uma função $f: \mathbb{R} \rightarrow \mathbb{R}$ é dita logarítmica se segue a lei $f(x)=\log _{a}(x)$, onde $a>0$ e $a \neq 1$.

Exemplo: Seja $f: \mathbb{R} \rightarrow \mathbb{R}$ tal que $f(x)=\log _{e}(x)=\ln (x)$.

Domínio: $D(f)=\mathbb{R}^{+}$.

Contradominio: $C D(f)=\mathbb{R}$.

Imagem: $\operatorname{Im}(f)=\mathbb{R}$.

Injetora: É injetora, pois diferentes valores do domínio associam-se a diferentes imagens.

Sobrejetora: É sobrejetora, pois o contradomínio é igual a imagem.

Bijetora: É bijetora, pois a função é simultaneamente injetora e sobrejetora.

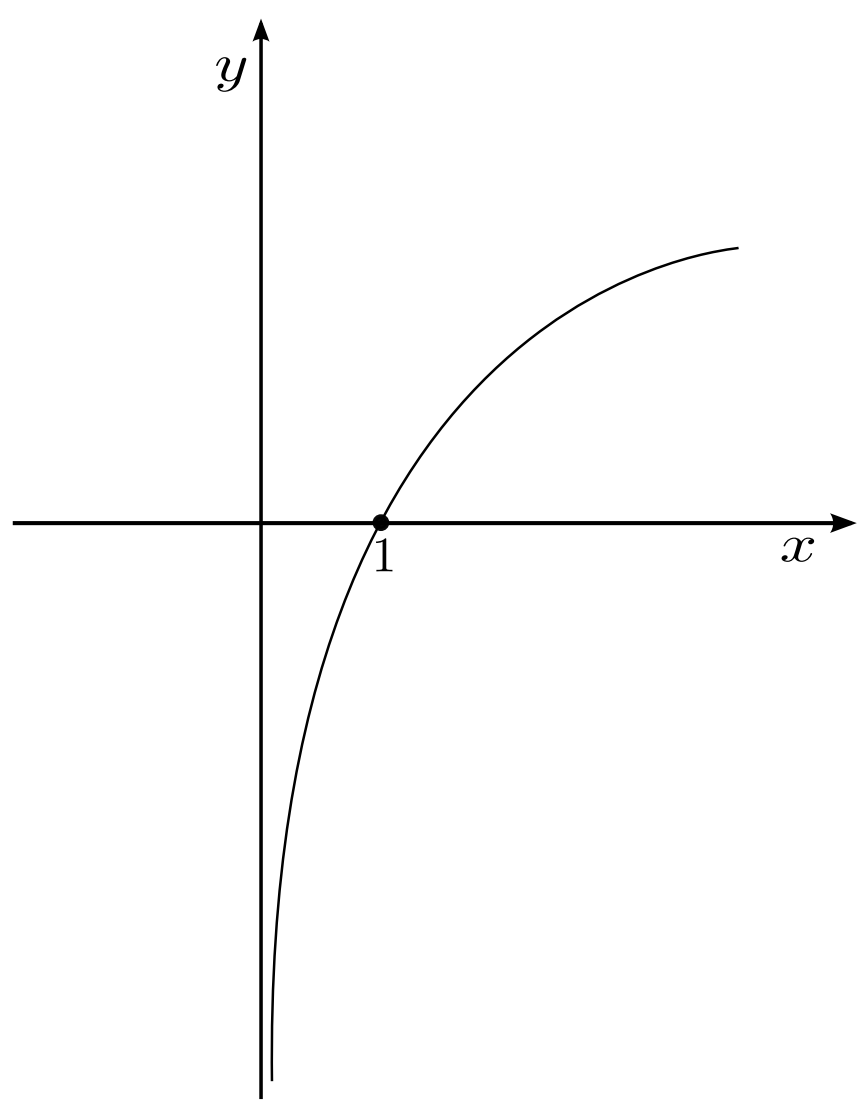

Figura 1.11: $f(x)=\log _{e}(x)=\ln (x)$

\section{Relação de duas variáveis que não representam uma função}

Exemplo: $x^{2}+y^{2}=9$.

Não é uma função, pois existem pontos que pertencem a equação cujas coordenados possuem abscissas iguais e ordenadas diferentes, o que descaracteriza uma função. 


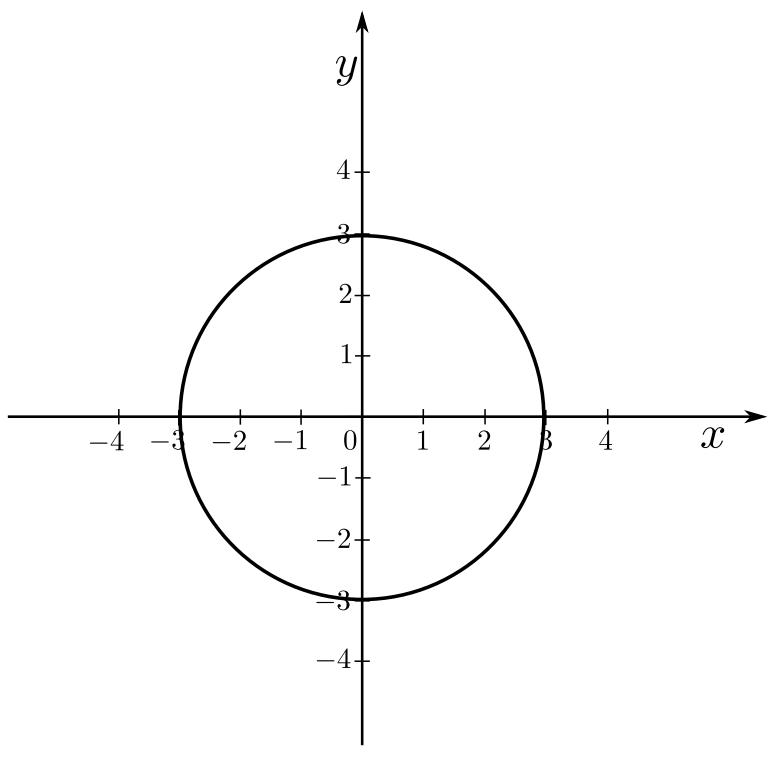

Figura 1.12: Curva $x^{2}+y^{2}=9$

Com os exemplos acima, percebemos que nem toda relação entre duas variáveis caracteriza uma função. Além disso, também observamos que não existe uma relação direta entre uma função ser injetora e sobrejetora, ou seja, uma função pode ser apenas injetora, apenas sobrejetora, não possuir nenhuma das duas classificações ou ainda possuir ambas. 


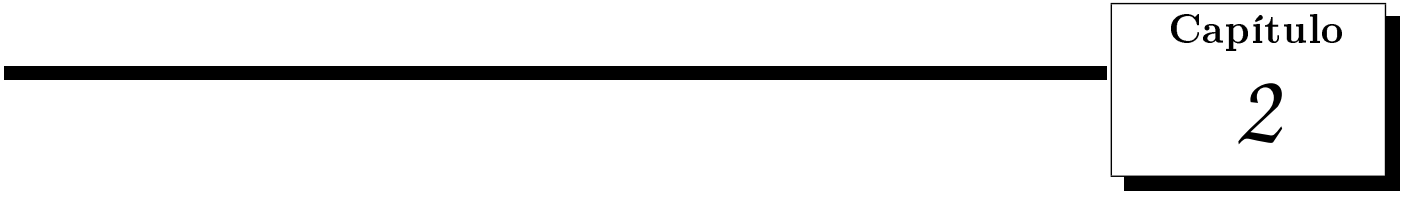 \\ Um Estudo Teórico Sobre Pontos Máximos e Mínimos de uma Função}

Durante todo o Ensino Médio, os alunos se deparam com questões que envolvem o cálculo de valores máximos e mínimos que uma função pode assumir e nem sempre conseguem captar a sua importância e seu leque de possibilidades de resolução. Em alguns casos, é ensinado como resolver um tipo de questão e, como máquinas, eles encontram resultados para diversos problemas sem sequer entender seu sentido ou o que aquele valor realmente significa.

No Brasil, uma introdução ao Cálculo Diferencial e Integral já fez parte do currículo das escolas secundárias por duas vezes, segundo Carvalho (1996): a primeira em 1891, com a reforma proposta por Benjamim Constant no início da República e uma segunda vez, no governo de Getúlio Vargas, na Reforma Capanema, em 1942, constando do currículo escolar oficialmente até 1961. Nas décadas de 60 e 70, o ensino de matemática no Brasil e em outros países foi influenciado pelo movimento da Matemática Moderna e, como consequência, houve a exclusão de alguns conteúdos dos antigos programas, dentre eles o cálculo.

Atualmente, alguns livros do Ensino Médio já apresentam tópicos relativos ao Cálculo Diferencial e Integral, como limite, derivada e integral. Alguns exemplos são os atuais livros adotados pelas escolas públicas do Distrito Federal dos autores: Ênio Silveira, Claudio Marques e Gelson Iezzi. Entretanto, esses temas, na maioria das vezes, não são ensinados sob o pretexto de serem difíceis e impróprios a esse segmento da educação, devendo ficar restritos ao ensino superior. Assim sendo, o Cálculo faz parte do livro didático, mas não do currículo do Ensino Médio.

Considerando o enunciado de três exercícios que serão expostos abaixo, levantam-se algumas questões:

(i) Será única a forma de resolver cada um desses problemas?

(ii) Será que no Ensino Médio é passada a forma mais eficiente de resolvê-los?

(iii) Não seria possível resolver esses e outros tipos de problema a partir de outra técnica?

Problema 2.1. $O$ custo $C$ de um produto fabricado por uma cooperativa agricola, em milhares de reais, é dado pela função $C(x)=6 x-4$, onde $x$ está em milhares de unidades. Verificou-se que o faturamento de venda desses produtos, também em milhares de reais, é dado pela função $F(x)=-x^{2}+9 x$. Sendo assim, calcule o lucro máximo que essa empresa pode ter. 
Problema 2.2. Comparando todos os retângulos que podem ser construídos dobrando-se um arame de $50 \mathrm{~cm}$, quanto vale, em $\mathrm{cm}^{2}$, a área máxima que pode ser demarcada?

Problema 2.3. Deseja-se construir uma caixa sem tampa a partir de uma folha quadrada de lado $30 \mathrm{~cm}$ da seguinte maneira: serão retirados quatro quadrados de lados " $x$ " centímetros, um de cada extremidade e em seguida serão dobradas as partes que sobraram obtendo assim a caixa desejada. De quanto deve ser o lado desses quadrados que serão retirados para que o volume da caixa criada seja o maior possivel?

Essas perguntas serão respondidas no decorrer do trabalho. Porém, é necessário apresentarmos algumas outras definições antes de entrarmos no assunto de máximos e mínimos de funções.

Note que no Capítulo 1, em todos os exemplos dados, foram definidos seus domínios e contradomínios. No entanto, é importante mencionar que em exercícios contextualizados, em geral, essa prática não é adotada, pois podemos inferir do próprio contexto quais seriam os possíveis valores reais para tornar aquela situação possível de existir através da discusão das soluções que de fato fatisfazem o problema.

Definição 2.1. Uma função $f: \mathbb{R} \rightarrow \mathbb{R}$ é dita crescente se para todo par de elementos $x_{1}$ e $x_{2}$ do dominio, com $x_{1}<x_{2}$, tivermos $f\left(x_{1}\right) \leq f\left(x_{2}\right)$.

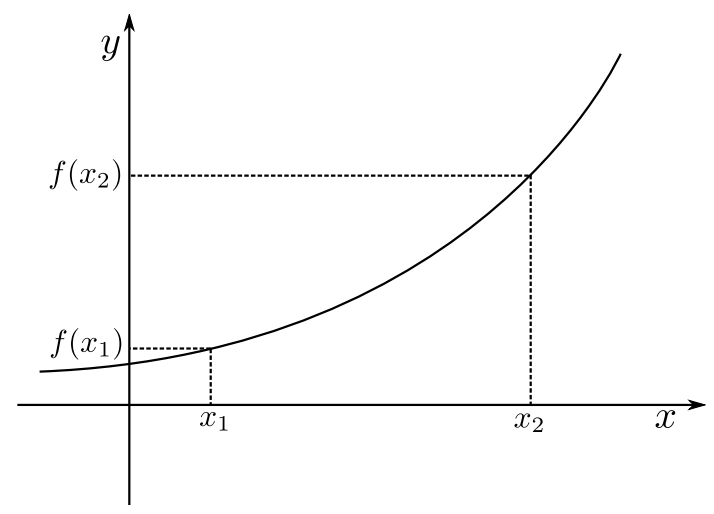

Figura 2.1: Função Crescente

Definição 2.2. Uma função $f: \mathbb{R} \rightarrow \mathbb{R}$ é dita decrescente se para todo par de elementos $x_{1}$ e $x_{2}$ do dominio, com $x_{1}<x_{2}$, tivermos $f\left(x_{1}\right) \geq f\left(x_{2}\right)$.

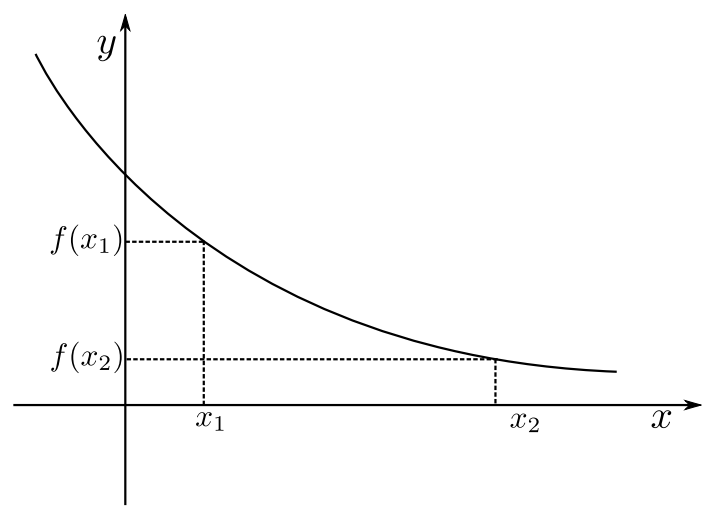

Figura 2.2: Função Decrescente 
A monotonicidade de uma função, estuda a relação entre os valores das coordenadas de pontos distintos desta função.

Uma função $f: \mathbb{R} \rightarrow \mathbb{R}$ é dita monótona crescente, ou estritamente crescente, se para todo par de elementos $x_{1}$ e $x_{2}$ do domínio, com $x_{1}<x_{2}$, tivermos $f\left(x_{1}\right)<f\left(x_{2}\right)$.

Uma função $f: \mathbb{R} \rightarrow \mathbb{R}$ é dita monótona decrescente, ou estritamente decrescente, se para todo par de elementos $x_{1}$ e $x_{2}$ do domínio, com $x_{1}<x_{2}$, tivermos $f\left(x_{1}\right)>f\left(x_{2}\right)$.

Uma função $f: \mathbb{R} \rightarrow \mathbb{R}$ é dita contínua quando seu gráfico não apresenta interrupção, ou seja, uma função que tem um gráfico que pode ser desenhado de modo interrupto.

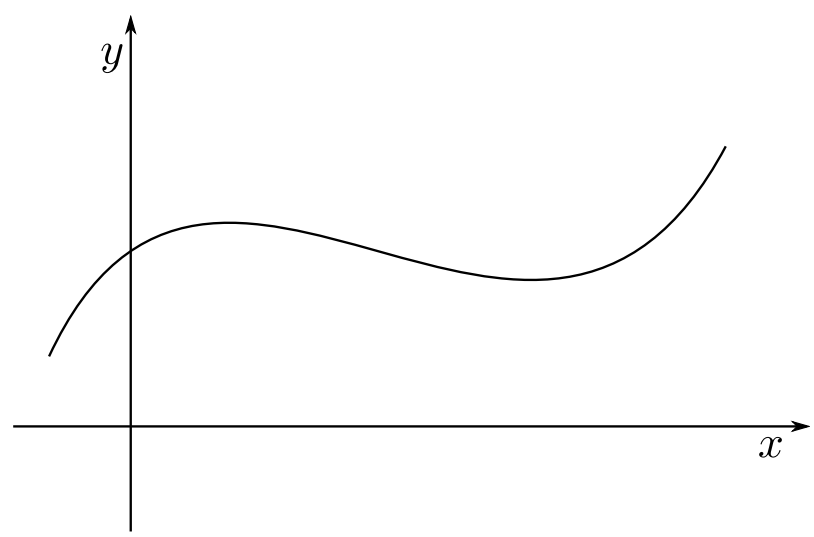

Figura 2.3: Função Contínua

Definição 2.3. Uma função $f: D \subset \mathbb{R} \rightarrow \mathbb{R}$ é dita limitada em seu domínio, quando sua imagem está toda contida em um intervalo, ou seja, $\operatorname{Im}(f) \subset[a, b]$, onde $a, b \in \mathbb{R}$.

Considerando uma função $f: D \subset \mathbb{R} \rightarrow \mathbb{R}$, dizemos que um valor $f(a)$ é um máximo local ou relativo de $f$ se existe um intervalo aberto $(c, d)$ contendo $a$, tal que $f(x) \leq f(a)$, para todos os valores de $x$ pertencentes à $(c, d)$, onde $(c, d) \subset D(f)$. Analogamente, dizemos que um valor $f(b)$ é um mínimo local ou relativo de $f$ se existe um intervalo aberto $(c, d)$ contendo $b$, tal que $f(x) \geq f(b)$, para todos os valores de $x$ pertencentes à $(c, d)$, onde $(c, d) \subset D(f)$.

Considerando uma função $f: D \subset \mathbb{R} \rightarrow \mathbb{R}$, dizemos que o valor $f(a)$ é um máximo global se $f(x)<f(a)$ para todos os valores de $x$ pertencentes a $D(f)$. Analogamente, dizemos que o valor $f(b)$ é um mínimo global se $f(x)>f(b)$, para todos os valores de $x$ pertencentes ao $D(f)$.

Observação 2.1. Toda função contínua e limitada em um intervalo fechado $[a, b]$ possui um valor máximo e um valor minimo global respectivamente.

Observação 2.2. Uma definição formal do conceito de continuidade será apresentado no Capítulo 4.

Considere o gráfio abaixo que representa uma função genérica, cujo domínio é o intervalo $[a, b]$.

Os valores da função em $P_{1}, P_{3}$ e $P_{5}$ são os maiores para os pontos do gráfico próximos a estes. Então esses são chamados máximos locais. Em $P_{0}, P_{2}$ e $P_{4}$, os valores da função são os menores para pontos do gráfico próximos a estes. Então esses são chamados mínimos locais. Além disso o ponto $P_{3}$ é definido como máximo global e o ponto $P_{2}$ é definido com mínimo global. Note que a função é crescente nos intervalos $\left[a, x_{1}\right),\left(x_{2}, x_{3}\right),\left(x_{4}, b\right]$ e é decrescente em $\left(x_{1}, x_{2}\right)$ e $\left(x_{3}, x_{4}\right)$. 


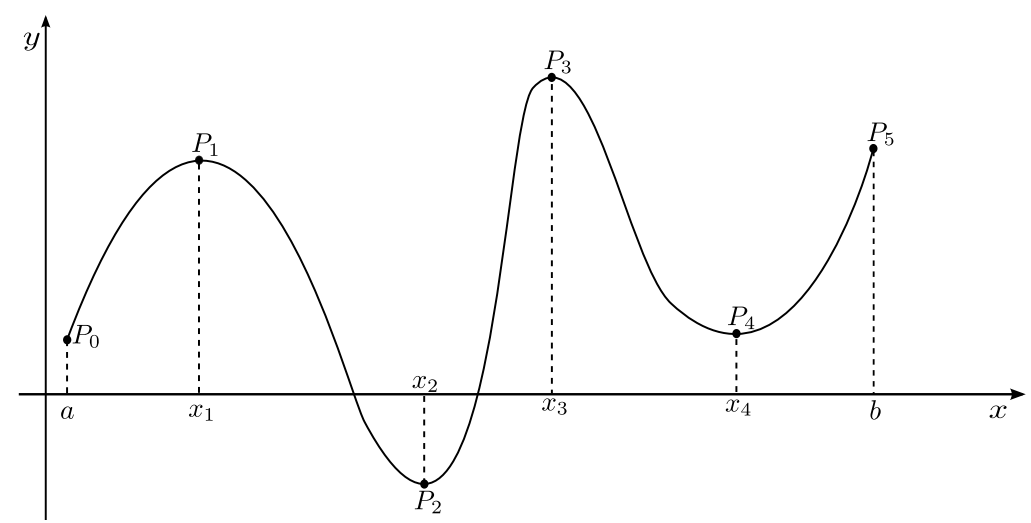

Figura 2.4: Máximos e Mínimos

Algumas observações sobre máximos e mínimos de funções.

(1) Nem toda função possui máximos e mínimos. De fato consideramos as funções $f:(1,8) \rightarrow(1,8)$ dada por $f(x)=x$ e $g: \mathbb{R} \rightarrow \mathbb{R}$ dada por $g(x)=e^{x}$, notamos que essas funções não possuem pontos de máximo e nem de mínimo, conforme ilustrado nos gráficos a seguir
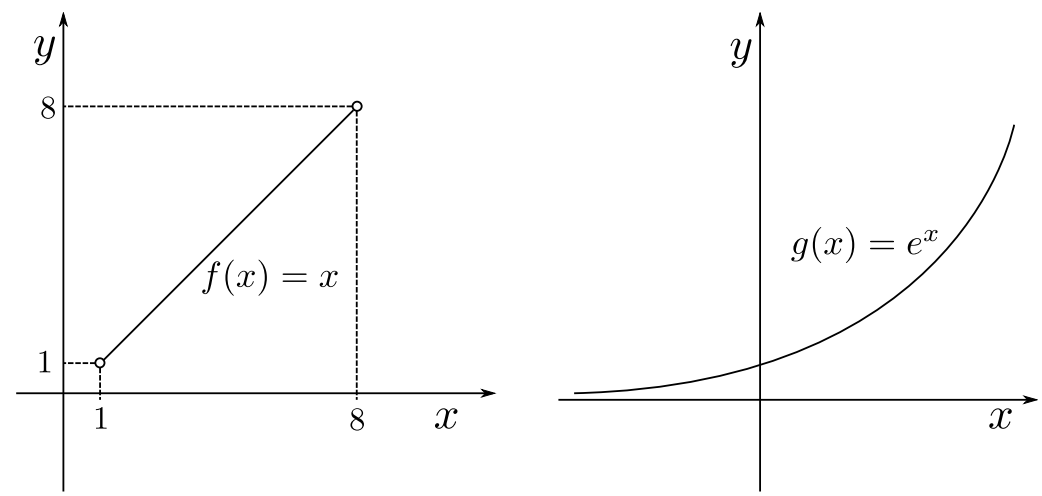

Figura 2.5: Gráfico das Funções

(2) Nem toda função possui simultaneamente máximo e mínimo. De fato consideramos as funções $f: \mathbb{R} \rightarrow \mathbb{R}$ dada por $f(x)=x^{2}$ e $g: \mathbb{R} \rightarrow \mathbb{R}$ dada por $g(x)=-x^{2}$, notamos que essas funções possuem apenas ponto de máximo e mínimo global respectivamente, como é ilustrado nos gráficos a seguir
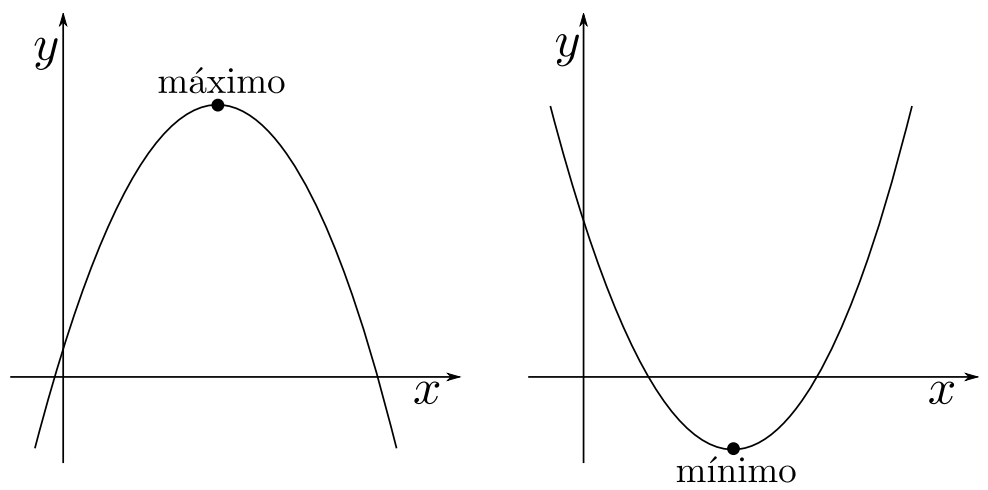

Figura 2.6: Máximo e Mínimo 
(3) Nem toda função possui máximo ou mínimo global, de fato, considere a função $: \mathbb{R} \rightarrow \mathbb{R}$ dada por $f(x)=x^{3}-x^{2}-4 x+4$, esta função possui ponto de máximo e mínimo local, contudo, não possui pontos de máximo e mínimo global, como visualizado na figura a seguir

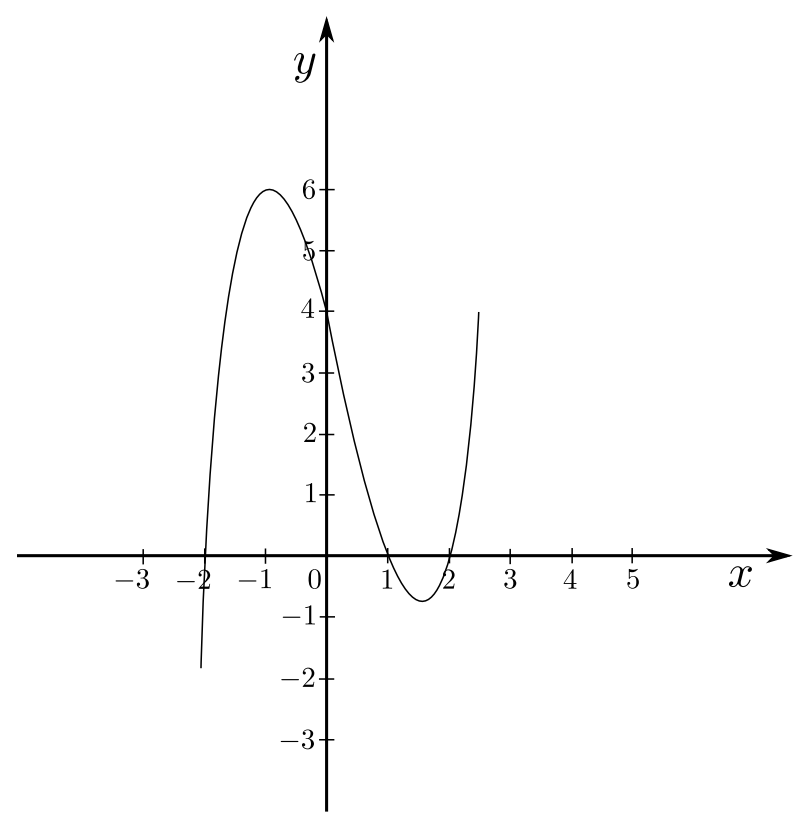

Figura 2.7: Função $f(x)=x^{3}-x^{2}-4 x+4$

O ensino de equações do segundo grau no Brasil é iniciado ainda no Ensino Fundamental. Ainda tratando-se dos autores Ênio Silveira e Claudio Marques mencionados anteriormente, quando são analisado seus livros escritos para o Ensino Fundamental, encontramos o assunto de Equações do Segundo Grau, assim como em quase todos os livros de Nono Ano do Fundamental II (Nomenclatura utilizada a partir de 2010 conforme a Lei ${ }^{\circ}$ 11.274/06 ? site do MEC 2009), tanto das escolas públicas como das particulares. São ensinadas técnicas de resolução como a "Fórmula de Bhaskara" (que por sinal não é de sua autoria) para o cálculo de raízes. Como mencionado em um artigo publicado no site da Editora Moderna por Kátia Dutra no dia 28 de março de 2012.

"A "fórmula de Bhaskara", bastante conhecida dos alunos do Ensino Fundamental II e Médio para a resolução de equações de segundo grau é um exemplo. Além de facilitar o processo didático, a fórmula é válida para qualquer equação do segundo grau. O grande detalhe é que não foi Bhaskara quem a descobriu. Alguns manuscritos de Sridara, um matemático indiano que viveu 100 anos antes de Bhaskara, já demonstram a utilização da famosa teoria com diferenças. Além disso, a teoria como conhecemos não poderia ter sido criado por Bhaskara, visto que este viveu na Índia durante o século XII, época em que os matemáticos buscavam regras que resolvessem tipos específicos de equação e não fórmulas gerais."

Outra fonte que traz referência a esse assunto é um texto que aparece no site do MEC, escrito pelo autor Oscar Guelli onde podemos destacar o seguinte trecho:

"Problemas que recaem numa equação do segundo grau já apareciam, há quase quatro mil anos, em textos escritos pelos babilônios. Nesses textos o que se tinha era uma receita (escrita em prosa, sem uso de símbolos) que ensinava como proceder para determinar as raízes em exemplos concretos com coeficientes numéricos."

Também é passada para os alunos uma maneira direta de cálculo dos valores máximos ou mínimos que 
uma função do segundo grau pode assumir. Uma demonstração precisa desse fato será feita no Capítulo 4. Durante o Ensino Médio, essas técnicas voltam a ser vistas, no entanto aplicadas a funções. Novamente suas provas costumam ser omitidas.

A "Fórmula de Bhaskara" é utilizada para o cálculo de raízes de uma equação ou função do segundo grau juntamente com o discriminante (delta) da função. Mais uma fórmula que normalmente é jogada para os alunos.

O nome de Bhaskara associado a essa fórmula, aparentemente só ocorre no Brasil. Não encontramos esta referência na literatura internacional. A nomenclatura "Fórmula de Bhaskara" não é adequada, pois problemas que recaem numa equação do segundo grau já apareciam quase quatro mil anos antes, em textos escritos pelos babilônios.

Nessas escrituras, o que se tinha era uma receita sem uso de símbolos matemáticos, que ensinava como proceder para determinar as raízes em exemplos concretos, quase sempre ligados a relações geométricas. Bhaskara não ter sido o autor da famosa fórmula que nos ajuda a resolver problemas que envolvem equações do segundo grau não isenta a sua grande contribuição à disciplina.

Bhaskara foi um importante matemático e astrônomo indiano cuja principal contribuição está associada ao estudo de Equações Indeterminadas (assunto para outra ocasião). Ele também foi o primeiro a demonstrar a regra de soma e subtração de arcos estudado na trigonometria no ensino médio.

Na álgebra, o discriminante de uma função é uma relação entre seus coeficientes, tipicamente representada pela letra grega delta $(\Delta)$. Ele informa a natureza de suas raízes. Por exemplo, o discriminante do polinômio quadrático $a x^{2}+b x+c$ é $\Delta=b^{2}-4 a c$.

No Ensino Médio, as funções polinomiais de segundo grau costumam ser estudadas segundo a estrutura $f(x)=a x^{2}+b x+c$, com $a \neq 0$. Portanto, nosso estudo também utilizará esta nomenclatura, tanto na teoria, quanto na resolução dos exercícios.

Diante de tantas informações para decorar, o gosto pela Matemática, que nessa fase já não costuma ser muito grande, diminui mais ainda. Então torna-se comum encontramos cadernos repletos de resumos, sem sentido aparente, tratando-se da função $f(x)=a x^{2}+b x+c$.

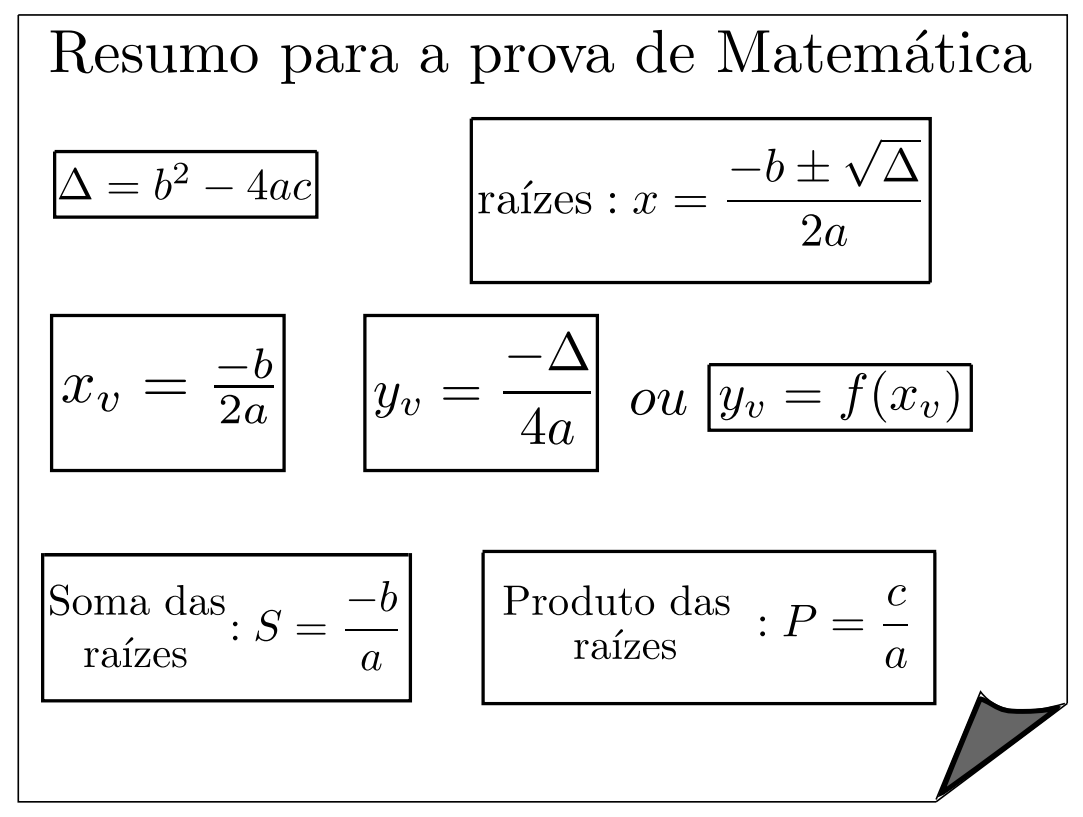

Figura 2.8: Resumo para a prova 
Todas essas fórmulas têm uma demonstração e serão expostas agora:

1) Demonstração da Fórmula de Bhaskara;

2) Demonstração da Fórmula de Soma e Produto;

3) Demonstrações das Fórmulas do $x_{v}$ e $y_{v}$.

\section{Demonstração da Fórmula de Bhaskara:}

Consideramos que

$$
a x^{2}+b x+c=0
$$

Logo, de modo equivalente temos:

$$
\begin{gathered}
(4 a)\left(a x^{2}+b x+c\right)=(4 a) \cdot 0 \Leftrightarrow 4 a^{2} x^{2}+4 a b x+4 a c=0 \Leftrightarrow \\
(2 a x)^{2}+2(2 a x) b=-4 a c \Leftrightarrow(2 a x)^{2}+2(2 a x) b+b^{2}=-4 a c+b^{2} \Leftrightarrow \\
(2 a x+b)^{2}=b^{2}-4 a c \Leftrightarrow|2 a x+b|=\sqrt{b^{2}-4 a c} .
\end{gathered}
$$

Agora se $(2 a x+b) \geq 0$, temos que

$$
2 a x+b=\sqrt{b^{2}-4 a c} \Leftrightarrow x=\frac{-b+\sqrt{b^{2}-4 a c}}{2 a} .
$$

Por outro lado, se $(2 a x+b)<0$, temos que

$$
2 a x+b=-\sqrt{b^{2}-4 a c} \Leftrightarrow x=\frac{-b-\sqrt{b^{2}-4 a c}}{2 a} .
$$

Portanto temos as duas raízes:

$$
r_{1}=\frac{-b+\sqrt{b^{2}-4 a c}}{2 a} \text { e } r_{2}=\frac{-b-\sqrt{b^{2}-4 a c}}{2 a}
$$

ou simplesmente

$$
x=\frac{-b \pm \sqrt{b^{2}-4 a c}}{2 a} .
$$

Várias questões de equações ou funções do segundo grau propostas durante a educação básica, são resolvidas utilizando uma técnica que normalmente é conhecida como "Soma e Produto". Esse método consiste em descobrir as raízes de uma função do segundo grau realizando pequenas divisões entre seus coeficientes e pensando quais números somados geram tal resultado e multiplicados geram outro.

Essas fórmulas podem ser facilmente demonstradas uma vez que partimos do princípio que as raízes $r_{1}$ e $r_{2}$ encontradas pela "Fórmula de Bhaskara" podem ser representadas da seguinte maneira:

\section{Demonstração da Fórmula de Soma e Produto:}

Sabemos que as raízes da equação $a x^{2}+b x+c=0$ são:

$$
r_{1}=\frac{-b+\sqrt{b^{2}-4 a c}}{2 a} \text { e } r_{2}=\frac{-b-\sqrt{b^{2}-4 a c}}{2 a}
$$


Se estamos querendo determinar a soma dessas duas raízes temos que:

$$
r_{1}+r_{2}=\frac{-b+\sqrt{b^{2}-4 a c}}{2 a}+\frac{-b-\sqrt{b^{2}-4 a c}}{2 a}=\frac{-2 b}{2 a}=\frac{-b}{a} .
$$

Portanto, se denotarmos por $S$ a soma das duas raízes, temos que:

$$
S=\frac{-b}{a}
$$

Por outro lado, o produto é obtido por um pensamento análogo, assim:

$$
r_{1} \cdot r_{2}=\left(\frac{-b+\sqrt{b^{2}-4 a c}}{2 a}\right)\left(\frac{-b-\sqrt{b^{2}-4 a c}}{2 a}\right)=\frac{b^{2}-\left(b^{2}-4 a c\right)}{4 a^{2}}=\frac{4 a c}{4 a a}=\frac{c}{a} .
$$

Portando, se denotarmos por $P$ o protudo das duas raízes, temos que:

$$
P=\frac{c}{a}
$$

\section{Demonstrações das Fórmulas do $x_{v}$ e $y_{v}$ :}

Sabemos que

$$
r_{1}=\frac{-b+\sqrt{\Delta}}{2 a} \text { e } r_{2}=\frac{-b-\sqrt{\Delta}}{2 a}
$$

Logo o $x_{v}$ é dado pelo ponto médio, pois a parábola é simétrica ao vértice, dessa forma temos:

$$
x_{v}=\frac{\left(\frac{-b+\sqrt{\Delta}}{2 a}\right)+\left(\frac{-b-\sqrt{\Delta}}{2 a}\right)}{2} \Leftrightarrow x_{v}=\frac{\frac{-b+\sqrt{\Delta}-b-\sqrt{\Delta}}{2 a}}{2} \Leftrightarrow x_{v}=\frac{-b}{2 a} .
$$

Agora para encontrarmos o valor do $y_{v}$ basta aplicarmos o valor do $x_{v}$ na lei da função quadrática:

$$
f(x)=a x^{2}+b x+c .
$$

Assim,

$$
y_{v}=a\left(x_{v}\right)^{2}+b x_{v}+c \Leftrightarrow y_{v}=a\left(\frac{-b}{2 a}\right)^{2}+b\left(\frac{-b}{2 a}\right)^{2}+c=\frac{-\left(b^{2}-4 a c\right)}{4 a}=\frac{-\Delta}{4 a} .
$$

Depois do que foi visto, podemos resolver os Problemas 2.1 e 2.2 propostos no começo deste capítulo.

Problema 2.1) O custo $C$ de um produto fabricado por uma cooperativa agrícola, em milhares de reais, é dado pela função $C(x)=6 x-4$, onde $x$ está em milhares de unidades. Verificou-se que o faturamento de venda desses produtos, também em milhares de reais, é dado pela função $F(x)=-x^{2}+9 x$. Sendo assim, calcule o lucro máximo que essa empresa pode ter. 
Solução. Sabemos que o lucro é dado pela diferença entre o faturamento e o custo de uma empresa, logo temos

$$
L=F-C
$$

Assim,

$$
L=F-C=-x^{2}+9 x-(6 x-4) \Rightarrow L=-x^{2}+3 x+4
$$

Notamos que obtemos uma equação do segundo grau, logo usaremos as expressões do $x_{v}$ e o $y_{v}$ para determinarmos o lucro máximo, isto é,

$$
x_{v}=\frac{-b}{2 a} \Rightarrow x_{v}=\frac{-3}{-2} \Rightarrow x_{v}=1,5
$$

e

$$
y_{v}=L\left(x_{v}\right)=-(1,5)^{2}+3 \cdot(1,5)+4=6,25 \text {. }
$$

Portanto, o lucro máximo da empresa pode chegar a 6,25 milhares de reais.

Problema 2.2) Comparando todos os retângulos que podem ser construídos dobrando-se um arame de $50 \mathrm{~cm}$, quanto vale, em $\mathrm{cm}^{2}$, a área máxima que pode ser demarcada?

Solução. Temos o retângulo do problema

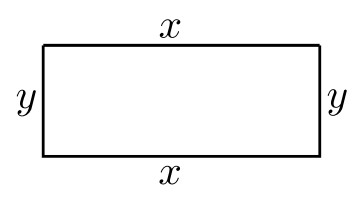

Figura 2.9: Retângulo de lados $x$ e $y$

Logo, o seu perímetro é dado por:

$$
P=x+x+y+y=2 x+2 y \Rightarrow P=2 x+2 y=25 \Rightarrow y=25-x .
$$

Por outro lado, sabemos que a área desse retângulo é dada por:

$$
A=x \cdot y \Rightarrow A=x \cdot(25-x)=-x^{2}+25 x \text {. }
$$

Como chegamos a uma equação do segundo grau, usaremos as expressões do $x_{v}$ e o $y_{v}$ para determinarmos as maiores dimensões possíveis:

$$
x_{v}=\frac{-b}{2 a} \Rightarrow x_{v}=\frac{-25}{-2} \Rightarrow x_{v}=12,5
$$

E como $y=25-x \Rightarrow y=25-12,5=12,5$. Portanto, as maiores dimensões são $x=12,5$ e $y=12,5$.

Problema 2.3) Deseja-se construir uma caixa sem tampa a partir de uma folha quadrada de lado $30 \mathrm{~cm}$ da seguinte maneira: serão retirados quatro quadrados de lados " $x$ " centímetros, um de cada extremidade e em seguida serão dobradas as partes que sobraram obtendo assim a caixa desejada. De quanto deve ser o lado desses quadrados que serão retirados para que o volume da caixa criada seja o 
maior possível?

Solução) Consideramos a caixa dada no problema como:
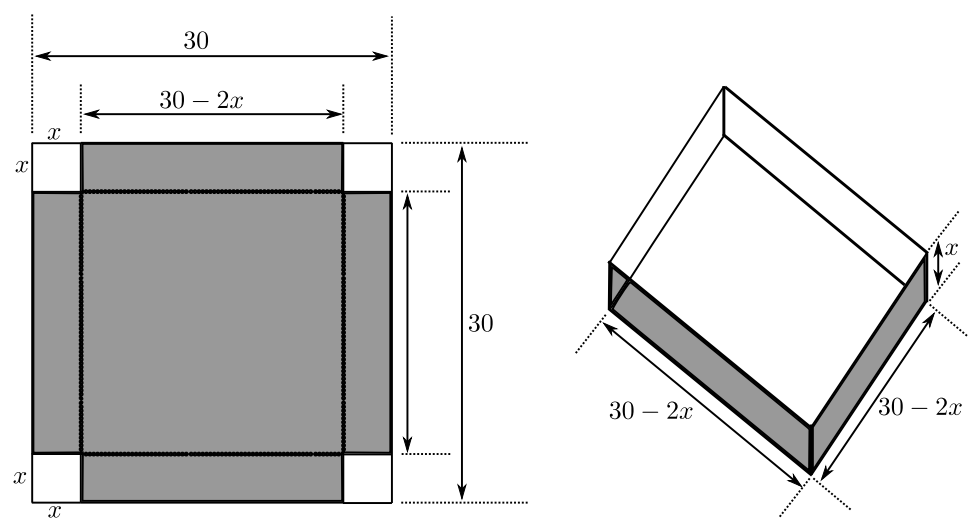

Figura 2.10: Caixa

Notamos que a caixa é um paralelepípedo, logo seu volume é dado por:

$$
V=(\text { área da base }) \cdot(\text { altura })=(30-2 x)^{2} \cdot x=4 x^{3}-120 x^{2}+900 x .
$$

Observe que encontramos um polinômio de grau três e desse modo, não poderemos usar a técnica gerada pela equação do segundo grau.

Deste modo, o Problema 2.3 pode ser entendido como motivador para o estudo de outra técnica de obtenção de valores de máximo e mínimos de funções, dado que os conhecimentos vistos até aqui não são suficientes para o cálculo do resultado. Esse problema será resolvido de modo completo no Capítulo 4. 


\section{Capítulo}

\section{Aprendendo na Prática Sobre Máximos e Mínimos}

Como já foi mencionado anteriormente, no decorrer do ensino básico, são trabalhadas muitas questões de máximos e mínimos (não apenas na Matemática) que podem ser resolvidas de diferentes maneiras. A maior parte delas está associada à funções polinomiais, mas também nos deparamos com exercícios dessa natureza na área da trigonometria, geometria, física, química, biologia, dentre outras.

O que vamos apresentar nesse capítulo é como resolver alguns modelos dessas questões apenas utilizando o conhecimento passado no Ensino Médio. Tentaremos trabalhar com questões dos mais variados conteúdos. Esse é um capítulo basicamente de resolução de problemas.

Para resolver a maioria dos problemas propostos aqui, utilizaremos as ideias e fórmulas desenvolvidas no final do Capítulo 2, principalmente aquelas associadas ao vértice de uma função do segundo grau. Lembrando que este ponto representa o valor máximo ou mínimo que a função pode assumir, dependendo da concavidade de sua parábola.

Problema 3.1. Considerando $f: \mathbb{R} \rightarrow \mathbb{R}$, calcule as coordenadas do valor mínimo que $f$ pode assumir, se $f(x)=x^{2}-4 x-5$.

Solução. Como $f$ é uma função quadrática (citada no Capítulo 1), aprende-se no ensino básico que para encontrar seus pontos de máximos e mínimos basta calcular as coordenadas do vértice da parábola. Essas coordenadas possuem uma fórmula prédefinida (essa ideia será utilizada repetida vezes neste capítulo):

$$
x_{v}=\frac{-b}{2 a} \quad \text { e } \quad y_{v}=\frac{-\Delta}{4 a}=\frac{b^{2}-4 a c}{4 a}
$$

Logo,

$$
x_{v}=\frac{-b}{2 a}=\frac{-(-4)}{2 \cdot 1}=\frac{4}{2}=2 \quad \text { e } \quad y_{v}=\frac{-\Delta}{4 a}=\frac{b^{2}-4 a c}{4 a}=\frac{-\left((-4)^{2}\right)-4 \cdot 1 \cdot(-5)}{4 \cdot 1}=\frac{-36}{4}=-9 .
$$

Assim, as coordenadas do ponto mínimo de $f$ são $P=(2, f(2))=(2,-9)$. 
Problema 3.2. Como escolher dois números positivos tais que sua soma é 1 e a soma de seus quadrados é a maior possivel.

Solução. Sejam $x$ e $y$ esses dois números positivos. Por hipótese temos que:

$$
x+y=1 \Rightarrow y=1-x
$$

Assim,

$$
(x+y)^{2}=(1)^{2} \Leftrightarrow x^{2}+2 x y+y^{2}=1 \quad \Leftrightarrow \quad x^{2}+y^{2}=1-2 x y .
$$

Definimos por $S$ a soma de seus quadrados. Logo,

$$
S=x^{2}+y^{2} \Rightarrow S=x^{2}+y^{2}=1-2 x y \quad \Leftrightarrow \quad S=1+2 x y=1+2 x(1-x)=-2 x^{2}+2 x+1 .
$$

Portanto,

$$
S=-2 x^{2}+2 x+1
$$

Como a soma resulta em uma equação do segundo grau, usaremos a expressão do $x_{v}$ para determinarmos deu máximo:

$$
x_{v}=\frac{-2}{-4}=\frac{1}{2}
$$

Por outro lado, como $y=1-x$, temos que $y=\frac{1}{2}$.

Portanto, os valores que esses dois números podem assumir são $\frac{1}{2} \mathrm{e} \frac{1}{2}$. Notando que não importa a ordem, mas apenas encontrar esses dois valores.

Problema 3.3. Considerando $f: \mathbb{R} \rightarrow \mathbb{R}$, calcule os valores máximo e mínimo que $f$ pode assumir, se $f(x)=\frac{1+2 \operatorname{sen}(x)}{3}$.

Solução. Para resolvermos questões envolvendo máximos e mínimos em trigonometria, em geral, precisamos lembrar que $-1 \leq \operatorname{sen}(x) \leq 1$. Tomando $f(x)=y$, temos:

$$
y=\frac{1+2 \operatorname{sen}(x)}{3} \Rightarrow 3 y=1+2 \operatorname{sen}(x) \Rightarrow 3 y-1=2 \operatorname{sen}(x) \Rightarrow \frac{3 y-1}{2}=\operatorname{sen}(x) .
$$

Agora, como a função seno varia de -1 a 1 , isto é, $-1 \leq \operatorname{sen}(x) \leq 1$, e $\frac{3 y-1}{2}=\operatorname{sen}(x)$, obtemos:

$$
-1 \leq \frac{3 y-1}{2} \leq 1 \Rightarrow-2 \leq 3 y-1 \leq 3 \Rightarrow-1 \leq 3 y \leq 3 \Rightarrow \frac{-1}{3} \leq y \leq 1 \Rightarrow \frac{-1}{3} \leq f(x) \leq 1
$$

Assim, temos que o valor mínimo que a função assume é -1/3 e o máximo é 1 . 
Problema 3.4. Um ônibus de 40 lugares foi fretado para uma excursão. A empresa exigiu de cada passageiro $R \$ 20,00$ mais $R \$ 2,00$ por lugar vago. Qual o número de passageiros para que a rentabilidade seja máxima?

Solução. Vamos primeiramente denotarmos por $R$ a rentabilidade da empresa e por $p$ o número de passageiros. Logo temos que:

$$
R=(20+2(40-p)) \cdot p \Rightarrow R=-2 p^{2}+100 p
$$

Como a rentabilidade em função do número de passageiros é representada através de uma função do segundo grau, usaremos a expressão do $x_{v}$ para determinarmos o máximo da rentabilidade. Assim:

$$
x_{v}=\frac{-100}{-4}=25
$$

Portanto, para a empresa ter a maior rentabilidade, 25 passageiros deverão ir para a excursão.

Problema 3.5. Um terreno retangular é cercado por $1500 \mathrm{~m}$ de cerca. Quais as dimensões desse terreno para que a sua área seja a maior possivel? E qual a área máxima?

\section{Solução.}

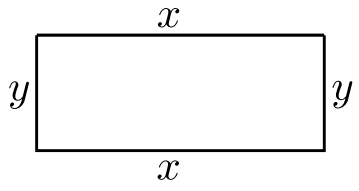

Figura 3.1: Terreno

Como o terreno é retangular, temos que o perímetro $(P)$ do terreno em função dos lados $x$ e $y$, pode ser representado pela seguinte equação: $P=2 x+2 y=1500$. Assim temos que $x+y=750$, ou de modo equivalente $y=750-x$.

Por outro lado, a área do retângulo pode ser representada da seguinte forma $A(x, y)=x . y$. Logo,

$$
A=x \cdot y=x(750-x)=750 x-x^{2}
$$

Notamos que a representação gráfica dessa função é uma parábola e seu ponto do máximo ocorre no $x$ do vértice, isto é, $X_{v}=\frac{-b}{2 a}$. Logo

$$
X_{v}=\frac{-b}{2 a}=\frac{-750}{-2}=375 .
$$

Assim, como $y=750-x$, temos que $y=375$. Portanto as dimensões do terreno são $x=375 \mathrm{e}$ $y=375$. Ou seja, o terreno é representado por um quadrado e sua área máxima é de

$$
A=x \cdot y=375 \cdot 375 \mathrm{~m}^{2}=140625 \mathrm{~m}^{2} .
$$

Observação 3.1. Note que após os cálculos, foi possivel perceber que dentre todos os retângulos de mesmo perímetro o que possui maior área é o quadrado. Esse fenômeno se repete nos outros polígonos. Dentre todos os pentágonos, hexágonos, n-ágonos quaisquer, o que possui maior área entre eles será sempre o regular. 
Problema 3.6. Uma área retangular está limitada por uma cerca de arame em três de seus lados e por um rio reto no quarto lado. Ache as dimensões do terreno de área máxima que pode ser cercado com $1000 \mathrm{~m}$ de arame.

\section{Solução.}

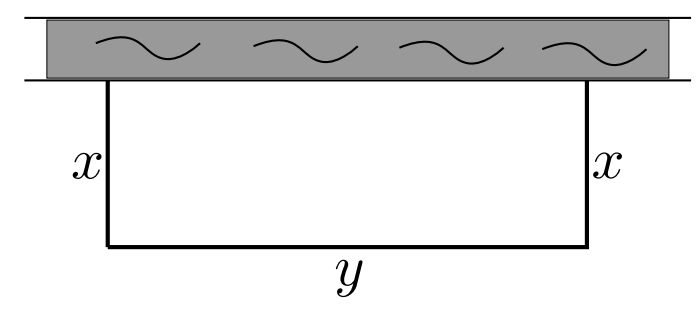

Figura 3.2: Terreno

Notamos que como um lado de nossa área não necessita de cerca por ter o rio que a delimita, o perímetro da região em questão é dado por:

$$
P=2 x+y=1000 \Rightarrow y=1000-2 x .
$$

E como a área da região retangular é dada por $A(x, y)=x \cdot y$, temos

$$
A=x \cdot(1000-2 x)=-2 x^{2}+1000 x
$$

Notamos que a representação gráfica dessa função é uma parábola e seu ponto do máximo ocorre no $x$ do vértice, isto é, $X_{v}=\frac{-b}{2 a}$. Logo

$$
x_{v}=\frac{-1000}{-4}=250 \mathrm{~m} .
$$

Por outro lado, como $y=1000-2 x=1000-2 \cdot 250=500 \mathrm{~m}$. Portanto as dimensões do terreno são $x=250 \mathrm{~m}$ e $y=500 \mathrm{~m}$.

Observação 3.2. Note que neste caso, diferentemente do problema 3.5, a figura encontrada depois dos cálculos não foi um quadrado. Isso ocorreu pois o material destinado para delimitar a região formaria apenas 3 dos lados de um quadrilátero. Se fossem 3 segmentos de mesmo tamanho, a área do retângulo formado (um quadrado), seria menor do que a área delimitada pelas dimensões encontradas.

Problema 3.7. Um terreno retangular deve ser cercado de duas formas. Dois lados opostos devem receber uma cerca reforçada que custa $R \$ 3,00$ o metro, enquanto os outros dois restantes recebem uma cerca-padrão de $R \$ 2,00$ o metro. Quais são as dimensões do terreno de maior área que pode ser cercado $\operatorname{com} R \$ 6000,00$ ?

\section{Solução.}

Como o terreno é retangular, temos que o perímetro do terreno é tal que $P=2 x+2 y$. Como os lados têm custos diferentes, temos que o custo total pode ser representado por:

$$
C(x)=2 x \cdot 3+2 y \cdot 2=6000 \Rightarrow 3 x+2 y=3000 \Rightarrow y=\frac{3000-3 x}{2} .
$$




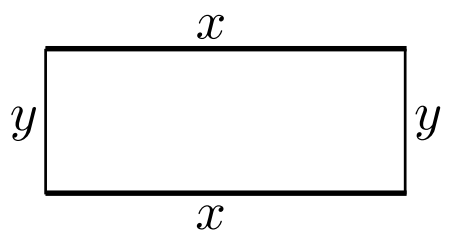

Figura 3.3: Terreno

A área da região retangular é representada por $A(x, y)=x \cdot y$. Então,

$$
A=x \cdot y=x \cdot(1500-1,5 x)=-1,5 x^{2}+1500 x
$$

Notamos que a representação gráfica dessa função é uma parábola e seu ponto do máximo ocorre no $x$ do vértice, isto é, $X_{v}=\frac{-b}{2 a}$. Logo

$$
x_{v}=\frac{-1500}{-3}=500 .
$$

Por outro lado, como $y=\frac{3000-3 x}{2}=\frac{3000-3 \cdot 500}{2}=750 \mathrm{~m}$, temos que as dimensões do terreno são $x=500 \mathrm{~m}$ e $y=750 \mathrm{~m}$.

Observação 3.3. Note que neste caso, assim como no problema 3.6, a figura encontrada depois dos cálculos não foi um quadrado. Isso ocorreu pois o preço dos materiais era diferente. Foi criado um outro fator que precisou ser levado em conta (o custo) por isso as dimensões $x$ e y são diferentes.

Problema 3.8. Um fazendeiro tem 200 bois, cada um pesando $300 \mathrm{Kg}$. Até agora ele gastou $R \$$ 380000,00 para criar os bois e continuará gastando $R \$ 2,00$ por dia para manter um boi. Os bois aumentam de peso a uma razão de $1,5 \mathrm{~kg}$ por dia. Seu preço de venda, hoje, é de $R \$ 18,00$ o quilo, mas o preço cai 5 centavos por dia. Quantos dias deveria o fazendeiro aguardar para ter o maior lucro possivel com a venda dos bois?

Solução. Vamos denotar por $d$ o número de dias e por $L$ o Lucro que é obtido a partir da diferença entre a Venda (V) e o Custo (C) de cada boi.

$$
V(d)=(18-0,05 d) \cdot(300+1,5 d) \cdot 200
$$

e

$$
C(d)=380000+2 d \cdot 200 .
$$

Portanto

$$
\begin{aligned}
L=V-C & =(18-0,05 d) \cdot(300+1,5 d) \cdot 200-(380000+2 d \cdot 200) \\
& =-15 d^{2}+2000 d+700000 .
\end{aligned}
$$

Notamos que a representação gráfica dessa função é uma parábola e seu ponto do máximo ocorre no $x$ do vértice, isto é, $X_{v}=\frac{-b}{2 a}$. Logo

$$
x_{v}=\frac{-2000}{-30} \approx 67 \text { dias. }
$$


Problema 3.9. Um retângulo é inscrito num triângulo de catetos medindo $9 \mathrm{~cm}$ e $12 \mathrm{~cm}$. Calcule quais devem ser as dimensões do retângulo para que este possua a maior área possível, supondo que a sua posição é dada na figura a seguir.

\section{Solução.}

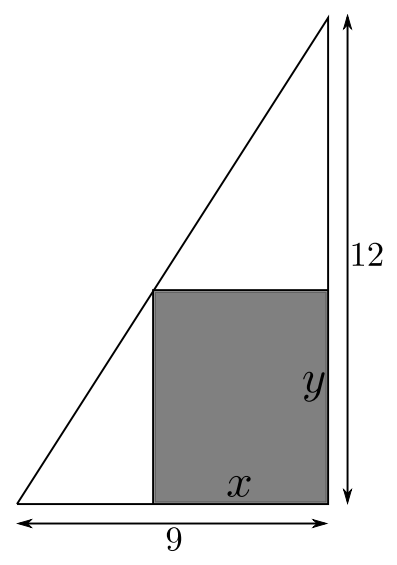

Figura 3.4: Área

Por semelhança de triângulos, temos que:

$$
\frac{12}{9}=\frac{12-y}{x} \Rightarrow 4 x=36-3 y \Rightarrow y=12-\frac{4 x}{3}
$$

Assim, a área do retângulo em questão pode ser representada por

$$
A=x \cdot y=x\left(12-\frac{4 x}{3}\right)=12 x-\frac{4 x^{2}}{3} \text {. }
$$

Notamos que a representação gráfica dessa função é uma parábola e seu ponto do máximo ocorre no $x$ do vértice, isto é, $X_{v}=\frac{-b}{2 a}$. Logo

$$
x_{v}=\frac{-12}{-8 / 3}=\frac{36}{8}=4,5 \text {. }
$$

Assim, como $y=12-\frac{4 x}{3}=12-6=6$

Portanto as dimensões são $x=4,5 \mathrm{~cm}$ e $y=6 \mathrm{~cm}$.

Problema 3.10. Uma forma líquida de penicilina vendida a um preço de $R \$ 200,00$ a unidade. Se o custo total de produção para $x$ unidades for $C(x)=500000+80 x+0,003 x^{2}$ e se a capacidade de produção da firma for, de no máximo, 30.000 unidades por mês, quantas unidades de penicilina devem ser fabricadas e vendidas nesse período para que o lucro seja máximo? E qual o valor do lucro máximo? 
Solução. Sabemos que a função lucro é dada pela diferença da venda pelo custo. Logo

$$
\text { Lucro }=\text { Venda }- \text { Custo, }
$$

assim:

$$
L(x)=200 x-\left(0,003 x^{2}+80 x+500000\right)=-0,003 x^{2}+120 x-500000 .
$$

Note que a representação gráfica dessa função é uma parábola e seu ponto do máximo ocorre no $x$ do vértice, isto é, $X_{v}=\frac{-b}{2 a}$. Logo

$$
x_{v}=\frac{-120}{0,006}=20000
$$

Como $y_{v}=L\left(x_{v}\right)=-0,003(20000)^{2}+120(20000)-500000=700000$ e $x_{v}$ é a quantidade necessária de unidades para obtermos o maior lucro, então, devemos vender 20000 para termos o lucro máximo.

Problema 3.11. Um pedaço de fio com 10 metros de comprimento é cortado em duas partes. Uma parte é dobrada em formato de um quadrado, ao passo que a outra é dobrada na forma de um triângulo equilátero. Como deve ser cortado o fio para que a área total englobada seja máxima?

\section{Solução.}
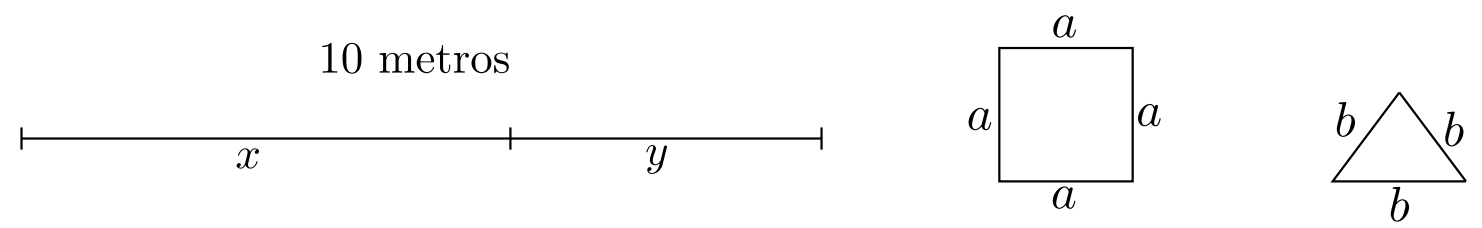

Figura 3.5: Áreas

Supomos que com o comprimento $x$ do segmento, construímos o quadrado de lado $a$, logo temos que

$$
4 a=x .
$$

Por outro lado, supomos que com o comprimento y do segmento dado construímos o triângulo equilátero, logo

$$
3 b=y \text {. }
$$

Portanto, do fato que $4 a=x, 3 b=y$ e $x+y=10$, obtemos:

$$
4 a+3 b=10 \Rightarrow a=\frac{10-3 b}{4} .
$$

Onde temos que a área total, que é a soma da área do quadrado mais a área do triângulo, é dada por:

$$
A=a^{2}+\frac{b^{2} \sqrt{3}}{4} .
$$

Agora como, $a=\frac{10-3 b}{4}$, temos que

$$
A=a^{2}+\frac{b^{2} \sqrt{3}}{4}=\frac{b^{2}(9+4 \sqrt{3})-60 b+100}{16} .
$$


Note que chegamos em uma equação do segundo grau cujo o gráfico tem a concavidade voltada para cima. Como neste caso o $x_{v}$ vai nos fornecer um valor mínimo, precisaremos encontrar uma outra maneira de determinar o valor máximo dessa função. Podemos garantir que esse valor máximo existe pois a função é contínua e limitada em um intervalo fechado. Da Observação 2.1 temos que ela possuirá um máximo e um mínimo global. A sugestão é analisarmos o valor da função nos extremos de seu domínio. Tendo como base a equação (3.1) que está em função de $b$ podemos definir o intervalo de seu domínio como $\left[0, \frac{10}{3}\right]$. Assim, temos:

$$
A(0)=\frac{100}{16}=6,25
$$

e

$$
A(10 / 3) \cong 4,81 \text {. }
$$

Assim, podemos perceber que a secção que deve ser feita no fio original para a obtenção de uma área máxima deve seguir a ideia da construção apenas de uma das figuras propostas (neste caso da construção do quadrado), pois a área será máxima quando o valor de $b=0 \mathrm{~cm}$ ou seja $a=2,5 \mathrm{~cm}$.

Portanto a área máxima é dada pela área do quadrado de lado $2,5 \mathrm{~cm}$ que vale $6,25 \mathrm{~cm}^{2}$. 


\section{Outro Método de Resolução de Problemas de Máximos e Mínimos}

Além dos exercícios do Ensino Médio, existem outros tipos de questões envolvendo máximos e mínimos de funções que o universo da educação básica não abrange. Alguns exemplos são propostos logo a seguir:

Problema 4.1. Um grupo de escoteiros possui uma peça de lona circular de $3 \mathrm{~m}$ de raio. Cortando-se um setor circular pode-se construir uma tenda de forma cônica. Quais as dimensões da tenda para que seu volume seja máximo?

Problema 4.2. Um cilindro deve ser fabricado para conter 6 litros. Que dimensões (raio e altura) deve ter este cilindro para custar o minimo possivel, conhecido os seguintes preços:

(i) O material do fundo custa $R \$ 5,00$ por $\mathrm{dm}^{2}$;

(ii) O material do lado custa $R \$ 3,00$ por $d m^{2}$;

(iii) O material da tampa custa $R \$ 2,00$ por $d m^{2}$

Problema 4.3. Um rio tem uma largura de $100 \mathrm{~m}$. Um ponto $C$ está deslocado de $400 \mathrm{~m}$ da projeção ortogonal do ponto A à outra margem, como mostra a figura. Deseja-se ir do ponto $A$ ao ponto $C$, fazendo o percurso $A B$ (remando) e depois BC (correndo pela margem). Sabendo que se pode remar a $40 \mathrm{~m} / \mathrm{min}$ e correr a $100 \mathrm{~m} / \mathrm{min}$, qual deve ser o valor de $x$ para que essa travessia seja feita no menor tempo possivel?

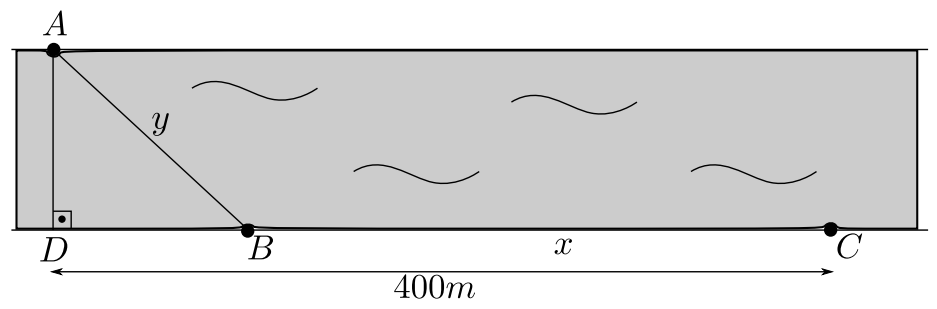

Figura 4.1: Rio

Os três exercícios propostos acima exigem um conhecimento prévio em Matemática e nem sempre são solucionados apenas o conhecimento adquiro até o terceiro ano do Ensino Médio. 
Tendo como base as questões propostas no início do Capítulo 2 e os estudos feitos até agora, é possível tecer algumas considerações.

Como quase tudo na vida, a maneira de se resolver problemas envolvendo máximos é mínimos não é única. Na Matemática não poderia ser diferente. É comum os alunos decorarem, muitas vezes por influência do professor, uma maneira de se resolver algum tipo de problema e adotá-la como uma verdade absoluta. Às vezes até criando um bloqueio para posteriores aprendizados.

Os alunos do Ensino Médio aprendem algumas técnicas para se obter os valores de máximos e mínimos de certas equações e funções, mas essas técnicas não são suficientes para resolver qualquer problema dessa natureza. Voltando aos autores mencionados no capítulo 2, Ênio Silveira, Claudio Marques e Gelson Iezzi e analisando suas livros utilizados hoje em dia para o ensino da matemática para o Ensino Médio, podemos encontrar neles a ideia do cálculo dos pontos de Máximos e Mínimos de funções do segundo grau. Não só eles, como quase todos os autores desse nível escolar tratam este conteúdo de forma parecida.

Elas podem ser eficientes dentro daquele universo e até bem práticas, mas infelizmente não podem ser utilizadas em todas as situações, como por exemplo não é suficiente para resolver os problemas propostos no começo deste capítulo.

Um dos intuitos desse trabalho é tornar mais acessível uma ferramenta que poderia ser de grande utilidade se estudada e aprendida com prazer e não apenas com a finalidade de obter um bom resultado em uma prova (realidade da maioria dos conteúdos vistos pelos alunos de todos os níveis de aprendizado). Maior utilidade ainda teria se ela fosse ensinada durante o ensino básico de formação dos nossos estudantes.

Muitos autores apoiam a implementação do ensino de limites e derivadas no Ensino Médio. No artigo revisado pelos autores Ronaldo da Silva Busse da UERJ e Flávia dos Santos Soares da IST (FAETEC) aparece o seguinte trecho:

"Introduzir o conceito, por exemplo, de derivada no Ensino Médio não torna o programa relativo a funções mais longo, como pode parecer a princípio. Pelo contrário, a compreensão de algumas propriedades se dá de maneira mais natural e contextualizada. A introdução da derivada deve ser acompanhada de várias de suas aplicações. Na Física, por exemplo, ela tem inúmeras utilidades na introdução de conceitos como pressão, densidade da massa, densidade de carga elétrica etc. Sendo assim, o Cálculo Diferencial e Integral é ferramenta necessária para a compreensão da Física e a falta desse tópico no Ensino Médio torna para o aluno a Física mais difícil do que realmente parece ser. Exemplo disso é o ensino da mecânica newtoniana, ensinado no Ensino Médio, que nasceu junto com o Cálculo e fica incoerente sem ele." (Damiana Santos USS ? 2006).

Além deles, temos um outro autor muito conhecido que também é a favor desse ensino. O professor Geraldo Ávila, em artigo publicado na Revista do Professor de Matemática fala que "o conceito de derivada pode ser ensinado, com grande vantagem, logo na primeira série do segundo grau, ao lado do ensino de funções" (ÁVILA, 1996). Para o autor, o ensino da derivada é de grande importância, tanto que ajuda no tratamento de inúmeras propriedades das funções. Seu ensino iniciado na primeira série do Ensino Médio pode-se integrar harmoniosamente com a Física no estudo do movimento, além de servir para o estudo de polinômios e outras aplicações científicas.

O professor Roberto Costallat Duclos (DUCLOS, 1992), em seu artigo "Cálculo no Segundo Grau", coloca sua opinião acerca do assunto através de relatos de experiências pessoais e profissionais, apoiando integralmente a opinião de Ávila. Para ambos, o Cálculo, desde que apresentado convenientemente, ao contrário de ser difícil, é muito gratificante pelas ideias novas que traz e pelo poder e alcance de seus 
métodos.

Essa outra técnica de estudo costuma ser ensinada, no Brasil, apenas a partir do ensino superior e é restrita para alguns curso que utilizam com frequência esse conteúdo. O nome dela é derivada, mas vem precedida por um importante embasamento teórico que nos permite desenvolver vários ramos de estudo.

A derivada é o nosso principal foco não só nesse capítulo como no trabalho em geral. Não que ela seja melhor ou mais eficiente que esta ou aquela maneira de resolver algum exercício, mas ela é certamente uma ferramenta muito útil para abrirmos um mundo novo de possibilidades de conhecimento em várias áreas distintas.

Quando falamos que a derivada é o nosso principal foco, não é pelo fato de apoiarmos sua implementação no ensino médio, apesar de também não sermos contra essa medida, mas o nosso intuito é construir um trabalho bem embasado teoricamente e didático para facilitar seu estudo por um aluno interessado.

Nosso principal objetivo é ajudar aquele aluno que tem facilidade de aprender sozinho e dar-lhe mais uma opção de resolução de exercícios que o mesmo encontra e encontrará em sua trajetória escolar, deixando a critério de cada um a escolha do método que melhor se aplica a cada situação

Antes dela ser estudada a fundo é necessária a consolidação de alguns conceitos.

Para obter a reta tangente a uma curva em um ponto $P_{0}$ no plano $x y$ vamos partir da ideia de reta secante, considerando $P_{1}$ um ponto qualquer que pertence à curva e distinto de $P_{0}$. A reta que passa por $P_{0}$ e $P_{1}$ é denominada reta secante à curva em $P_{0}$. A intuição sugere que, se movermos o ponto $P_{1}$ em direção a $P_{0}$, então a reta secante irá girar em direção a uma posição limite. A reta nessa posição limite é o que consideramos ser a reta tangente.

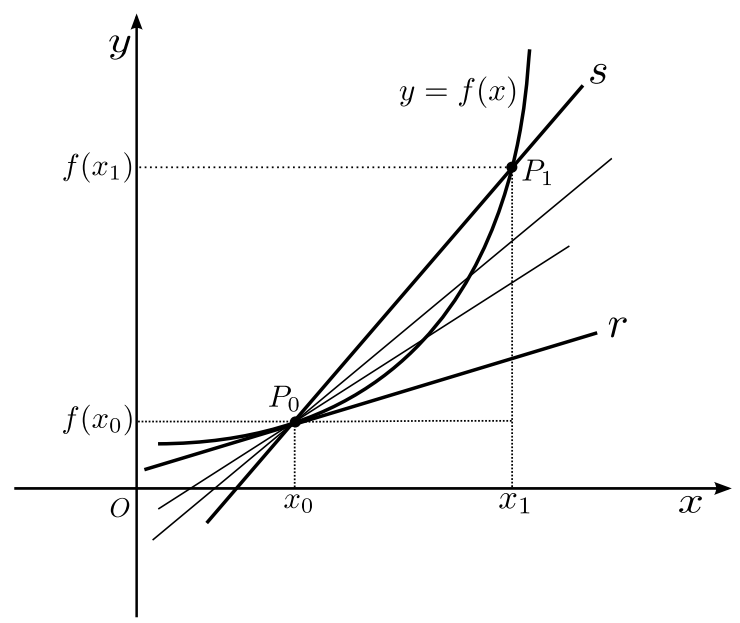

Figura 4.2: Reta Secante $s$ e Reta Tangente $r$

Definição 4.1. Se os valores de $f(x)$ puderem ser tomados tão próximos quanto queiramos de L, desde que tomemos os valores de $x$ suficientemente próximos de a (mas não necessariamente iguais ao ponto a), então escreveremos:

$$
\lim _{x \rightarrow a} f(x)=L \quad \text { ou } \quad f(x) \rightarrow L \quad \text { quando } x \rightarrow a .
$$

Que deve ser lido como "o limite de $f(x)$ quando $x$ tende para a é $L$ ", ou " $f(x)$ tende a $L$ quando $x$ tende para a". O valor $L$ é dito o limite de $f(x)$ quando $x \rightarrow a$. Ou ainda, de modo equivalente em 
linguagem matemática: para todo $\varepsilon>0$, existe um $\delta>0$, tal que $|x-a|<\delta$, então $|f(x)-L|<\varepsilon$, geometricamente temos
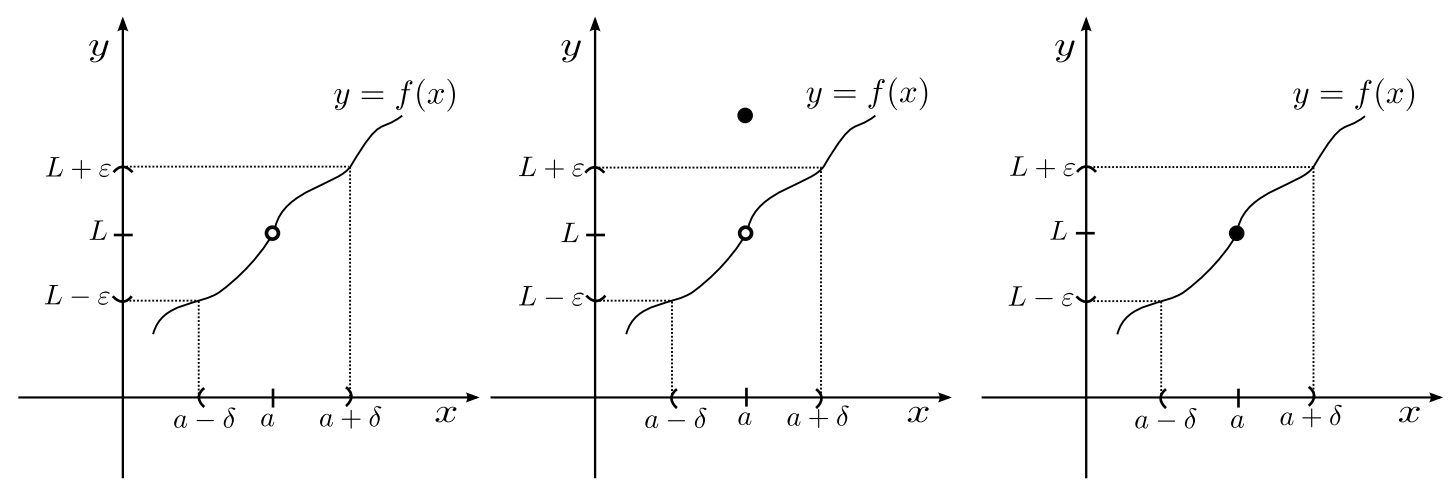

Figura 4.3: Limite

Observação 4.1. Pela figura acima, pode-se perceber que a função não precisa estar necessariamente definida no ponto para que seu limite exista.

Definição 4.2. Se os valores de $f(x)$ puderem ser levados tão próximos de L quanto queiramos desde que tomemos os valores de $x$ suficientemente próximos de a (mas maiores do que a), então escrevemos:

$$
\lim _{x \rightarrow a^{+}} f(x)=L
$$

e L assim obtido é chamado de limite lateral à direita do ponto a.

E se os valores de $f(x)$ puderem ser levados tão próximos de $M$ quanto queiramos desde que tomemos os valores de $x$ suficientemente próximos de a (mas menores do que a), então escrevemos:

$$
\lim _{x \rightarrow a^{-}} f(x)=M
$$

e M assim obtido é chamado de limite lateral à esquerda do ponto a.
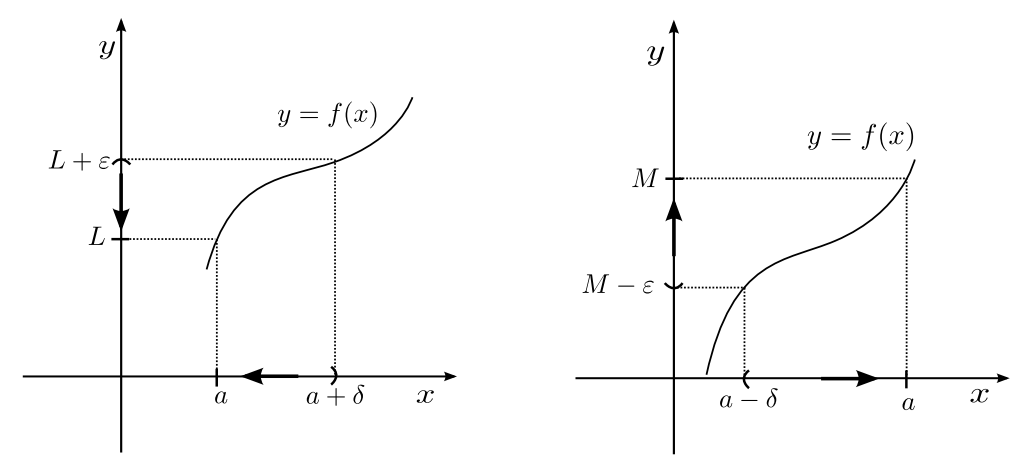

Figura 4.4: Limites Laterais 
A seguir apresentaremos a definição formal de continuidade de uma função $f$ em um ponto $c$.

Definição 4.3. Dizemos que uma função $f$ é contínua em $x=c$ se as seguintes condições estiverem satisfeitas:

(i) $f(c)$ está definida;

(ii) $\lim _{x \rightarrow c}$ existe;

(iii) $\lim _{x \rightarrow c}=f(c)$.

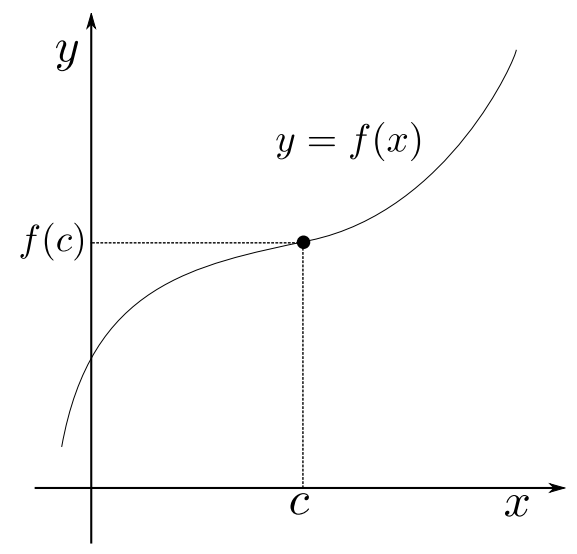

Figura 4.5: Função Contínua

Suponha que $x_{0}$ seja um ponto do domínio da função $f$. A reta tangente à curva $y=f(x)$ no ponto $P\left(x_{0}, f\left(x_{0}\right)\right)$ é a reta de equação:

$$
y-f\left(x_{0}\right)=m_{t g}\left(x-x_{0}\right) \quad \text { onde } \quad m_{t g}=\lim _{x \rightarrow x_{0}} \frac{f(x)-f\left(x_{0}\right)}{x-x_{0}},
$$

sempre que existir o limite. Para simplificar, também dizemos que essa reta é a reta tangente a $y=f(x)$ em $x_{0}$.

Exemplo 4.1. Encontre a equação geral da reta tangente à parábola $y=x^{2}$ no ponto $P(1,1)$.

Solução: Podemos descobrir o coeficiente angular da reta em questão aplicando a fórmula vista acima:

$$
m_{t g}=\lim _{x \rightarrow 1} \frac{f(x)-f(1)}{x-1}=\lim _{x \rightarrow 1} \frac{x^{2}-1}{x-1}=\lim _{x \rightarrow 1} \frac{(x+1)(x-1)}{x-1}=\lim _{x \rightarrow 1} x+1=2 .
$$

Assim, a reta tangente a $y=x^{2}$ em $(1,1)$ tem a equação:

$$
y-1=2(x-1) \Rightarrow y=2 x-1 .
$$

Suponha que uma partícula em movimento retilíneo ao longo de um eixo $s$ tenha uma função posição $s=f(t)$. A velocidade média da partícula em um intervalo de tempo $\left[t_{0}, t_{0}+h\right]$, com $h>0$, é definida como

$$
v_{m}=\frac{\text { Deslocamento }}{\text { Tempo Decorrido }}=\frac{f\left(t_{0}+h\right)-f\left(t_{0}\right)}{h} .
$$

Para definir a velocidade escalar média, usamos a distância percorrida pela partícula, e não seu deslocamento. 
Exemplo 4.2. Suponha que $s=f(t)=1+3 t-2 t^{2}$ seja a função posição de uma partícula, onde s está em metros e $t$ em segundos. Encontre o deslocamento e a velocidade média da partícula nos intervalos de tempo $(a)[0,1]$ e $(b)[1,3]$.

Solução: Aplicando na fórmula temos que:
a) $v_{m}=\frac{f\left(t_{0}+h\right)-f\left(t_{0}\right)}{h} \Rightarrow v_{m}=\frac{f(0+1)-f(0)}{1} \Rightarrow v_{m}=\frac{2-1}{1} \Rightarrow v_{m}=1 \mathrm{~m} / \mathrm{s}$.
b) $v_{m}=\frac{f\left(t_{0}+h\right)-f\left(t_{0}\right)}{h} \Rightarrow v_{m}=\frac{f(1+2)-f(1)}{2} \Rightarrow v_{m}=\frac{-8-2}{2} \Rightarrow v_{m}=-5 \mathrm{~m} / \mathrm{s}$.

A velocidade média descreve o comportamento de uma partícula em movimento retilíneo em um intervalo de tempo enquanto a velocidade instantânea descreve seu comportamento em um instante específico. Se analisarmos a fórmula da velocidade média é como se quiséssemos utilizá-la para um $h$ suficientemente pequeno, tendendo a zero. Em outras palavras, temos que a velocidade instantânea é definida como

$$
v_{i}=\lim _{h \rightarrow 0} \frac{f\left(t_{0}+h\right)-f\left(t_{0}\right)}{h} .
$$

Geometricamente a velocidade instantânea $v_{i}$ no instante $t_{0}$ é a inclinação da reta tangente à curva posição versus tempo no ponto $P\left(t_{0}, f\left(t_{0}\right)\right)$.

Exemplo 4.3. Utilizando a mesma função do exemplo da velocidade média, vamos calcular agora a velocidade instantânea da partícula para $t=3$.

Solução: Aplicando na fórmula temos que:

$$
\begin{aligned}
v_{i} & =\lim _{h \rightarrow 0} \frac{f(t+h)-f(t)}{h} \\
& =\lim _{h \rightarrow 0} \frac{f(3+h)-f(3)}{h} \\
& =\lim _{h \rightarrow 0} \frac{-2(3-h)^{2}+3(3-h)+1-\left(-2(3)^{2}+3(3)+1\right)}{h} \\
& =\lim _{h \rightarrow 0} \frac{-2\left(9-6 h+h^{2}\right)+3(3-h)+1-(-18+9+1)}{h} \\
& =\lim _{h \rightarrow 0} \frac{-18+12 h-2 h^{2}+9-3 h+1+18-9-1}{h} \\
& =\lim _{h \rightarrow 0} \frac{-2 h^{2}+9 h}{h} \\
& =\lim _{h \rightarrow 0} \frac{h(-2 h+9)}{h \cdot 1} \\
& =\lim _{h \rightarrow 0} \frac{-2 h+9}{1} \\
& =9 .
\end{aligned}
$$


Agora será apresentada uma nova ferramenta da Matemática que facilita muitos cálculos e abre portas para tratar de assuntos que antes eram limitados pela bagagem teórica que tinha sido apresentada até então. Essa operação é chamada de derivada. O limite que apareceu quando foi apresentado o conceito de reta tangente a um ponto em uma curva específica é a base para a definição formal de derivada.

Definição 4.1. A derivada de uma função $f(x)$ em relação à variável $x$ é a função $f^{\prime}(x)$ cujo valor em $x$ é:

$$
f^{\prime}(x)=\lim _{h \rightarrow 0} \frac{f(x+h)-f(x)}{h},
$$

desde que o limite exista.

Observação 4.2. Dizemos que uma função $f$ é derivável quando existe a derivada em todos os pontos de seu dominio. Além disso, outras notações de derivadas podem ser usadas no lugar de $y^{\prime}=f^{\prime}(x)$, como por exemplo: $D_{x} f(x)$ (leia-se derivada de $f(x)$ em relação a $x$ ), $\frac{d y}{d x}$ (leia-se derivada de y em relação a $x)$.

Observação 4.3. Como podemos ter que $h=x_{1}-x_{0}$, então uma definição equivalente de derivada em relação à variável $x$ no ponto $x_{0}$ é dada por:

$$
f^{\prime}\left(x_{0}\right)=\lim _{x_{1} \rightarrow x_{0}} \frac{f\left(x_{1}\right)-f\left(x_{0}\right)}{x_{1}-x_{0}} .
$$

Além disso, se agora escrevermos $h=x_{1}-x_{0}$, então

$$
x_{1} \rightarrow x_{0} \text { é equivalente a } h \rightarrow 0,
$$

logo, uma definição equivalente de derivada em relação à variável $x$ no ponto $x_{0}$ é a seguinte:

$$
f^{\prime}\left(x_{0}\right)=\lim _{h \rightarrow 0} \frac{f\left(x_{0}+h\right)-f\left(x_{0}\right)}{h} .
$$

Exemplo 4.4. Dada a função $f(x)=2 x^{2}+7 x-3$, determine $f^{\prime}(5)$ usando a definição de derivada.

Solução. Usando a definição de derivada no ponto $x=5$, temos que:

$$
\begin{aligned}
f^{\prime}(5) & =\lim _{h \rightarrow 0} \frac{f(5+h)-f(5)}{h} \\
& =\lim _{h \rightarrow 0} \frac{2(5+h)^{2}+7(5+h)-3-\left(2.5^{2}+7.5-3\right)}{h} \\
& =\lim _{h \rightarrow 0} \frac{2\left(25+10 h+h^{2} x\right)+35+7 h-3-50-35+3}{h} \\
& =\lim _{h \rightarrow 0} \frac{20 h+2 h^{2} x+7 h}{h} \\
& =\lim _{h \rightarrow 0} \frac{h(20+2 h+7)}{h} \\
& =\lim _{h \rightarrow 0}(20+2 h x+7) \\
& =27 .
\end{aligned}
$$

Exemplo 4.5. Dada a função $f(x)=\sqrt{x}$, determine $f^{\prime}(9)$ usando a definição de derivada. 
Solução. Por uma das definições equivalentes de derivada, temos que $f^{\prime}(9)$ é dada por:

$$
\begin{aligned}
f^{\prime}(9) & =\lim _{x \rightarrow 9} \frac{f(x)-f(9)}{x-9} \\
& =\lim _{x \rightarrow 9} \frac{\sqrt{x}-3}{x-9} \\
& =\lim _{x \rightarrow 9} \frac{\sqrt{x}-3}{x-9}\left(\frac{\sqrt{x}+3}{\sqrt{x}+3}\right) \\
& =\lim _{x \rightarrow 9} \frac{(x-9)}{(x-9)(\sqrt{x}+3)} \\
& =\frac{1}{6} .
\end{aligned}
$$

Teorema 4.1. Se $f$ possui derivada em $x=c$, então $f$ é contínua em $x=c$.

Prova. Temos que $f^{\prime}(c)$ existe e com isso precisamos mostrar que $f$ é contínua em $x=c$, em outras palavras:

a) $f(c)$ existe;

b) $\lim _{x \rightarrow c} f(x)$ existe;

c) $\lim _{x \rightarrow c} f(x)=f(c)$.

Por hipótese, temos que $f^{\prime}(c)$ existe, isto é, $f^{\prime}(c)=\lim _{x \rightarrow c} \frac{f(x)-f(c)}{x-c}$, concluímos que $f(c)$ deve existir para que o limite acima tenha sentido e desse modo, verificando o item $a$ ), note também que:

$$
\begin{aligned}
\lim _{x \rightarrow c}[f(x)-f(c)] & =\lim _{x \rightarrow c}[f(x-f(c))]\left(\frac{x-c}{x-c}\right) \\
& =\lim _{x \rightarrow c} \frac{f(x)-f(c)}{x-c} \cdot \lim _{x \rightarrow c}(x-c) \\
& =f^{\prime}(c) \cdot 0 \\
& =0 .
\end{aligned}
$$

Portanto, temos que:

$$
\begin{aligned}
\lim _{x \rightarrow c} f(x) & =\lim _{x \rightarrow c}[f(x)-f(c)-f(c)] \\
& =\lim _{x \rightarrow c}[f(x)-f(c)]+\lim _{x \rightarrow c} f(c) \\
& =f(c) .
\end{aligned}
$$

Verificando os itens $b$ ) e $c$ ), assim se $f^{\prime}(c)$ existe, então $f$ é contínua em $x=c$.

Daremos agora a definição de derivadas laterais

Definição 4.2. Seja $y=f(x)$ uma função definida em a, então a derivada à direita de $f$ no ponto a, denotada por $f_{+}^{\prime}(a)$ é definida por:

$$
f_{+}^{\prime}(a)=\lim _{h \rightarrow 0^{+}} \frac{f(a+h)-f(a)}{h}=\lim _{x \rightarrow a^{+}} \frac{f(x)-f(a)}{x-a},
$$

desde que o limite exista.

E a derivada à esquerda é dada de modo análogo, como segue: 
Definição 4.3. Seja $y=f(x)$ uma função definida em b, então a derivada à esquerda de $f$ no ponto $b$, denotada por $f_{-}^{\prime}(b)$ é definida por:

$$
f_{-}^{\prime}(b)=\lim _{h \rightarrow 0^{-}} \frac{f(b+h)-f(b)}{h}=\lim _{x \rightarrow b^{-}} \frac{f(x)-f(b)}{x-b},
$$

desde que o limite exista.

Observação 4.4. Uma função $y=f(x)$ será derivável em um intervalo aberto $(a, b)$ se tiver derivada em cada ponto do intervalo e $y=f(x)$ será derivável no intervalo fechado $[a, b]$ se for derivável no interior $(a, b)$ e se a derivada à direita em a e a derivada ̀̀ esquerda em b existir.

Observação 4.5. Uma função $y=f(x)$ é derivável em um ponto, quando as derivadas à direita e à esquerda nesse ponto existirem e forem iguais, além disso, quando as derivadas laterais existirem e forem diferentes em um ponto c, dizemos que neste ponto a função não é derivável.

Exemplo 4.6. Mostre que a função $y=f(x)=|x|$ não é derivável em $x=0$.

Solução. Vamos calcular as derivadas à esquerda e à direita de $x=0$. Note que:

$$
\begin{aligned}
f_{+}^{\prime}(0) & =\lim _{h \rightarrow 0^{+}} \frac{f(0+h)-f(0)}{h} \\
& =\lim _{h \rightarrow 0^{+}} \frac{h}{h} \quad|h|=h \text { quando } h>0 \\
& =\lim _{h \rightarrow 0^{+}} 1=1
\end{aligned}
$$

e

$$
\begin{aligned}
f_{-}^{\prime}(0) & =\lim _{h \rightarrow 0^{-}} \frac{f(0+h)-f(0)}{h} \\
& =\lim _{h \rightarrow 0^{-}} \frac{-h}{h} \quad|h|=-h \text { quando } h<0 \\
& =\lim _{h \rightarrow 0^{-}}-1=-1 .
\end{aligned}
$$

Logo, a função $y=f(x)=|x|$ não é derivável em $x=0$, pois neste ponto as derivadas laterais são diferentes.

Observação 4.6. Sabemos que a função módulo $y=f(x)=|x|$ é contínua em $x=0$, contudo, como acabamos de verificar no exemplo acima essa função não é derivável em $x=0$. Portanto, concluímos que nem toda função contínua é derivável, por outro lado como provado no teorema 4.1, temos que toda função derivável em um ponto c é continua neste ponto.

\subsection{Regras de Derivação}

Nesta seção, apresentaremos algumas regras de derivação que serão úteis para determinar as derivadas das funções sem usarmos a definição.

Proposição 4.2. Seja $k$ uma constante e $f(x)=k$ para todo $x$, então $f^{\prime}(x)=0$. 
Prova. Pela definição de derivada, temos que:

$$
\begin{aligned}
f^{\prime}(x) & =\lim _{h \rightarrow 0} \frac{f(x+h)-f(x)}{h} \\
& =\lim _{h \rightarrow 0} \frac{k-k}{h} \\
& =\lim _{h \rightarrow 0} 0 \\
& =0 .
\end{aligned}
$$

Proposição 4.3. Seja $n$ um número inteiro positivo e $f(x)=x^{n}$, então $f^{\prime}(x)=n . x^{n-1}$.

Prova. Pela definição de derivada, temos que:

$$
\begin{aligned}
f^{\prime}(x) & =\lim _{h \rightarrow 0} \frac{f(x+h)-f(x)}{h} \\
& =\lim _{h \rightarrow 0} \frac{(x+h)^{n}-x^{n}}{h} .
\end{aligned}
$$

Agora, usando o Binômio de Newton para expandirmos $(x+h)^{n}$, temos que:

$$
\begin{aligned}
f^{\prime}(x) & =\lim _{h \rightarrow 0} \frac{\left(x^{n}+n x^{n-1} h+\frac{n(n+1)}{2 !} x^{n-2} h^{2}+\ldots+n x h^{n-1}+h^{n}\right)-x^{n}}{h} \\
& =\lim _{h \rightarrow 0} \frac{h\left(n x^{n-1}+\frac{n(n+1)}{2 !} x^{n-2} h+\ldots+n x h^{n-2}+h^{n-1}\right)}{h} \\
& \left.=\lim _{h \rightarrow 0}\left(n x^{n-1}+\frac{n(n+1)}{2 !} x^{n-2} h+\ldots+n x h^{n-2}+h^{n-1}\right)\right) \\
& =n \cdot x^{n-1} .
\end{aligned}
$$

Proposição 4.4. Seja $f$ uma função derivável em $x$ e c uma constante, então:

$$
\frac{d}{d x}(c f(x))=c \frac{d f(x)}{d x}=c f^{\prime}(x)
$$

Prova. Por hipótese, temos que:

$$
\frac{d f(x)}{d x}=f^{\prime}(x)=\lim _{h \rightarrow 0} \frac{f(x+h)-f(x)}{h},
$$

assim,

$$
\begin{aligned}
\frac{d}{d x}(c f(x)) & =\lim _{h \rightarrow 0} \frac{c f(x+h)-c f(x)}{h} \\
& =\lim _{h \rightarrow 0} c\left(\frac{f(x+h)-f(x)}{h}\right) \\
& =c \lim _{h \rightarrow 0} \frac{f(x+h)-f(x)}{h} \\
& =c \frac{d f(x)}{d x}=c f^{\prime}(x) .
\end{aligned}
$$


Proposição 4.5. Sejam $f$ e $g$ duas funções deriváveis em $x$, então:

$$
\frac{d}{d x}(f(x)+g(x))=\frac{d f(x)}{d x}+\frac{d g(x)}{d x}=f^{\prime}(x)+g^{\prime}(x) .
$$

Prova. Por hipótese, temos que:

$$
\frac{d f(x)}{d x}=f^{\prime}(x)=\lim _{h \rightarrow 0} \frac{f(x+h)-f(x)}{h} \quad \text { e } \quad \frac{d g(x)}{d x}=g^{\prime}(x)=\lim _{h \rightarrow 0} \frac{g(x+h)-g(x)}{h}
$$

assim, tem-se:

$$
\begin{aligned}
\frac{d}{d x}(f(x)+g(x)) & =\lim _{h \rightarrow 0} \frac{[f(x+h)+g(x+h)]-[f(x)+g(x)]}{h} \\
& =\lim _{h \rightarrow 0} \frac{[f(x+h)-f(x)]+[g(x+h)-g(x)]}{h} \\
& =\lim _{h \rightarrow 0} \frac{f(x+h)-f(x)}{h}+\lim _{h \rightarrow 0} \frac{g(x+h)-g(x)}{h} \\
& =f^{\prime}(x)+g^{\prime}(x) .
\end{aligned}
$$

Proposição 4.6. Sejam $f$ e $g$ duas funções deriváveis em $x$, então:

$$
\frac{d}{d x}(f(x) \cdot g(x))=\frac{d f(x)}{d x} \cdot g(x)+f(x) \cdot \frac{d g(x)}{d x}=f^{\prime}(x) \cdot g(x)+f(x) \cdot g^{\prime}(x) .
$$

Prova. Por hipótese, temos que:

$$
\frac{d f(x)}{d x}=f^{\prime}(x)=\lim _{h \rightarrow 0} \frac{f(x+h)-f(x)}{h}
$$

$$
\frac{d g(x)}{d x}=g^{\prime}(x)=\lim _{h \rightarrow 0} \frac{g(x+h)-g(x)}{h},
$$

com essa hipótese e observando que como a função $f$ é derivável em $x$, então, pelo teorema 4.1, temos que $f$ é contínua, isto é, $\lim _{h \rightarrow 0} f(x+h)=f(x)$, além disso, somaremos e subtrairemos no numerador a expressão $f(x+h) \cdot g(x)$, logo:

$$
\begin{aligned}
\frac{d}{d x}(f(x) \cdot g(x)) & =\lim _{h \rightarrow 0} \frac{f(x+h) g(x+h)-f(x+h) g(x)+f(x+h) g(x)-f(x) g(x)}{h} \\
& =\lim _{h \rightarrow 0} \frac{f(x+h)[g(x+h)-g(x)]+g(x)[f(x+h)-f(x)]}{h} \\
= & \lim _{h \rightarrow 0}\left[f(x+h) \cdot \frac{g(x+h)-g(x)}{h}\right]+\lim _{h \rightarrow 0}\left[g(x) \cdot \frac{f(x+h)-f(x)}{h}\right] \\
= & \lim _{h \rightarrow 0} f(x+h) \cdot \lim _{h \rightarrow 0} \frac{g(x+h)-g(x)}{h}+\lim _{h \rightarrow 0} g(x) \cdot \lim _{h \rightarrow 0} \frac{f(x+h)-f(x)}{h} \\
= & f(x) \cdot g^{\prime}(x)+g(x) \cdot f^{\prime}(x) \\
= & f^{\prime}(x) \cdot g(x)+f(x) \cdot g^{\prime}(x) .
\end{aligned}
$$


Proposição 4.7. Sejam $f$ e $g$ duas funções deriváveis em $x$, em que $g(x) \neq 0$, então:

$$
\frac{d}{d x}\left(\frac{f(x)}{g(x)}\right)=\frac{\frac{d f(x)}{d x} \cdot g(x)-f(x) \cdot \frac{d g(x)}{d x}}{[g(x)]^{2}}=\frac{f^{\prime}(x) \cdot g(x)-f(x) \cdot g^{\prime}(x)}{[g(x)]^{2}} .
$$

Prova. Por hipótese, temos que:

$$
\frac{d f(x)}{d x}=f^{\prime}(x)=\lim _{h \rightarrow 0} \frac{f(x+h)-f(x)}{h}
$$

e

$$
\frac{d g(x)}{d x}=g^{\prime}(x)=\lim _{h \rightarrow 0} \frac{g(x+h)-g(x)}{h},
$$

com essa hipótese e observando que como $g$ é derivável em $x$, então, pelo teorema 4.1, temos que $g$ é contínua, isto é, $\lim _{h \rightarrow 0} g(x+h)=g(x)$, além disso, somaremos e subtrairemos no numerador a expressão $f(x) \cdot g(x), \log$ :

$$
\begin{aligned}
\frac{d}{d x}\left(\frac{f(x)}{g(x)}\right) & =\lim _{h \rightarrow 0} \frac{\frac{f(x+h)}{g(x+h)}-\frac{f(x)}{g(x)}}{h} \\
& =\lim _{h \rightarrow 0} \frac{1}{h}\left[\frac{f(x+h) g(x)-f(x) g(x+h)}{g(x+h) g(x)}\right] \\
& =\lim _{h \rightarrow 0} \frac{1}{h}\left[\frac{f(x+h) g(x)-f(x) g(x)+f(x) g(x)-f(x) g(x+h)}{g(x+h) g(x)}\right] \\
& =\lim _{h \rightarrow 0}\left[\frac{f(x+h)-f(x)}{h} \cdot g(x)-f(x) \cdot \frac{g(x+h)-g(x)}{h}\right] \\
& =\frac{\lim _{h \rightarrow 0} \frac{f(x+h)-f(x)}{h} \cdot \lim _{h \rightarrow 0} g(x)-\lim _{h \rightarrow 0} f(x) \cdot \lim _{h \rightarrow 0} \frac{g(x+h)-g(x)}{h}}{\lim _{h \rightarrow 0} g(x+h) \cdot \lim _{h \rightarrow 0} g(x)} \\
& =\frac{f^{\prime}(x) \cdot g(x)-f(x) \cdot g^{\prime}(x)}{[g(x)]^{2}} .
\end{aligned}
$$

Proposição 4.8. Seja $f(x)=x^{-n}$ com $n$ um número inteiro positivo e $x \neq 0$, então, $f^{\prime}(x)=-n x^{-n-1}$.

Prova. De início, note que $f(x)=x^{-n}=\frac{1}{x^{n}}$, agora, usando a proposição 4.7, temos:

$$
f^{\prime}(x)=\frac{(1)^{\prime} \cdot x^{n}-1 \cdot\left(x^{n}\right)^{\prime}}{\left(x^{n}\right)^{2}}=\frac{0 \cdot x^{n}-1 \cdot n x^{n-1}}{\left(x^{n}\right)^{2}}=\frac{-n x^{n-1}}{x^{2 n}}=-n x^{-n-1} .
$$

Exemplo 4.9. Calcule a derivada da função $f(x)=\frac{1}{x^{12}}+\frac{1}{x^{3}}$.

Solução. Usando a propriedade da derivada de uma soma de funções e a Proposição 4.8, tem-se:

$$
\begin{aligned}
\frac{d}{d x} f(x)=\frac{d}{d x}\left(\frac{1}{x^{12}}+\frac{1}{x^{3}}\right) & =\frac{d}{d x}\left(x^{-12}+x^{-3}\right)=\frac{d}{d x}\left(x^{-12}\right)+\frac{d}{d x}\left(x^{-3}\right) \\
& =-12 x^{-13}-3 x^{-4}
\end{aligned}
$$




\subsection{Derivada como Taxa de Variação}

Vamos pensar, agora, em variação como a mudança em relação ao tempo, contudo, outras variáveis podem ser tratadas da mesma maneira. Assim, interpretando a razão incremental $[f(x+h)-f(x)] / h$ como a taxa de variação média de uma função $f$ no intervalo de $x$ até $x+h$, e tomando seu limite quando $h \rightarrow 0$, podemos interpretar como a taxa com que $f$ varia no ponto $x$.

Definição 4.4. A taxa de variação instantânea de $f$ em relação a $x$ em $x_{0}$ é a derivada:

$$
f^{\prime}\left(x_{0}\right)=\lim _{h \rightarrow 0} \frac{f\left(x_{0}+h\right)-f\left(x_{0}\right)}{h},
$$

desde que o limite exista.

Exemplo 4.7. Calcule a taxa de variação do volume de um balão esférico em relaçãa ao seu raio $r$, quando o raio do balão for igual a $5 \mathrm{~cm}$.

Solução. Sabemos que a expressão para o volume de um balão esférico de raio $r$ é dado por:

$$
V(r)=\frac{4 \pi r^{3}}{3},
$$

desse modo, a taxa de variação do volume em relação ao raio é:

$$
\begin{aligned}
\frac{d}{d r} V(r) & =\frac{d}{d r}\left(\frac{4 \pi r^{3}}{3}\right) \\
& =\frac{4 \pi}{3} \cdot 3 r^{2} \\
& =4 \pi r^{2} .
\end{aligned}
$$

Quando $r=5$, o volume varia a uma taxa de $4 \pi 5^{2}=100 \pi \mathrm{cm}^{2}$.

Observação 4.7. Pelo exemplo foi possivel perceber que a fórmula da área da esfera vista no exemplo 4.7 é a derivada do seu volume, ou seja, em outras palavras é a taxa de variação do volume em função do seu raio.

Na sequência mostraremos como calcular as derivadas das seis funções trigonométricas.

\section{Derivada da Função Seno}

Consideramos a função $f(x)=\operatorname{sen}(x)$, com $x$ medido em radianos, além da identidade da soma para a função seno, dada por: $\operatorname{sen}(x+h)=\operatorname{sen}(x) \cos (h)+\cos (x) \operatorname{sen}(h)$, logo, temos que a derivada da função seno é:

$$
\begin{aligned}
f^{\prime}(x) & =\lim _{h \rightarrow 0} \frac{f(x+h)-f(x)}{h} \\
& =\lim _{h \rightarrow 0} \frac{\operatorname{sen}(x+h)-\operatorname{sen}(x)}{h} \\
& =\lim _{h \rightarrow 0} \frac{(\operatorname{sen}(x) \cos (h)+\cos (x) \operatorname{sen}(h))-\operatorname{sen}(x)}{h} \\
& =\lim _{h \rightarrow 0}\left(\operatorname{sen}(x) \cdot \frac{\cos (h)-1}{h}\right)+\lim _{h \rightarrow 0}\left(\cos (x) \cdot \frac{\operatorname{sen}(h)}{h}\right) \\
& =\cos (x) .
\end{aligned}
$$




\section{Derivada da Função Cosseno}

Consideramos a função $f(x)=\cos (x)$, com $x$ medido em radianos, além da identidade da soma para a função cosseno, dada por:

$$
\cos (x+h)=\cos (x) \cos (h)-\operatorname{sen}(x) \operatorname{sen}(h),
$$

logo, temos que a derivada da função cosseno é:

$$
\begin{aligned}
f^{\prime}(x) & =\lim _{h \rightarrow 0} \frac{f(x+h)-f(x)}{h} \\
& =\lim _{h \rightarrow 0} \frac{\cos (x+h)-\cos (x)}{h} \\
& =\lim _{h \rightarrow 0} \frac{(\cos (x) \cos (h)-\operatorname{sen}(x) \operatorname{sen}(h))-\cos (x)}{h} \\
& =\lim _{h \rightarrow 0} \frac{\cos (x)(\cos (h)-1)-\operatorname{sen}(x) \operatorname{sen}(h)}{h} \\
& =\lim _{h \rightarrow 0} \cos (x) \cdot \frac{\cos (h)-1}{h}-\lim _{h \rightarrow 0} \operatorname{sen}(x) \cdot \frac{\operatorname{sen}(h)}{h} \\
& =\cos (x) \cdot \lim _{h \rightarrow 0} \frac{\cos (h)-1}{h}-\operatorname{sen}(x) \cdot \lim _{h \rightarrow 0} \frac{\operatorname{sen}(h)}{h} \\
& =\cos (x) \cdot 0-\operatorname{sen}(x) \cdot 1 \\
& =-\operatorname{sen}(x) .
\end{aligned}
$$

Consideramos duas funções deriváveis $f$ e $g$, nas quais denotaremos $y=f(u)$ e $u=g(x)$, tal que para todo $x, g(x)$ está no domínio de $f$, poderemos escrever $y=f(u)=f(g(x))$, isto é, a função composta $(f \circ g)(x)$.

Exemplo 4.8. Determine a derivada de $y=16 x^{4}-8 x^{2}+1$.

Solução. Note, primeiramente, que $y=16 x^{4}-8 x^{2}+1=\left(4 x^{2}-1\right)^{2}$, isto é, uma função composta de $y=u^{2}$ e $u=4 x^{2}-1$. Calculando as derivadas, observamos que:

$$
\frac{d y}{d u} \cdot \frac{d u}{d x}=2 u \cdot(8 x)=2\left(4 x^{2}-1\right) \cdot 8 x=64 x^{3}-16 x .
$$

Por outro lado, calculando a derivada a partir da fórmula expandida, tem-se:

$$
\frac{d y}{d x}=\frac{d}{d x}\left(16 x^{4}-8 x^{2}+1\right)=64 x^{3}-16 x .
$$

Verificando que:

$$
\frac{d y}{d u} \cdot \frac{d u}{d x}=\frac{d y}{d x} .
$$

A seguir, apresentamos a regra da cadeia que é uma das mais importantes e amplamente utilizada.

Teorema 4.10. Seja $f(u)$ derivável no ponto $u=g(x)$ e $g(x)$ derivável em $x$, então a função composta $(f \circ g)(x)=f(g(x))$ é derivável em $x$ e

$$
(f \circ g)^{\prime}(x)=f^{\prime}(g(x)) \cdot g^{\prime}(x) .
$$


Em outra notação, se $y=f(u)$ e $u=g(x)$, então:

$$
\frac{d y}{d x}=\frac{d y}{d u} \cdot \frac{d u}{d x}
$$

em que $\frac{d y}{d u}$ é calculada em $u=g(x)$.

Exemplo 4.9. Calcule a derivada de $f(x)=\left(x^{4}+x^{2}-1\right)^{234}$.

Solução. Usando o Teorema da Regra da Cadeia, temos que:

$$
\begin{aligned}
f^{\prime}(x) & =\frac{d}{d x}(f(x)) \\
& =\frac{d}{d x}\left(x^{4}+x^{2}-1\right)^{234} \\
& =234\left(x^{4}+x^{2}-1\right)^{233} \cdot \frac{d}{d x}\left(x^{4}+x^{2}-1\right) \\
& =234\left(x^{4}+x^{2}-1\right)^{233} \cdot\left(4 x^{3}+2 x\right) .
\end{aligned}
$$

Analizaremos a derivada da função exponencial natural dada por $f(x)=e^{x}$, usando a definição de derivada, temos que:

$$
\begin{aligned}
f^{\prime}(x) & =\lim _{h \rightarrow 0} \frac{f(x+h)-f(x)}{h}=\lim _{h \rightarrow 0} \frac{e^{x+h}-e^{x}}{h} \\
& =\lim _{h \rightarrow 0} \frac{e^{x} \cdot e^{h}-e^{x}}{h}=\lim _{h \rightarrow 0} \frac{e^{x}\left(e^{h}-1\right)}{h}=\lim _{h \rightarrow 0} e^{x} \cdot \lim _{h \rightarrow 0} \frac{e^{h}-1}{h} .
\end{aligned}
$$

Observamos que o limite $\lim _{h \rightarrow 0} \frac{e^{h}-1}{h}=1$, pois $\lim _{h \rightarrow 0^{+}} \frac{e^{h}-1}{h}=1$ e $\lim _{h \rightarrow 0^{-}} \frac{e^{h}-1}{h}=1$. Portanto, tem-se:

$$
f^{\prime}(x)=\lim _{h \rightarrow 0} \frac{e^{x+h}-e^{x}}{h}=\lim _{h \rightarrow 0} e^{x} \cdot \lim _{h \rightarrow 0} \frac{e^{h}-1}{h}=e^{x} \cdot 1=e^{x} .
$$

Logo, verificamos que a derivada da função exponencial é a própria exponencial.

Observação 4.8. Se u é uma função derivável em $x$, podemos aplicar a regra da cadeia para obtermos:

$$
\frac{d}{d x} e^{u}=e^{u} \cdot \frac{d u}{d x}
$$

Exemplo 4.10. Determine a derivada da função $h(x)=e^{x^{2}+\cos (x)+2}$.

Solução. Para calcularmos a derivada da função $h$, usaremos a observação 4.8, isto é:

$$
\begin{aligned}
h^{\prime}(x) & =\left(e^{x^{2}+\cos (x)+2}\right)^{\prime} \\
& =e^{x^{2}+\cos (x)+2} \cdot \frac{d}{d x}\left(x^{2}+\cos (x)+2\right) \\
& =e^{x^{2}+\cos (x)+2} \cdot(2 x-\operatorname{sen}(x)) .
\end{aligned}
$$

Agora, como já sabemos calcular a derivada da função $f(x)=e^{x}$, para encontrar a derivada de sua inversa que é função dada por $f^{-1}(x)=\ln (x)$. 
Isto é, vamos determinar a derivada da função logarítmica. Notamos que:

$$
\begin{aligned}
\left(f^{-1}\right)^{\prime}(x) & =\frac{1}{f^{\prime}\left(f^{-1}(x)\right)} \\
& =\frac{1}{e^{f^{-1}(x)}} \quad f^{\prime}(x)=e^{x} \Rightarrow f^{\prime}\left(f^{-1}(x)\right)=e^{f^{-1}(x)} \\
& =\frac{1}{e^{\ln (x)}} \\
& =\frac{1}{x} \quad \text { relação da função inversa: } f\left(f^{-1}(x)\right)=x
\end{aligned}
$$

Observação 4.9. Se u é uma função derivável em $x$ com $u>0$, podemos aplicar a regra da cadeia para obtermos:

$$
\frac{d}{d x}(\ln (u))=\frac{1}{u} \cdot \frac{d u}{d x}
$$

Exemplo 4.11. Determine a derivada da função $h(x)=\ln \left(2 x^{2}+\operatorname{sen}(x)+7\right)$.

Solução. Para calcularmos a derivada da função $h$, usaremos a Observação 4.9, isto é:

$$
\begin{aligned}
h^{\prime}(x) & =\left(\ln \left(2 x^{2}+\operatorname{sen}(x)+7\right)\right)^{\prime} \\
& =\frac{1}{2 x^{2}+\operatorname{sen}(x)+7} \cdot \frac{d}{d x}\left(2 x^{2}+\operatorname{sen}(x)+7\right) \\
& =\frac{1}{2 x^{2}+\operatorname{sen}(x)+7} \cdot(4 x+\cos (x)) .
\end{aligned}
$$

Proposição 4.11. O número e pode ser calculado como o limite:

$$
\lim _{x \rightarrow 0}(1+x)^{\frac{1}{x}}=e
$$

Prova. Seja $f(x)=\ln (x)$, então $f^{\prime}(x)=\frac{1}{x}$ e $f^{\prime}(1)=1$. Contudo, por outro lado, pela definição de derivada, temos que:

$$
\begin{aligned}
f^{\prime}(1) & =\lim _{x \rightarrow 0} \frac{f(1+x)-f(1)}{x} \\
& =\lim _{x \rightarrow 0} \frac{\ln (1+x)-\ln (1)}{x} \\
& =\lim _{x \rightarrow 0} \frac{1}{x} \ln (1+x) \\
& =\lim _{x \rightarrow 0} \ln (1+x)^{\frac{1}{x}} \\
& =\ln \left(\lim _{x \rightarrow 0}(1+x)^{\frac{1}{x}}\right) .
\end{aligned}
$$

Agora, como $f^{\prime}(1)=1$, temos que:

$$
\ln \left(\lim _{x \rightarrow 0}(1+x)^{\frac{1}{x}}\right)=1
$$

Portanto, fazendo a exponenciação de ambos os lados, temos que:

$$
\lim _{x \rightarrow 0}(1+x)^{\frac{1}{x}}=e .
$$




\subsection{Derivadas de Ordem Superior}

Seja $f$ uma função derivável em um certo intervalo $I$, se a função $f^{\prime}(x)$, que é conhecida como derivada primeira de $f(x)$, é novamente derivável no mesmo intervalo, então existe a função derivada de $f^{\prime}(x)$, denotada por $f^{\prime \prime}(x)$ ou $\left(\frac{d^{2}}{d x^{2}} f(x)\right)$ que é chamada de derivada segunda de $f(x)$. Diz-se, então, que $f(x)$ é duas vezes derivável.

Considerando esse procedimento sucessivamente e, supondo que $f(x)$ é $n$ vezes derivável, obtémse a função derivada $n$-ésima ou derivada de ordem $n$, de $f(x)$ indicada como $f^{(n)}(x)$. As funções $f^{\prime}(x), f^{\prime \prime}(x), \ldots, f^{(n)}(x)$ são chamadas de derivadas sucessivas de $f(x)$.

Exemplo 4.12. Determine a derivada terceira de $f(x)=x^{5}+3 x^{3}-2 x+1$.

Solução. Aplicando as regras de derivação, temos que:

$$
\begin{aligned}
& f^{\prime}(x)=5 x^{4}+9 x^{2}-2 ; \\
& f^{\prime \prime}(x)=20 x^{3}+18 x ; \\
& f^{\prime \prime \prime}(x)=60 x^{2}+18 .
\end{aligned}
$$

Exemplo 4.12. Determine a derivada segunda de $f(x)=e^{x^{2}}+3 x$.

Solução. Aplicando as regras de derivação, temos que:

$$
\begin{aligned}
& f^{\prime}(x)=e^{x^{2}} \cdot 2 x+3 ; \\
& f^{\prime \prime}(x)=e^{x^{2}} \cdot 2 x \cdot 2 x+e^{x^{2}} \cdot 2 .
\end{aligned}
$$

\subsection{Máximos e Mínimos}

Vamos localizar e identificar valores extremos de uma função contínua a partir de sua derivada. Para isso, começamos com a seguinte definição

Definição 4.5. Seja $f$ uma função de dominio A, dizemos que $f$ tem um valor de máximo global em $A$, em um certo ponto $x_{1}$ se,

$$
f(x) \leq f\left(x_{1}\right), \quad \text { para todo } x \text { em } A,
$$

e f tem um valor de minimo global em $A$ em um ponto $x_{0}$ se,

$$
f(x) \geq f\left(x_{0}\right), \quad \text { para todo } x \text { em } A \text {. }
$$

Definição 4.6. Uma função $f$ tem um valor de máximo local em um ponto interior $x_{1}$ de seu domínio se

$$
f(x) \leq f\left(x_{1}\right),
$$

para qualquer $x$ em um intervalo aberto que contenha o ponto $x_{1}$. Por outro lado, uma função $f$ tem um valor de minimo local em um ponto interior $x_{0}$ de seu domínio se,

$$
f(x) \geq f\left(x_{0}\right),
$$

para qualquer $x$ em um intervalo aberto que contenha o ponto $x_{0}$. 
Teorema 4.13. Seja $f$ uma função contínua em um intervalo fechado $[a, b]$. Então $f$ assume tanto um valor de máximo $M$ como um valor de mínimo $m$ em $[a, b]$. Isto é, existem $x_{0}$ e $x_{1}$ em $[a, b]$, tais que $f\left(x_{0}\right)=m$ e $f\left(x_{1}\right)=M$.

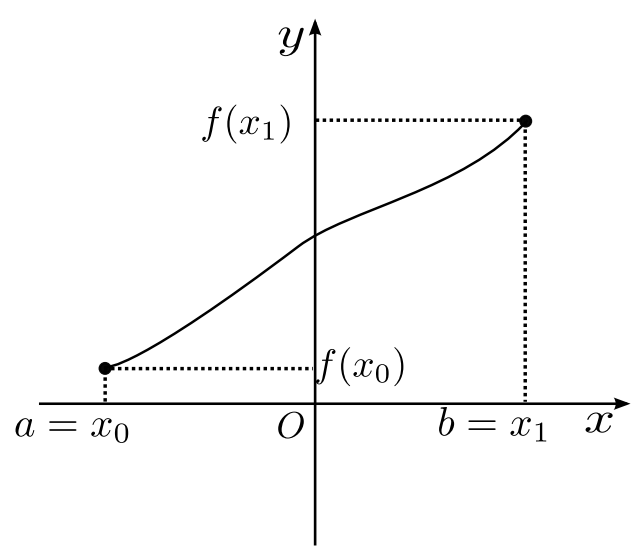

Máximo e mínimo nas extremidades

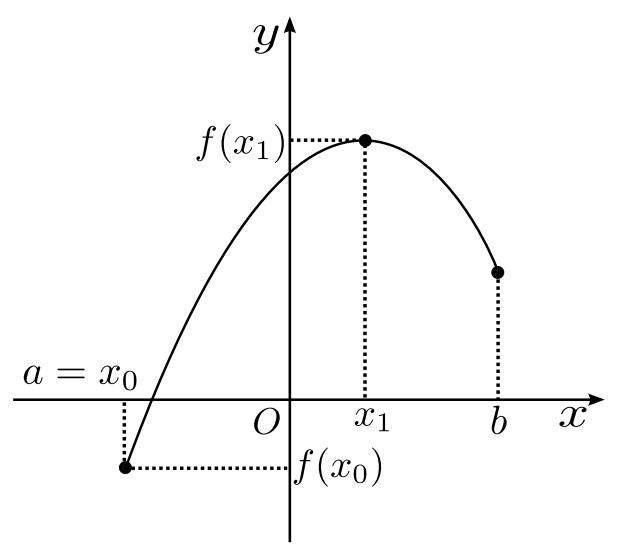

Máximo interior e mínimo na extremidade

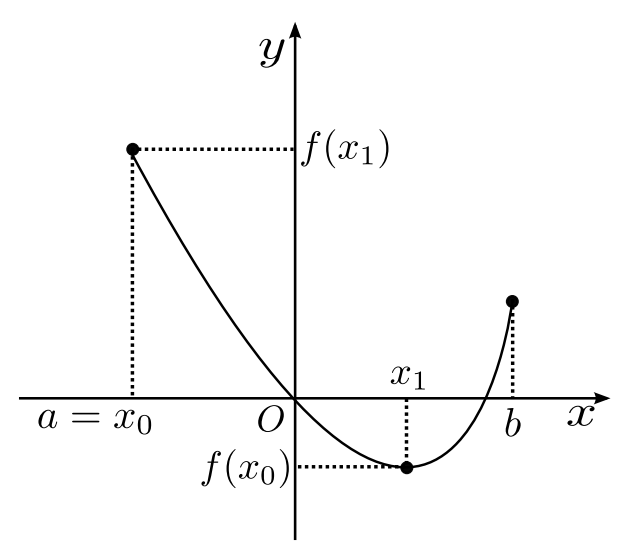

Máximo na extremidade e mínimo no interior

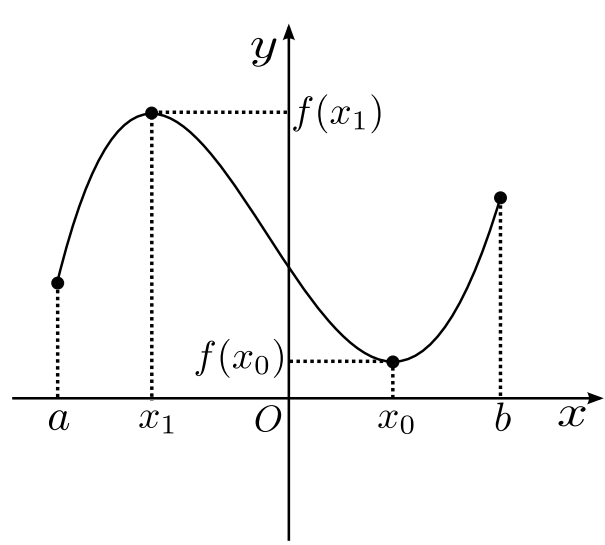

Máximo e mínimo interiores

Figura 4.6: Pontos de Extremo

Teorema 4.14. Se uma função $f$ possui um valor de máximo ou minimo local em um ponto $x_{0}$ interior de seu domínio e se $f^{\prime}$ é definida em $x_{0}$, então:

$$
f^{\prime}\left(x_{0}\right)=0
$$

Prova. Sem perda da generalidade, vamos supor que a função $f$ tenha um valor mínimo local quando $x=x_{0}$, de modo análogo, mostra-se quando temos um valor de máximo local, como temos um valor de mínimo, tem-se que $f(x)-f\left(x_{0}\right) \geq 0$, para qualquer $x$ próximo de $x_{0}$. Agora, como $x_{0}$ é um ponto interior do domínio de $f$, temos que $f^{\prime}\left(x_{0}\right)$ é definida pelo limite bilateral, dado por:

$$
f^{\prime}\left(x_{0}\right)=\lim _{x \rightarrow x_{0}} \frac{f(x)-f\left(x_{0}\right)}{x-x_{0}} .
$$


Portanto, temos a existência de ambos os limites, à esquerda e à direita do ponto $x_{0}$. Desse modo, analisando esses limites separadamente, temos:

$$
f^{\prime}\left(x_{0}\right)=\lim _{x \rightarrow x_{0}^{+}} \frac{f(x)-f\left(x_{0}\right)}{x-x_{0}} \geq 0
$$

pois, $f(x)-f\left(x_{0}\right) \geq 0$ e $x-x_{0}>0$. De modo análogo, tem-se:

$$
f^{\prime}\left(x_{0}\right)=\lim _{x \rightarrow x_{0}^{-}} \frac{f(x)-f\left(x_{0}\right)}{x-x_{0}} \leq 0
$$

em razão de $f(x)-f\left(x_{0}\right) \geq 0$ e $x-x_{0}<0$. Logo, observando os dois limites laterais concluímos que $f^{\prime}\left(x_{0}\right)$ não pode ser positiva e nem negativa, assim, o único número que não é nem positivo e nem negativo é zero, então, temos que $f^{\prime}\left(x_{0}\right)=0$.

Definição 4.7. Um ponto $x_{0}$ interior do dominio de uma dada função $f$ é dito um ponto crítico, se $f^{\prime}$ é zero ou não existe no ponto $x_{0}$.

Observação 4.10. Um ponto crítico é um candidato a extremo local, isto é, ser um ponto de máximo ou minimo local, falamos em candidato, pois nem todo ponto crítico conduz a um extremo local, conforme apresentado no contra-exemplo a seguir.

Exemplo 4.13. Mostre que $f(x)=x^{3}$ não possui extremos locais.

Solução. Notamos, primeiramente, que a derivada da função $f(x)=x^{3}$ é $f^{\prime}(x)=3 x^{2}$ e o único ponto em que a função derivada $f^{\prime}$ é zero é no ponto $x=0$, desse modo, o ponto $x=0$ é o único ponto crítico. Além disso, se $x>0$, então a função $f(x)$ é positiva e se $x<0$ a função $f(x)$ é negativa. Portanto, $f(0)$ não é nem máximo e nem mínimo local e como um extremo deve ocorrer em um ponto crítico, concluímos que a função $f(x)=x^{3}$ não possui extremos locais.

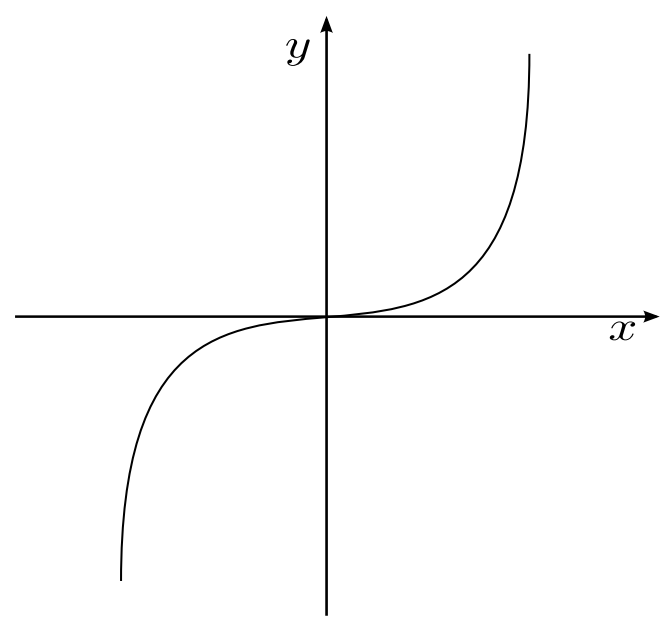

Figura 4.7: $f(x)=x^{3}$

Com os resultados anteriores, podemos definir alguns procedimentos para determinar os extremos de uma função contínua $f$ no intervalo fechado $[a, b]$.

(i) Devemos determinar todos os pontos críticos de $f$ em $(a, b)$; 
(ii) Devemos calcular $f(c)$ para cada número crítico $c$ encontrado em $(i)$;

(iii) Devemos calcular os valores extremos $f(a)$ e $f(b)$;

(iv) Os valores de máximo e mínimo da função $f$ em $[a, b]$ são os maiores e os menores valores da função, respectivamente, encontrados em (ii) e (iii).

Exemplo 4.14. Considere $f(x)=x^{3}-12 x$. Determine os pontos críticos de $f$ e os valores de máximo e minimo de $f$, no intervalo $[-3,6]$.

Solução. Para determinarmos os pontos críticos de $f$, vamos analisar a sua derivada, assim:

$$
f^{\prime}(x)=3 x^{2}-12=3\left(x^{2}-4\right)=3(x+2)(x-2) \text {. }
$$

Como a função derivada $f^{\prime}$ existe para todo $x \in \mathbb{R}$, os pontos críticos são aqueles em que a derivada é zero, isto é, -2 e 2 . Notamos que, como $f$ é contínua em $[-3,3]$, segue pelo resultado acima que os valores de máximo e mínimo estão entre os valores de $f(-3), f(-2), f(2)$ e $f(3)$, assim, calculando esses valores temos:

$$
f(-3)=9, \quad f(-2)=16, \quad f(2)=-16 \quad \text { e } \quad f(6)=144 .
$$

Logo, o valor de mínimo é $f(2)=-16$ e o valor de máximo é $f(6)=144$.

Exemplo 4.15. Considere $f(x)=x^{\frac{2}{3}}=\sqrt[3]{x^{2}}$. Determine os pontos críticos de $f$ e os valores de máximo e minimo de $f$ no intervalo $[-1,8]$.

Solução. Para determinarmos os pontos críticos de $f$ vamos analisar a sua derivada, assim:

$$
f^{\prime}(x)=\frac{2}{3} x^{-\frac{1}{3}}=\frac{2}{3} \cdot \frac{1}{x^{\frac{1}{3}}}=\frac{2}{3 \sqrt[3]{x}} .
$$

Notamos que $f^{\prime}$ não existe em $x=0$ e como $x=0 \in D(f)$, pois o $D(f)=\mathbb{R}$, temos que $x=0$ é um ponto crítico, além disso, notamos que não existe nenhum ponto em que a derivada de $f$ é igual a zero. Assim, como $f$ é contínua em $[-1,8]$, segue pelo resultado acima que os valores de máximo e mínimo estão entre os valores de $f(-1), f(0)$ e $f(8)$, logo, calculando esses valores temos:

$$
f(-1)=1, \quad f(0)=0 \quad \text { e } \quad f(8)=4 .
$$

Portanto, o valor de mínimo é $f(0)=0$ e o valor de máximo é $f(8)=4$.

Exemplo 4.16. Considere $f(x)=\frac{x^{2}}{x-1}$. Determine os pontos críticos de $f$.

Solução. Para determinarmos os pontos críticos de $f$, vamos analisar a sua derivada que é dada por:

$$
f^{\prime}(x)=\frac{2 x(x-1)-x^{2} \cdot 1}{(x-1)^{2}}=\frac{2 x^{2}-2 x-x^{2}}{(x-1)^{2}}=\frac{x^{2}-2 x}{(x-1)^{2}} .
$$

Notamos que $f^{\prime}$ não existe em $x=1$, contudo, $x=1$ não pertence ao domínio de $f$, pois $\operatorname{Dom}(f)=$ $\mathbb{R} \backslash\{1\}, \operatorname{logo} x=1$ não é um ponto crítico de $f$. Resta, ainda, analisarmos quando a derivada de $f$ é igual a zero, desse modo, temos:

$$
f^{\prime}(x)=\frac{x^{2}-2 x}{(x-1)^{2}}=0
$$

assim:

$$
x^{2}-2 x=0 \Leftrightarrow x(x-2)=0,
$$


$\operatorname{logo}, x=0$ ou $x=2$ são os pontos críticos de $f(x)=\frac{x^{2}}{x-1}$.

\subsection{Teorema do Valor Médio}

Já sabemos que a derivada de uma função $f(x)=c$ é zero, em que $c$ é uma constante, contudo, será que se $f^{\prime}(x)=0$ para todos os pontos $x$ pertencentes a um certo intervalo, então a função $f$ é constante? Além disso, se duas funções $f(x)$ e $g(x)$ possuem a mesma derivada, qual será a relação entre essas duas funções? Essas e outras perguntas serão respondidas neste momento.

Teorema 4.15. Seja $f$ uma função contínua em todos os pontos de um intervalo fechado $[a, b]$ e derivável em todos os pontos de seu interior $(a, b)$. Se tivermos que $f(a)=f(b)$, então existe ao menos um número $x_{0}$ em $(a, b)$ tal que:

$$
f^{\prime}\left(x_{0}\right)=0
$$

Prova. Como $f$ é contínua, pelo Teorema 4.13, temos que $f$ possui máximos e mínimos absolutos em $[a, b]$, em que isso pode ocorrer em pontos interiores, tal que $f^{\prime}$ é zero, em pontos interiores, nos quais $f^{\prime}$ não existe ou ainda nas extremidades do domínio da função $f$, que nesse caso são os próprios pontos $a$ e $b$. Contudo, por hipótese, temos que $f$ tem derivada em $(a, b)$, logo, excluímos a possibilidade dos pontos serem interiores em que $f^{\prime}$ não existe.

Por outro lado, se o máximo ou o mínimo ocorrem em um ponto $x_{0}$ entre $a$ e $b$, então, pelo Teorema 4.14 , temos que $f^{\prime}\left(x_{0}\right)=0$ e, assim, encontramos um ponto que satisfaz o teorema. Agora, se o máximo e o mínimo absolutos estão nas extremidades, e como $f(a)=f(b)$, teríamos que a função $f$ é uma constante, isto é, $f(x)=f(a)=f(b)$ para todo $x \in[a, b]$. Logo, $f^{\prime}(x)=0$ e o ponto $x_{0}$ pode ser escolhido em qualquer lugar no interior de $(a, b)$.
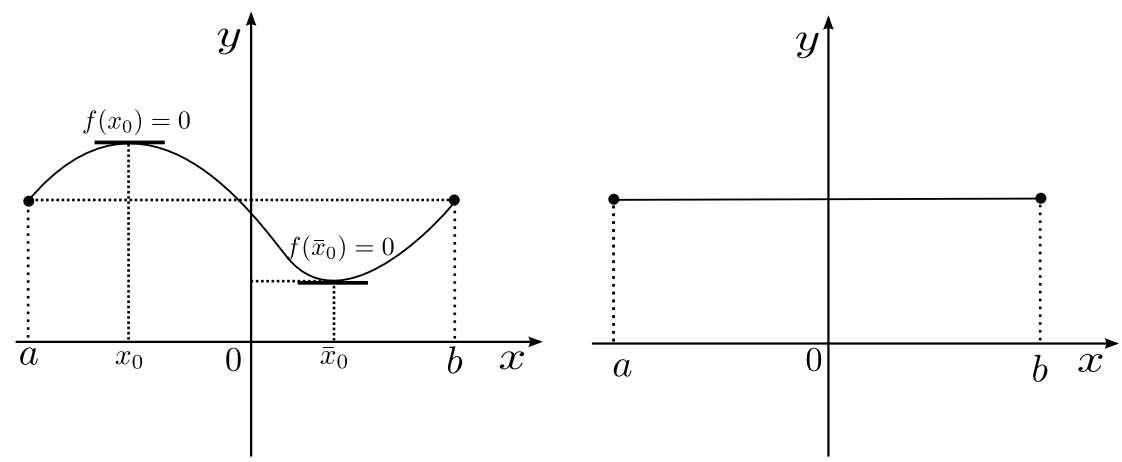

Figura 4.8: Máximos e Mínimos Absolutos

O teorema a seguir, conhecido com Teorema do Valor Médio, é uma generalização do Teorema 4.16, como segue:

Teorema 4.16. Seja $f$ uma função contínua em todos os pontos de um intervalo fechado $[a, b]$ e derivável em todos os pontos de seu interior $(a, b)$. Então, existe ao menos um número $x_{0}$ em $(a, b)$, tal que:

$$
f^{\prime}\left(x_{0}\right)=\frac{f(b)-f(a)}{b-a} .
$$


Prova. Consideramos o gráfico de $f$ e a reta secante que passa pelos pontos $P_{0}=(a, f(a))$ e $P_{1}=(b, f(b))$, em que essa reta tem a seguinte equação:

$$
h(x)=y(x)=f(a)+\frac{f(b)-f(a)}{b-a}(x-a) .
$$

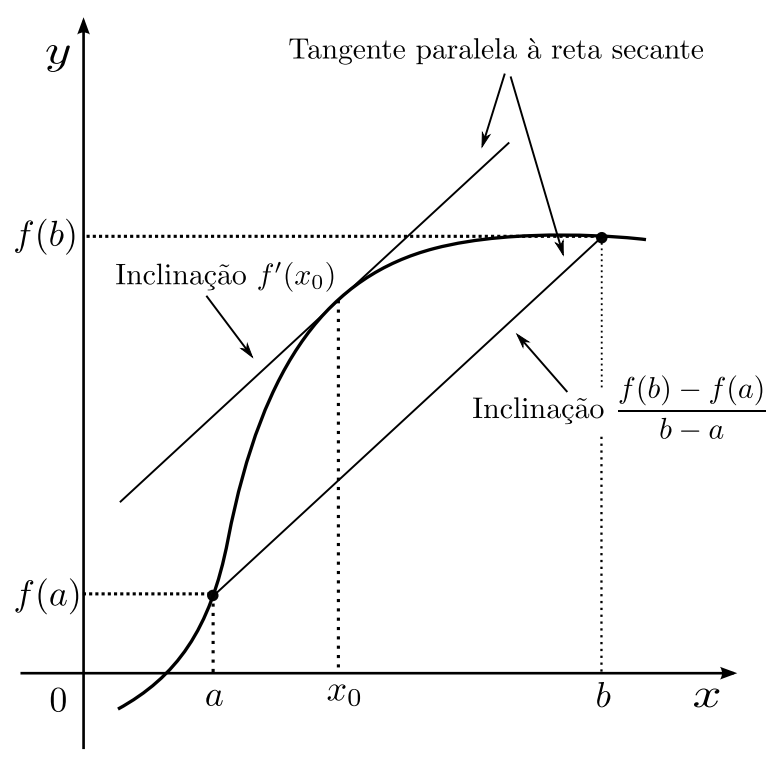

Figura 4.9: Teorema do Valor Médio

Agora, consideramos a diferença na vertical entre os gráficos de $f$ e $h$ em $x$, assim:

$$
v(x)=f(x)-h(x)=f(x)-f(a)-\frac{f(b)-f(a)}{b-a}(x-a),
$$

note que $v(a)=v(b)=0$ e, além disso, $v$ é contínua em $[a, b]$ e derivável em $(a, b)$. Logo, estamos sobre as hipóteses do Teorema 4.16. Assim, $v^{\prime}=0$ em algum ponto $x_{0} \in(a, b)$ e esse é o ponto desejado, para verificar isso, derivamos a equação (4.1) em ambos os lados em relação a $x$ e fazemos $x=x_{0}$, de fato,

$$
v^{\prime}(x)=f^{\prime}(x)-\frac{f(b)-f(a)}{b-a},
$$

$\log \mathrm{o}$

$$
0=v^{\prime}\left(x_{0}\right)=f^{\prime}\left(x_{0}\right)-\frac{f(b)-f(a)}{b-a},
$$

portanto,

$$
f^{\prime}\left(x_{0}\right)=\frac{f(b)-f(a)}{b-a} .
$$

Corolário 4.5.1. Seja $f$ uma função, se $f^{\prime}(x)=0$ para todos os pontos de um intervalo aberto $(a, b)$, então, a função $f$ é uma constante, isto é, $f(x)=K$ para todo $x \in(a, b)$.

Prova. Para provarmos esse resultado, consideramos $x_{1}$ e $x_{2}$ dois pontos diferentes quaisquer em $(a, b)$ e mostraremos que $f\left(x_{1}\right)=f\left(x_{2}\right)$, verificando, desse modo, que $f$ é uma função constante. De fato, supomos sem perda da generalidade que $x_{1}<x_{2}$, além disso, note que $f$ satisfaz as hipóteses do Teorema 
do Valor Médio no intervalo dado por $\left[x_{1}, x_{2}\right]$, dessa forma:

$$
f^{\prime}\left(x_{0}\right)=\frac{f\left(x_{2}\right)-f\left(x_{1}\right)}{x_{2}-x_{1}},
$$

para algum ponto $x_{0} \in\left(x_{1}, x_{2}\right)$. Contudo, como $f^{\prime}(x)=0$ para valores de $x$ em $(a, b)$, temos que:

$$
0=f^{\prime}\left(x_{0}\right)=\frac{f\left(x_{2}\right)-f\left(x_{1}\right)}{x_{2}-x_{1}} .
$$

Assim, $f\left(x_{1}\right)=f\left(x_{2}\right)$, concluindo que $f$ é uma constante, isto é, existe $K \in \mathbb{R}$, tal que $f(x)=K$.

Corolário 4.5.2. Sejam $f$ e $g$ duas funções tais que, $f^{\prime}(x)=g^{\prime}(x)$ para todos os pontos de um intervalo aberto $(a, b)$ então as funçôes $f$ e $g$ diferem por uma constante real $K$, isto é, $f(x)=g(x)+K$ para todo $x \in(a, b)$.

Prova. Seja $s(x)=f(x)-g(x)$, em que para cada $x \in(a, b)$, sua derivada é dada por:

$$
s^{\prime}(x)=f^{\prime}(x)-g^{\prime}(x)=0,
$$

logo, pelo Corolário 4.5.1, temos $s(x)=K$ em $(a, b)$, isto é,

$$
f(x)-g(x)=K,
$$

ou seja, $f(x)=g(x)+K$.

Exemplo 4.17. Mostre que:

$$
\ln (x \cdot a)=\ln (x)+\ln (a)
$$

Solução. Notemos, de início, que:

$$
(\ln (x \cdot a))^{\prime}=\frac{1}{a x} \cdot a=\frac{1}{x}
$$

e

$$
(\ln (x))^{\prime}=\frac{1}{x} .
$$

Logo, temos que as funções $\ln (x . a)$ e $\ln (x)$ possuem a mesma derivada, assim, pelo corolário 4.5.2, temos que essas funções diferem apenas por uma constante, isto é,

$$
\ln (x \cdot a)=\ln (x)+K,
$$

contudo, como essa última equação é válida para qualquer valor positivo de $x$, então, consideramos $x=1$. Desse modo, temos que:

$$
\ln (a)=\ln (1)+K=0+K,
$$

assim, concluímos que $K=\ln (a)$ e, portanto,

$$
\ln (x \cdot a)=\ln (x)+\ln (a) .
$$




\subsection{O Teste da Derivada Primeira}

Mostraremos no teorema a seguir como o sinal da derivada de uma função $f^{\prime}$ será importante para determinarmos em que lugar a função $f$ é crescente ou decrescente.

Teorema 4.17. Seja $f$ uma função contínua em $[a, b]$ e diferenciável em $(a, b)$.

Se $f^{\prime}(x)>0$ para todo $x$ em $(a, b)$, então $f$ é crescente em $[a, b]$.

Se $f^{\prime}(x)<0$ para todo $x$ em $(a, b)$, então $f$ é decrescente em $[a, b]$.

Prova. Provaremos para o caso, quando $f^{\prime}(x)>0$ para todo $x$ em $(a, b)$, para o caso em que $f^{\prime}(x)<0$ será análogo, desse modo, consideramos $x_{1}$ e $x_{2}$ em $[a, b]$ tais que $x_{1}<x_{2}$ para verificarmos que $f$ é crescente, precisamos mostrar que $f\left(x_{1}\right)<f\left(x_{2}\right)$. Para comprovarmos isso, usaremos o Teorema do Valor Médio ao intervalo $\left[x_{1}, x_{2}\right]$, assim, temos que:

$$
f^{\prime}\left(x_{0}\right)\left(x_{2}-x_{1}\right)=f\left(x_{2}\right)-f\left(x_{1}\right)
$$

para algum $x_{0}$ no intervalo aberto $\left(x_{1}, x_{2}\right)$, além disso, como $x_{2}-x_{1}>0$ e por hipótese $f^{\prime}\left(x_{0}\right)>0$, temos que:

$$
0<f^{\prime}\left(x_{0}\right)\left(x_{2}-x_{1}\right)=f\left(x_{2}\right)-f\left(x_{1}\right)
$$

logo, $0<f\left(x_{2}\right)-f\left(x_{1}\right)$. Portanto, $f\left(x_{1}\right)<f\left(x_{2}\right)$.

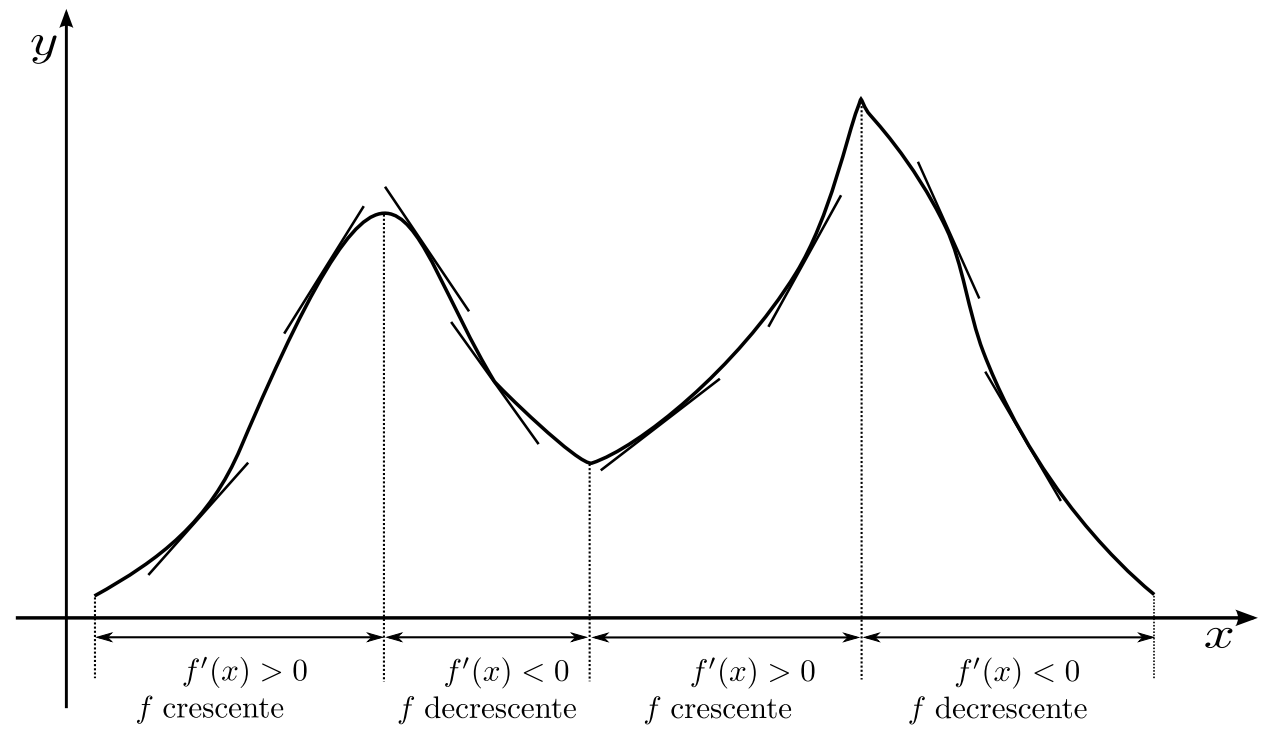

Figura 4.10: Teste da Derivada Primeira

Para determinarmos os extremos locais, primeiramente, determinamos os pontos críticos da função, na sequência testamos todos esses pontos críticos para determinarmos a ocorrência, ou não, de um extremo local. Teorema, a seguir, apresenta um teste para determinarmos a ocorrência desses extremos.

Teorema 4.18. Seja $x_{0}$ um número crítico de uma função $f$, e suponhamos que $f$ seja continua em $x_{0}$ e derivável em um intervalo aberto $I$ contendo o ponto $x_{0}$, exceto possivelmente no próprio $x_{0}$, assim, se: 
(i) $f^{\prime}$ passa de positiva para negativa em $x_{0}$, então $f\left(x_{0}\right)$ é um máximo local de $f$;

(ii) $f^{\prime}$ passa de negativa para positiva em $x_{0}$, então $f\left(x_{0}\right)$ é um minimo local de $f$;

(iii) $f^{\prime}(x)>0$ ou se $f^{\prime}(x)<0$ para todo $x$ em $I$, exceto em $x=x_{0}$, então $f\left(x_{0}\right)$ não é extremo local de $f$.

Prova. Provaremos apenas o item $(i)$, pois os itens $(i i)$ e (iii) são análogos. De fato, se $f^{\prime}$ passa de positiva para negativa em $x_{0}$, então, existe um intervalo aberto $(a, b)$ contendo $x_{0}$, tal que:

$$
f^{\prime}(x)>0 \text { para } a<x<x_{0} \quad \text { e } \quad f^{\prime}(x)<0 \text { para } x_{0}<x<b .
$$

Por outro lado, podemos escolher $a$ e $b$ tal que $f$ seja contínua em $[a, b]$. Assim, pelo Teorema 4.17, temos que $f$ é crescente em $\left[a, x_{0}\right]$ e decrescente em $\left[x_{0}, b\right]$. Portanto, $f(x)<f\left(x_{0}\right)$ para todo $x \in(a, b)$, desse modo, $f\left(x_{0}\right)$ é um máximo local de $f$.

(i)
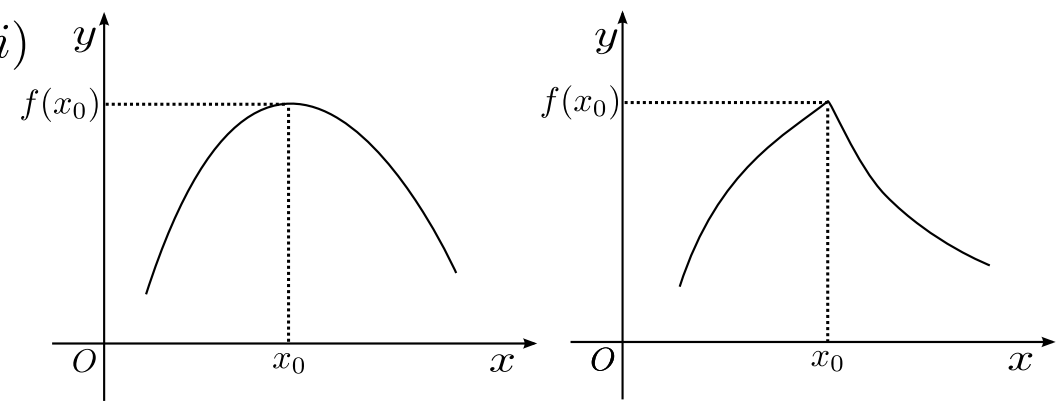

$f\left(x_{0}\right)$ máximo local

(ii)

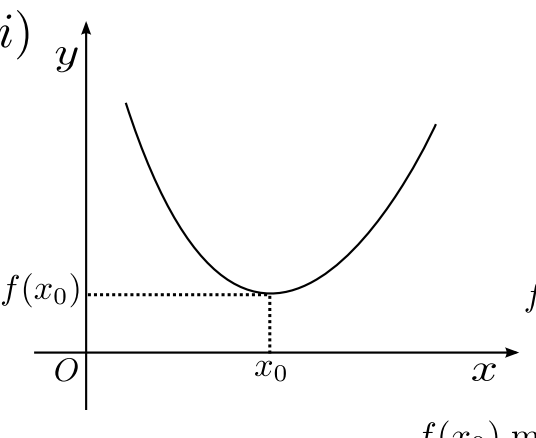

$f\left(x_{0}\right)$ mínimo local

(iii)
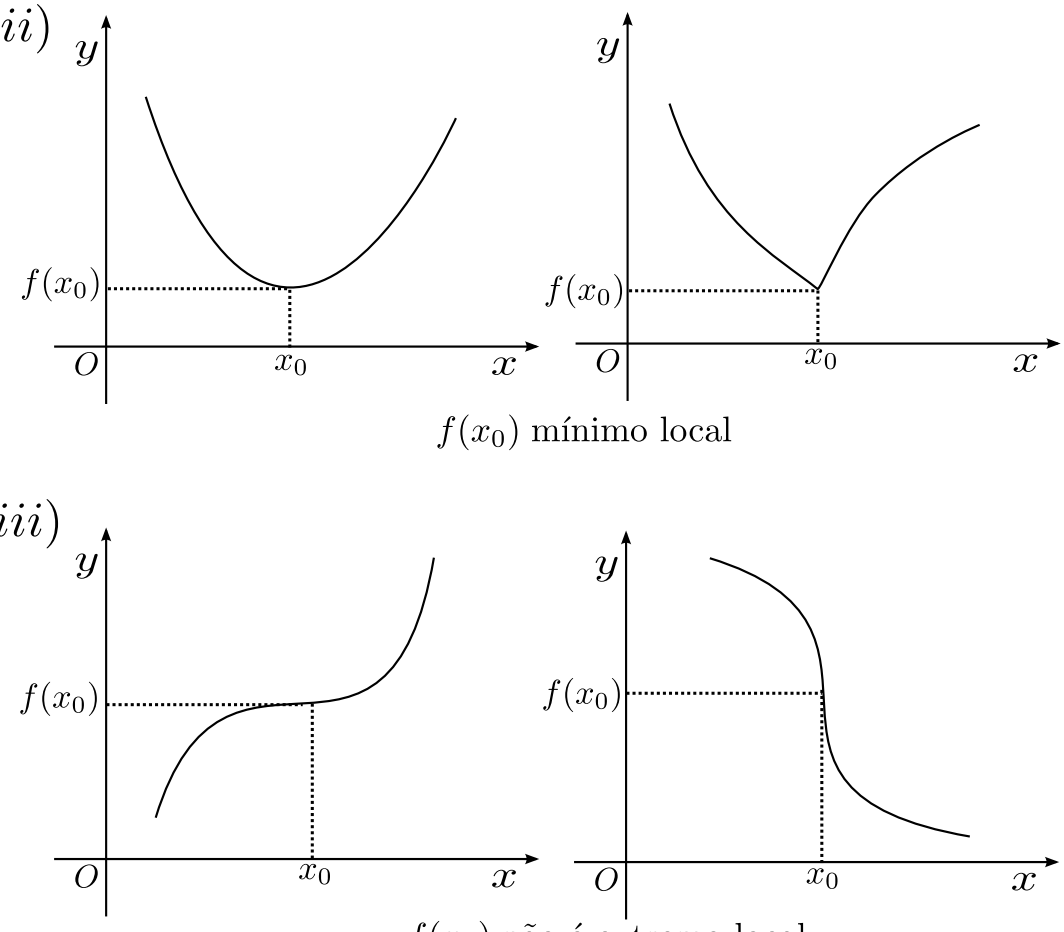

local

$f\left(x_{0}\right)$ não é extremo local

Figura 4.11: Teste da Derivada Primeira para Extremos. 
Exemplo 4.18. Determine os extremos locais de $f(x)=2 x^{3}+x^{2}-20 x+1$ e os intervalos em que $f$ é crescente ou decrescente.

Solução. Primeiramente, vamos determinar os pontos críticos de $f$ e analisar a sua derivada, que é dada por:

$$
f^{\prime}(x)=6 x^{2}+2 x-20 .
$$

Como a função derivada $f^{\prime}$ existe para todo $x \in \mathbb{R}$, os pontos críticos são aqueles em que a derivada é zero, logo, $f^{\prime}(x)=6 x^{2}+2 x-20=0$, isto é, $x=-2$ e $x=\frac{5}{3}$. Vamos analisar os intervalos em que $f$ é crescente ou decrescente.

Caso $x \in(-\infty,-2)$ : Notamos que $f^{\prime}(x)$ é nula apenas em $x=-2$ e $x=\frac{5}{3}$, desse modo, no intervalo $(-\infty,-2)$, teremos que $f^{\prime}$ terá o mesmo sinal ou positiva ou negativa. Para determinar esse sinal, basta escolhermos um valor arbitrário no intervalo $(-\infty,-2)$, por exemplo, $x=-3$ (notamos que poderia ser qualquer número, como: $-4,-13$, etc..., desde que esteja no intervalo $x \in(-\infty,-2)$ ), assim, temos que $f^{\prime}(-3)=6(-3)^{2}+2(-3)-20=28>0$, portanto, $f$ é crescente no intervalo $(-\infty,-2]$.

Caso $x \in\left(-2, \frac{5}{3}\right)$ : Usando o mesmo argumento feito no caso anterior, escolhemos um número entre $\left(-2, \frac{5}{3}\right)$, seja por exemplo, $x=0$, e notamos que $f^{\prime}(0)=6(0)^{2}+2.0-20=-20<0$, logo, $f$ é decrescente em $\left(-2, \frac{5}{3}\right)$.

Caso $x \in\left(\frac{5}{3},+\infty\right):$ Escolhemos o número $x=3$, note que $3 \in\left(\frac{5}{3},+\infty\right)$ e que $f^{\prime}(3)=6(3)^{2}+$ $2.3-20=40>0$, logo, $f$ é crescente em $\left(\frac{5}{3},+\infty\right)$.

Agora, usando o teorema 4.18, concluímos que $x=-2$ é um ponto de máximo e seu valor é $f(-2)=29$, já o ponto $x=\frac{5}{3}$ é um ponto de mínimo e seu valor é $f\left(\frac{5}{3}\right)=-\frac{548}{27}$.

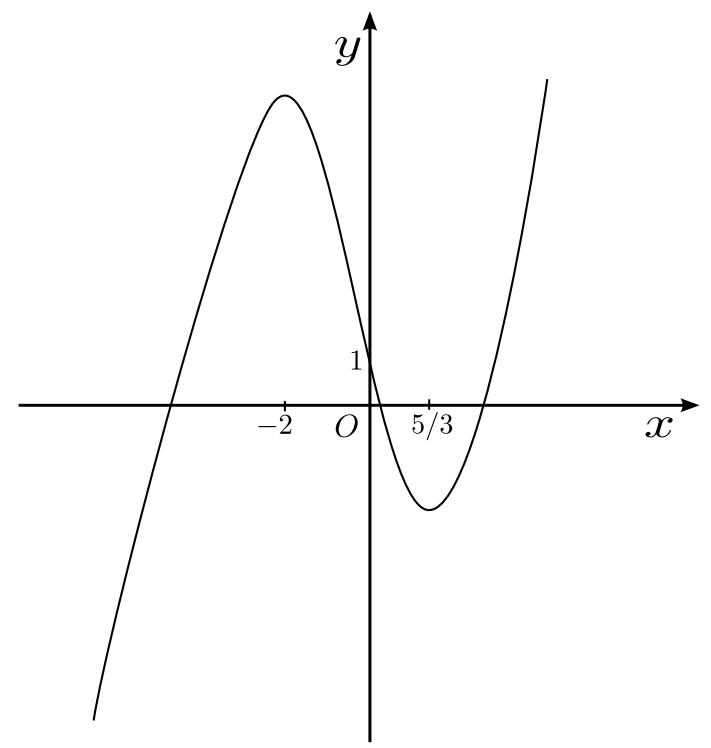

Figura 4.12: Gráfico de $f(x)=2 x^{3}+x^{2}-20 x+1$. 


\subsection{Concavidade e Pontos de Inflexão}

Vamos estudar o sinal da derivada segunda de $f$, para determinarmos onde a derivada $f^{\prime}$ é crescente ou decrescente. Note que, se $f^{\prime \prime}(x)>0$ em um certo intervalo $I$, então $f^{\prime}(x)$ é crescente em $I$, se isso acontecer, dizemos que o gráfico de $f$ é côncavo para cima em $I$. De modo análogo, temos que se $f^{\prime \prime}(x)<0$ em um intervalo $I$, então $f^{\prime}(x)$ é decrescente em $I$, se isso acontecer dizemos que o gráfico de $f$ é côncavo para baixo em $I$.

Definição 4.8. Definição Seja $f$ uma função derivável em um intervalo aberto $I$. O gráfico de $f$ é:

(i) côncavo para cima em I, se $f^{\prime}$ é crescente em I;

(ii) côncavo para baixo em I, se f'é decrescente em $I$.

O próximo resultado apresenta um teste para a determinação da concavidade do gráfico de uma certa função $f$.

Proposição 4.19. Seja $f$ uma função contínua no intervalo $[a, b]$ e duas vezes derivável no intervalo $(a, b)$, se:

(i) $f^{\prime \prime}(x)>0$ para todo $x \in(a, b)$, então $f$ é côncava para cima em $(a, b)$;

(ii) $f^{\prime \prime}(x)<0$ para todo $x \in(a, b)$, então $f$ é côncava para baixo em $(a, b)$.

Prova. Vamos verificar apenas o item $(i)$, já que o item $(i i)$ é análogo. De fato, se $f^{\prime \prime}(x)=\left(f^{\prime}(x)\right)^{\prime}>$ 0 , para todo $x \in(a, b)$, logo, $f^{\prime}(x)$ é crescente no intervalo $(a, b)$. Logo, $f$ é côncava para cima em $(a, b)$.

Podemos ter pontos do gráfico de uma função contínua em que a concavidade muda de sentido, esses pontos são chamados de pontos de inflexão.

Definição 4.9. Um ponto $\left(x_{0}, f\left(x_{0}\right)\right)$ do gráfico de $f$ é um ponto de inflexão se são verificadas as duas condições:

(i) $f$ é continua em $x_{0}$;

(ii) Existe um intervalo aberto $(a, b)$ contendo $x_{0}$, tal que o gráfico é côncavo para cima em $\left(a, x_{0}\right)$ e côncavo para baixo em $\left(x_{0}, b\right)$, ou vice-versa.

Observação 4.11. Cuidado com a definição de pontos de inflexão, pois às vezes cremos que se $f^{\prime \prime}\left(x_{0}\right)=$ 0 , então $x_{0}$ é um ponto de inflexão, contudo, isso nem sempre é verdade, o contra exemplo é a função $f(x)=x^{4}$, note que $f^{\prime \prime}(x)=12 x^{2}$, e o único ponto $x_{0}$, em que $f^{\prime \prime}$ é zero, é o ponto $x_{0}=0$, porém, $x_{0}$ não é um ponto de inflexão, pois não temos a mudança de concavidade do gráfico no ponto $x_{0}=0$.

Observação 4.12. Antes de resolver alguns exercícios propostos anteriormente no trabalho, vamos trazer outra demonstração das coordenadas de $x_{v}$ e $y_{v}$ para o gráfico de funções polinomiais do segundo grau. A demonstração anterior, colocada no final do Capítulo 2, foi feita sem a utilização da ideia de derivada.

Assumindo uma equação de segundo grau com a forma geral $h(x)=a x^{2}+b x+c$, vimos que $h^{\prime}(x)=0$ é o ponto de máximo ou mínimo e ele nos permite descobrir a abscissa do vértice desta representação gráfica.

A segunda derivada de uma função qualquer de segundo grau $h^{\prime \prime}(x)$ é igual a $2 a$. Sendo a positivo, pelo teste da segunda derivada, temos um mínimo global no vértice. Analogamente, sendo a negativo, temos um máximo global no vértice. Desta forma, apenas sabendo o valor de a, pode-se dizer qual a concavidade da parábola, pois o sinal de $h^{\prime \prime}(x)$ depende apenas do sinal de a. Agora, calcularemos as coordenadas do vértice da parábola. Sendo $h^{\prime \prime}(x)=0$, assim temos que, $2 a x+b=0$. Dessa forma, a coordenada $x$ do vértice é igual ao valor $\frac{-b}{2 a}$. 
Uma vez de posse da coordenada $x$ do vértice, podemos novamente substituí-la na função $h$ (como feito anteriormente no capítulo dois), logo temos

$$
h\left(x_{v}\right)=a \cdot\left(\frac{-b}{2 a}\right)^{2}+b \cdot\left(\frac{-b}{2 a}\right)^{2}+c=\frac{-\left(b^{2}-4 a c\right)}{4 a}=\frac{-\Delta}{4 a} .
$$

Logo, usando os testes da primeira derivada e segunda derivadas, descobrimos que as coordenadas do vértice são $V(-b / 2 a,-\Delta / 4 a)$ e que a concavidade é definida pelo valor de a, pelo teste da segunda derivada.

O resultado a seguir é conhecido como teste da derivada segunda, teste esse que busca a classificação de extremos locais.

Proposição 4.20. Seja $f$ diferenciável em um intervalo aberto, contendo $x_{0}$, e $f^{\prime}\left(x_{0}\right)=0$, se:

(i) $f^{\prime \prime}\left(x_{0}\right)<0$, então $f$ tem um ponto de máximo local em $x_{0}$;

(ii) $f^{\prime \prime}\left(x_{0}\right)>0$, então $f$ tem um ponto de minimo local em $x_{0}$.

Prova. Verificaremos apenas o item $(i)$, pois o item $(i i)$ é inteiramente análogo. Note que, se $f^{\prime}\left(x_{0}\right)=0$, então, temos que a reta tangente ao gráfico no ponto $P_{0}=\left(x_{0}, f\left(x_{0}\right)\right)$ é horizontal e além disso, por hipótese, temos que $f^{\prime \prime}\left(x_{0}\right)<0$, desse modo, o gráfico é côncavo para baixo em $x_{0}$, logo, existe um intervalo aberto $I$ contendo $x_{0}$, tal que o gráfico está abaixo da reta tangente que passa pelo ponto $P_{0}$, assim, $f\left(x_{0}\right)$ é um máximo local.

Observação 4.13. Caso $f^{\prime \prime}\left(x_{0}\right)=0$, não se pode aplicar o teste da derivada segunda. Em tais casos, devemos aplicar o teste da derivada primeira.

De fato, notamos que as funções $f(x)=x^{3}$ e $f(x)=x^{4}$ tem derivadas segundas nulas em $x=0$, contudo, na função $f(x)=x^{3}$ o $x=0$ é um ponto de inflexão e não será nem ponto de máximo e nem mínimo, já na função $f(x)=x^{4}$ o $x=0$ é um ponto de mínimo.

De posse deste conhecimento, podemos resolver agora tanto o Problema 2.3 proposto no início do Capítulo 2, quanto os propostos neste capítulo.

Resolução do Problema 2.3.

Problema 2.3. Deseja-se construir uma caixa sem tampa a partir de uma folha quadrada de lado $30 \mathrm{~cm}$ da seguinte maneira: serão retirados quatro quadrados de lados " $x$ " centímetros, um de cada extremidade e em seguida serão dobradas as partes que sobraram obtendo assim a caixa desejada. De quanto deve ser o lado desses quadrados que serão retirados para que o volume da caixa criada seja o maior possível?

Solução. Consideramos a caixa dada no problema como:

Notamos que a caixa é um paralelepípedo, logo seu volume é dado por:

$$
V=(\text { área da base }) \cdot(\text { altura })=(30-2 x)^{2} \cdot x=4 x^{3}-120 x^{2}+900 x \text {. }
$$

Agora como os pontos críticos são os candidatos a serem os pontos de máximo e/ou mínimo, logo calculando a derivada da função volume, assim: 

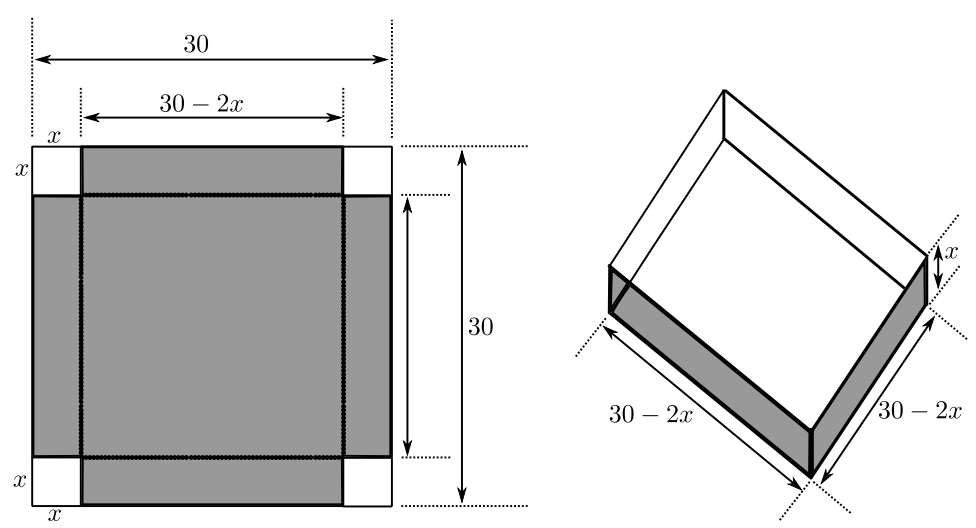

Figura 4.13: Caixa

$$
V^{\prime}(x)=12 x^{2}-240 x+900 .
$$

Note que $V^{\prime}(x)$ existe para todo valor, logo, analisaremos apenas os pontos onde $V^{\prime}(x)=0$, logo

$$
V^{\prime}(x)=12 x^{2}-240 x+900=0 \Rightarrow x_{1}=5 \text { e } x_{2}=15 .
$$

Note que o valor $x_{2}=15$ não convém devido as condições propostas no enunciado. Para verificarmos se $x=5$ é o valor que proporcionará o maior volume, usaremos o critério da derivada segunda, isto é,

$$
V^{\prime \prime}(x)=24 x-240 \Rightarrow V^{\prime \prime}(5)=-120<0 .
$$

Portanto, $x=5$ é o valor máximo possível.

Resolução do Problema 4.1.

Problema 4.1. Um grupo de escoteiros possui uma peça de lona circular de $3 m$ de raio. Cortando-se um setor circular pode-se construir uma tenda de forma cônica. Quais as dimensões da tenda para que seu volume seja máximo?

Solução. Consideramos que
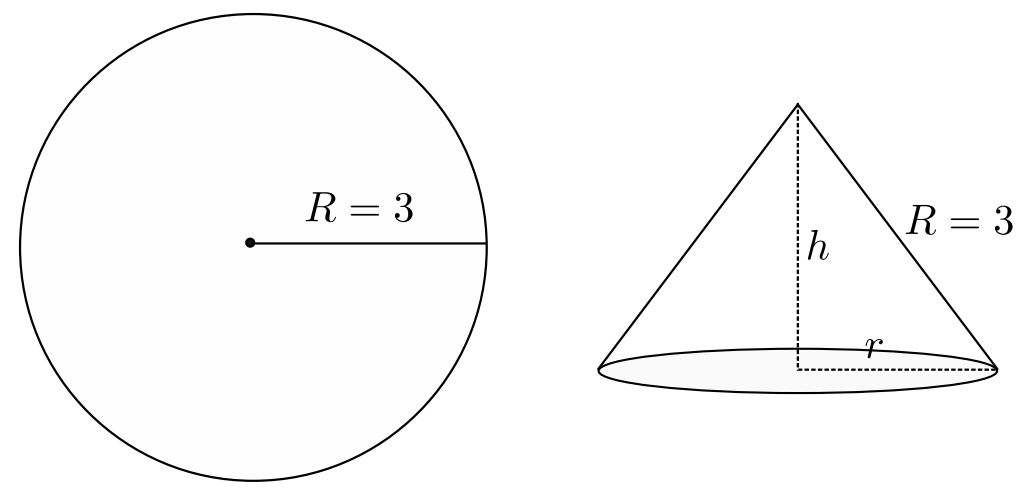

Figura 4.14: Volume 
Notamos primeiramente, que a peça de lona é circular de raio $3 m$, isto é, um círculo de raio $3 m$. Onde os mesmo a cortaram e construíram uma tenda no formato de cone, e sabemos que o volume de um cone circular de raio da base igual a $r$ e altura $h$ é dado por:

$$
V=\frac{(\text { área da base }) \cdot(\text { altura })}{3}
$$

Logo,

$$
V=\frac{\pi r^{2} h}{3}
$$

Por outro lado, por Pitágoras, temos que

$$
3^{2}=h^{2}+R^{2} \Rightarrow h=\sqrt{9-r^{2}} .
$$

Dessa forma,

$$
V(r)=\frac{\pi r^{2} \sqrt{9-r^{2}}}{3}
$$

Agora como os pontos críticos são os candidatos a serem os pontos de máximo e/ou mínimo, logo calculando a derivada da função volume, assim:

$$
V^{\prime}(r)=\frac{\pi}{3}\left(2 r \sqrt{9-r^{2}}+r^{2} \cdot \frac{1}{2} \cdot \frac{(-2 r)}{\sqrt{9-r^{2}}}\right) .
$$

Note que $V^{\prime}(r)$ não existe quando $r= \pm 3$, contudo, esses pontos não são pontos críticos, pois $\pm 3 \notin$ $D(V)$. Logo, analisaremos apenas os pontos onde $V^{\prime}(r)=0$, assim:

$$
V^{\prime}(r)=\frac{\pi}{3}\left(2 r \sqrt{9-r^{2}}+r^{2} \cdot \frac{1}{2} \cdot \frac{(-2 r)}{\sqrt{9-r^{2}}}\right)=0 \Rightarrow\left(9-r^{2}\right) \cdot 2=r^{2} \Rightarrow 18=3 r^{2} \Rightarrow r=\sqrt{6} .
$$

Usaremos agora o critério da derivada segunda para comprovarmos que $r=\sqrt{6}$ é de máximo, de fato.

$$
V^{\prime \prime}(r)=\frac{\pi\left(2 r^{4}-27 r^{2}+54\right)}{\left(9-r^{2}\right)^{3 / 2}} .
$$

Logo, $V^{\prime \prime}(\sqrt{6})<0$. Portanto $r=\sqrt{6}$ é de máximo. Por outro lado, como $h=\sqrt{9-r^{2}} \Rightarrow h=\sqrt{3}$. Logo as dimensões da tenta cônica para ter volume máximo é $r=\sqrt{6}$ e $h=\sqrt{3}$.

Resolução do problema 4.2

Problema 4.2. Um cilindro deve ser fabricado para conter 6 litros. Que dimensões (raio e altura) deve ter este cilindro para custar o mínimo possível, conhecido os seguintes preços:

(i) O material do fundo custa $R \$ 5,00$ por $d m^{2}$;

(ii) O material do lado custa $R \$ 3,00$ por $d m^{2}$;

(iii) O material da tampa custa $R \$ 2,00$ por $d m^{2}$.

Solução. Consideramos o cilindro do problema de raio da base $r$ e altura $h$, Sabemos que o volume do cilindro é dado por:

$$
V=(\text { área da base).(altura), }
$$




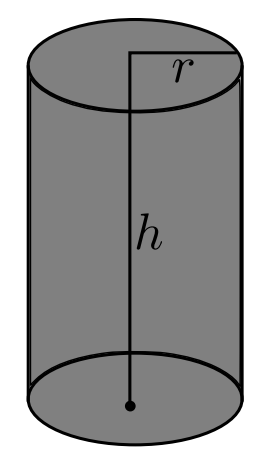

Figura 4.15: Lata

$\log 0$

$$
V=\left(\pi r^{2}\right) h \Rightarrow V=\left(\pi r^{2}\right) h=6 \Rightarrow h=\frac{6}{\pi r^{2}} .
$$

Por outro lado, temos que a função custo é dada por

$$
C=\pi r^{2} \cdot 5+2 \pi r h \cdot 3+\pi r^{2} \cdot 2=7 \pi r^{2}+\frac{36}{r}
$$

Como os pontos críticos são os candidatos a serem os pontos de máximo e/ou mínimo, logo calculando a derivada da função custo, assim:

$$
C^{\prime}(r)=14 \pi r-\frac{36}{r^{2}}
$$

Note que $C^{\prime}(r)$ não existe quando $r=0$, contudo, esse ponto não é um ponto crítico, pois $0 \notin D(C)$. Logo, analisaremos os pontos onde $C^{\prime}(r)=0$, assim:

$$
C^{\prime}(r)=14 \pi r-\frac{36}{r^{2}}=0 \Rightarrow r^{3}=\frac{36}{14 \pi} \Rightarrow r=0,935 .
$$

Usaremos agora o critério da derivada segunda para comprovarmos que $r=0,935$ é de mínimo, de fato.

$$
C^{\prime \prime}(r)=14 \pi+\frac{72}{r^{3}} \Rightarrow C^{\prime \prime}(0,935)=14 \pi+\frac{72}{(0,935)^{3}}>0 .
$$

Portanto, $r=0,935$ é o raio mínimo para termos o menor custo, e como $h=\frac{6}{\pi r^{2}} \Rightarrow h=2,183$.

Resolução do problema 4.3.

Problema 4.3. Um rio tem uma largura de $100 \mathrm{~m}$. Um ponto $C$ está deslocado de $400 \mathrm{~m}$ do ponto $D$ (o ponto $D$ representa a projeção ortogonal do ponto $A$ à outra margem), como mostra a figura. Desejase ir do ponto $A$ ao ponto $C$, fazendo o percurso $A B$ (remando) e depois $B C$ (correndo pela margem). Sabendo que se pode remar a $40 \mathrm{~m} / \mathrm{min}$ e correr a $100 \mathrm{~m} / \mathrm{min}$, qual deve ser o valor de $x$ para que essa travessia seja feita no menor tempo possível?

Solução. Consideramos a figura que representa o rio: 


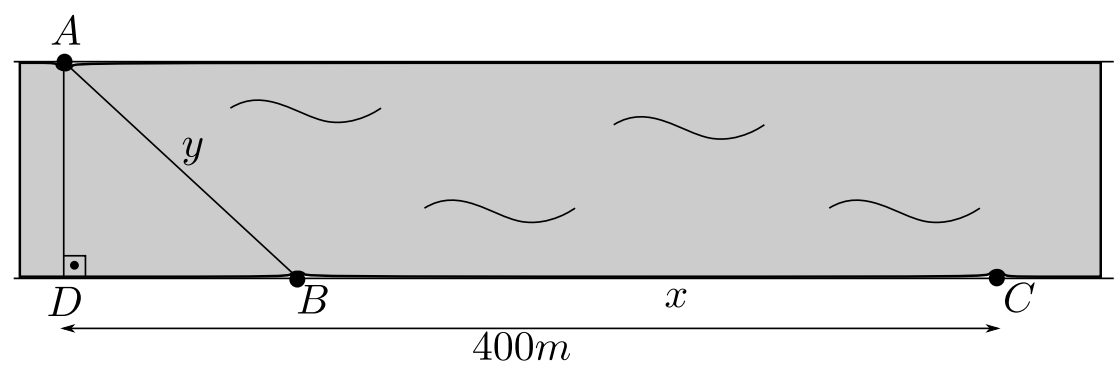

Figura 4.16: Máximos e Mínimos

Sabemos que a velocidade é dada pela variação do espaço pelo tempo. Logo,

$$
V=\frac{S}{T} \Rightarrow T=\frac{S}{V}
$$

Assim,

$$
T=\frac{y}{40}+\frac{x}{100} \Rightarrow T=\frac{\sqrt{(400-x)^{2}+100^{2}}}{40}+\frac{x}{100} .
$$

Como os pontos críticos são os candidatos a serem os pontos de máximo e/ou mínimo, é necessário calcular a derivada da função tempo.

$$
T^{\prime}(x)=\frac{1}{40} \frac{(400-x)(-1)}{\sqrt{(400-x)^{2}+100^{2}}}+\frac{1}{100} .
$$

Analisaremos os pontos onde $T^{\prime}(x)=0$.

$$
T^{\prime}(x)=\frac{1}{40} \frac{(400-x)(-1)}{\sqrt{(400-x)^{2}+100^{2}}}+\frac{1}{100}=0 \Rightarrow x=400 \pm \frac{25 \sqrt{6}}{3} .
$$

Vamos considerar apenas o valor $x=400-\frac{25 \sqrt{6}}{3}$, pois o outro valor gera uma indeterminação com o problema. Usaremos agora o critério da derivada segunda para comprovarmos que $x=400-\frac{25 \sqrt{6}}{3}$, é o valor que minimiza o tempo de travessia.

$$
T^{\prime \prime}(x)=\frac{10000}{\left(x^{2}-800 x+170000\right)^{3 / 2}} \Rightarrow T^{\prime \prime}\left(400-\frac{25 \sqrt{6}}{3}\right)>0 .
$$

Portanto, $x=400-\frac{25 \sqrt{6}}{3}$, é o valor que minimiza o tempo de travessia. 


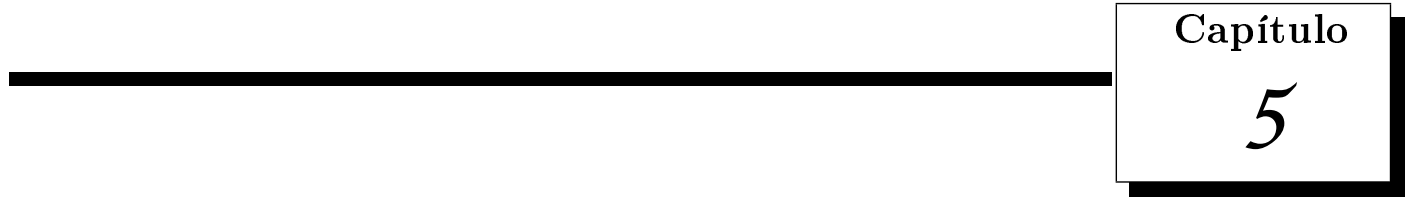 \\ Problemas do Ensino Médio sob uma Nova Ótica}

Neste capítulo resolveremos todos os exercícios apresentados no Capítulo 3, utilizando a técnica de derivação que acabamos de apresentar no capítulo anterior. Nem sempre a resolução será mais rápida, ainda mais porque essa técnica exige um rigor de verificação que o método de resolução do Capítulo 3 não exigia.

No entanto, o objetivo não é convencer de que um método ou outro é mais eficiente, mas sim, apresentar uma outra maneira de resolver o mesmo problema. O que diferencia esta nova ferramenta dos conhecimentos que possuíamos anteriormente, é que a partir dela poderemos resolver uma variedade de exercícios que não conseguiríamos apenas com os conhecimentos anteriores.

Problema 5.1. Considerando $f: \mathbb{R} \rightarrow \mathbb{R}$, calcule as coordenadas do valor minimo que $f$ pode assumir, se $f(x)=x^{2}-4 x-5$.

Solução. Dada a função $f(x)=x^{2}-4 x-5$. Agora da teoria, sabemos que os pontos críticos são os candidatos a serem os pontos de máximo ou mínimo. Calculando a derivada da função dada, temos:

$$
f^{\prime}(x)=2 x-4,
$$

Como os pontos críticos, são obtidos quando a derivada é zero ou não existe, analisaremos apenas o que ocorre com $f^{\prime}(x)=0$. Como a derivada de $f$ sempre existe, estudaremos apenas essa situação.

$$
f^{\prime}(x)=2 x-4=0 \Rightarrow x=2 .
$$

Para verificarmos que esse valor é o mínimo, usaremos o critério da derivada segunda.

$$
f^{\prime \prime}(x)=2 .
$$

Analisando o ponto $x=2$, temos $f^{\prime \prime}(2)=2>0$.

Portanto, o ponto $x=2$ é mínimo local e suas coordenadas são $(2, f(2))=(2,-9)$. 
Problema 5.2. Como escolher dois números positivos tais que sua soma é 1 e a soma de seus quadrados é a maior possivel.

Solução. Sejam $x$ e $y$ esses dois números positivos Por hipótese, temos que:

$$
x+y=1 \Rightarrow y=1-x
$$

Assim,

$$
(x+y)^{2}=(1)^{2} \Leftrightarrow x^{2}+2 x y+y^{2}=1 \Leftrightarrow x^{2}+y^{2}=1-2 x y
$$

Definimos por $S$ a soma de seus quadrados, assim

$$
S=x^{2}+y^{2} \Rightarrow S=x^{2}+y^{2}=1-2 x y \quad \Leftrightarrow \quad S=1+2 x y=1+2 x(1-x)=-2 x^{2}+2 x+1 .
$$

Portanto,

$$
S(x)=-2 x^{2}+2 x+1 .
$$

Como os pontos críticos são os candidatos a serem os pontos de máximo ou mínimo, é necessário calcular a derivada da função dada. Então,

$$
S^{\prime}(x)=-4 x+2
$$

Como os pontos críticos, são obtidos quando a derivada é zero ou não existe, analisaremos apenas o que ocorre com $S^{\prime}(x)=0$. Já que a derivada de $S$ sempre existe, estudaremos apenas esta situação.

$$
S^{\prime}(x)=-4 x+2=0 \Rightarrow x=\frac{1}{2}
$$

Usaremos agora o critério da derivada segunda para encontrarmos o valor máximo que a função assume. Primeiramente note que

$$
S^{\prime \prime}(x)=-4
$$

Analisando o ponto $x=\frac{1}{2}$, temos

$$
S^{\prime \prime}\left(\frac{1}{2}\right)=-4<0
$$

Portanto o ponto $x=\frac{1}{2}$ é máximo local e como $y=1-x$, temos que $y=\frac{1}{2}$.

Por outro lado, como $y=1-x$, temos que $y=\frac{1}{2}$. Portanto os valores são $x=\frac{1}{2}$ e $y=\frac{1}{2}$.

Problema 5.3. Considerando $f: \mathbb{R} \rightarrow \mathbb{R}$, calcule os valores máximo e mínimo que $f$ pode assumir, se $f(x)=\frac{1+2 \operatorname{sen}(x)}{3}$.

Solução. Dada a função $f(x)=\frac{1+2 \operatorname{sen}(x)}{3}$. Agora, da teoria, sabemos que os pontos críticos são os candidatos a serem os pontos de máximo e/ou mínimo, logo calculando a derivada da função dada, temos:

$$
f^{\prime}(x)=\frac{2 \cos (x)}{3}
$$

como os pontos críticos, são obtidos quando a derivada é zero ou não existe, analisaremos apenas o que 
ocorre com $f^{\prime}(x)=0$, já que a derivada de $f$ sempre existe estudaremos apenas essa situação, logo

$$
f^{\prime}(x)=\frac{2 \cos (x)}{3}=0 \Rightarrow x=\frac{\pi}{2} \text { ou } \frac{3 \pi}{2} .
$$

Para determinarmos se os pontos $x=\frac{\pi}{2}$ ou $\frac{3 \pi}{2}$ são de máximo ou de mínimo usaremos o critério da derivada segunda, primeiramente, note que

$$
f^{\prime \prime}(x)=-\frac{2 \operatorname{sen}(x)}{3}
$$

Analisando os pontos $x=\frac{\pi}{2} \mathrm{e} \frac{3 \pi}{2}$, temos

$$
f^{\prime \prime}\left(\frac{\pi}{2}\right)=-\frac{2}{3}<0 \quad \text { e } \quad f^{\prime \prime}\left(\frac{3 \pi}{2}\right)=\frac{2}{3}>0 .
$$

Portanto o ponto $x=\frac{\pi}{2}$ é máximo local e $\frac{3 \pi}{2}$ é mínimo local e suas coordenadas respectivamente são, $\left(\frac{\pi}{2}, f\left(\frac{\pi}{2}\right)\right)=\left(\frac{\pi}{2}, 1\right)$ e $\left(\frac{3 \pi}{2}, f\left(\frac{3 \pi}{2}\right)\right)=\left(\frac{3 \pi}{2},-\frac{1}{3}\right)$.

Problema 5.4. Um ônibus de 40 lugares foi fretado para uma excursão. A empresa exigiu de cada passageiro $R \$ 20,00$ mais $R \$ 2,00$ por lugar vago. Qual o número de passageiros para que a rentabilidade seja máxima?

Solução. Vamos primeiramente denotar por $R$ a rentabilidade da empresa e por $p$ o número de passageiros, logo temos que:

$$
R=(20+2(40-p)) \cdot p \Rightarrow R=-2 p^{2}+100
$$

Agora da teoria, sabemos que os pontos críticos são os candidatos a serem os pontos de máximo ou mínimo, logo calculando a derivada da função dada, temos:

$$
R^{\prime}(p)=-4 p+100
$$

como os pontos críticos, são obtidos quando a derivada é zero ou não existe, analisaremos apenas o que ocorre com $R^{\prime}(p)=0$, já que a derivada de $R$ sempre existe estudaremos apenas essa situação, logo

$$
R^{\prime}(p)=-4 p+100=0 \Rightarrow p=25 .
$$

Para determinarmos que esse valor seja máximo usaremos o critério da derivada segunda, primeiramente, note que

$$
R^{\prime \prime}(p)=-4
$$

Analisando o ponto $p=25$, temos

$$
R^{\prime \prime}(25)=-4<0
$$

Portanto $p=25$ representa a quantidade máxima de passageiros para que a empresa tenha a maior rentabilidade. 
Problema 5.5. Um terreno retangular é cercado por $1500 \mathrm{~m}$ de cerca. Quais as dimensões desse terreno para que a sua área seja a maior possivel? E qual a área máxima?

\section{Solução.}

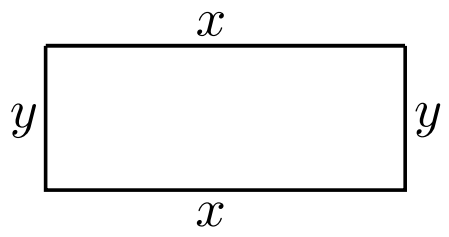

Figura 5.1: Terreno

Como temos um tereno retangular seu perímetro é dado por:

$$
A=2 x+2 y=1500 \Rightarrow x+y=1500 \Rightarrow y=750-x .
$$

Por outro lado, a área do tereno retangular de lados $x$ e $y$ como na figura é dada por:

$$
A=x y \Rightarrow A=x(750-x) \Rightarrow A=-x^{2}+750 x .
$$

Da teoria, sabemos que os pontos críticos são os candidatos a serem os pontos de máximo ou mínimo, logo calculando a derivada da função área, temos:

$$
A^{\prime}(x)=-2 x+750,
$$

como os pontos críticos, são obtidos quando a derivada é zero ou não existe, analisaremos apenas o que ocorre com $A^{\prime}(x)=0$, já que a derivada de $A$ sempre existe estudaremos apenas essa situação, logo

$$
A^{\prime}(x)=-2 x+750=0 \Rightarrow x=375 .
$$

Para determinarmos que esse valor seja máximo usaremos o critério da derivada segunda, primeiramente, note que

$$
A^{\prime \prime}(x)=-2 \text {. }
$$

Analisando o ponto $x=375$, temos que:

$$
A^{\prime \prime}(375)=-2<0 \text {. }
$$

Portando $x=375$ é máximo e como $y=750-x$, temos que $y=375$.

Problema 5.6. Uma área retangular está limitada por uma cerca de arame em três de seus lados e por um rio reto no quarto lado. Ache as dimensões do terreno de área máxima que pode ser cercado com $1000 \mathrm{~m}$ de arame.

\section{Solução.}

Notamos que como um lado de nossa área não será cercada, pois temos o rio que a delimita, assim o perímetro da nossa região, sem um dos lados é dada por:

$$
P=2 x+y=1000 \Rightarrow y=1000-2 x .
$$




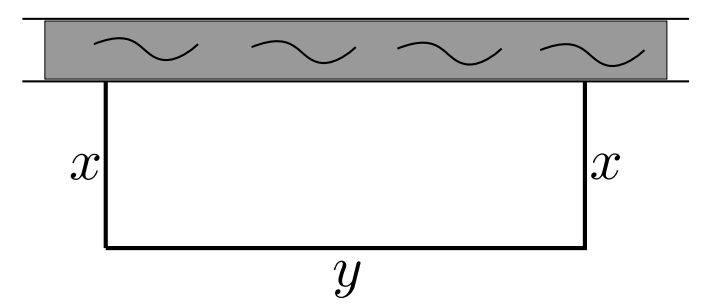

Figura 5.2: Terreno

E como a área da região retangular é dada por $A(x, y)=x \cdot y$, temos

$$
A=x \cdot(1000-2 x)=-2 x^{2}+1000 x .
$$

Da teoria, sabemos que os pontos críticos são os candidatos a serem os pontos de máximo ou mínimo, logo calculando a derivada da função área, temos:

$$
A^{\prime}(x)=-4 x+1000
$$

como os pontos críticos, são obtidos quando a derivada é zero ou não existe, analisaremos apenas o que ocorre com $A^{\prime}(x)=0$, já que a derivada de $A$ sempre existe estudaremos apenas essa situação, logo

$$
A^{\prime}(x)=-4 x+1000=0 \Rightarrow x=250 .
$$

Para determinarmos que esse valor seja máximo usaremos o critério da derivada segunda, primeiramente, note que

$$
A^{\prime \prime}(x)=-4 .
$$

Analisando o ponto $x=250$, temos que:

$$
A^{\prime \prime}(250)=-4<0 .
$$

Portando $x=250$ é máximo e como $y=1000-2 x$, temos que $y=500$.

Problema 5.7. Um terreno retangular deve ser cercado de duas formas. Dois lados opostos devem receber uma cerca reforçada que custa $R \$ 3,00$ o metro, enquanto os outros dois restantes recebem uma cerca-padrão de $R \$ 2,00$ o metro. Quais são as dimensões do terreno de maior área que pode ser cercado com $R \$ 6000,00$ ?

\section{Solução.}

Considere que o terreno do problema seja representado por um retângulo de lados $x$ e $y$.

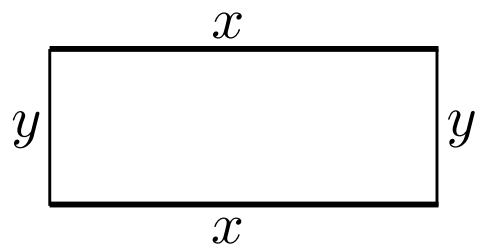

Figura 5.3: Terreno 
Como o terreno é retangular, temos que o perímetro do terreno é tal que $P=2 x+2 y$. Como cada dois lados o custo da cerca é diferente, temos que o custo total fica:

$$
C(x)=2 x \cdot 3+2 y \cdot 2=6000 \Rightarrow 3 x+2 y=3000 \Rightarrow y=\frac{3000-3 x}{2} .
$$

E como a área da região retangular é dada por $A(x, y)=x . y$, temos

$$
A=x \cdot y=x(1500-1,5 x)=-1,5 x^{2}+1500 x \text {. }
$$

Da teoria, sabemos que os pontos críticos são os candidatos a serem os pontos de máximo ou mínimo, logo calculando a derivada da função área, temos:

$$
A^{\prime}(x)=-3 x+1500
$$

como os pontos críticos, são obtidos quando a derivada é zero ou não existe, analisaremos apenas o que ocorre com $A^{\prime}(x)=0$, já que a derivada de $A$ sempre existe estudaremos apenas essa situação, logo

$$
A^{\prime}(x)=-3 x+1500=0 \Rightarrow x=500 .
$$

Para determinarmos que esse valor seja máximo usaremos o critério da derivada segunda, primeiramente, note que

$$
A^{\prime \prime}(x)=-3
$$

Analisando o ponto $x=500$, temos que:

$$
A^{\prime \prime}(500)=-3<0 .
$$

Portanto $x=500$ representa a maior dimensão no caso do valor do $x$ para termos a área máximo $\mathrm{e}$ como $y=\frac{3000-3 x}{2}, \log 0 y=750$.

Problema 5.8. Um fazendeiro tem 200 bois, cada um pesando $300 \mathrm{Kg}$. Até agora ele gastou $R \$ 380000,00$ para criar os bois e continuará gastando $R \$ 2,00$ por dia para manter um boi. Os bois aumentam de peso a uma razão de $1,5 \mathrm{Kg}$ por dia. Seu preço de venda, hoje, é de $R \$ 18,00$ o quilo, mas o preço cai 5 centavos por dia. Quantos dias deveria o fazendeiro aguardar para ter o maior lucro possivel?

\section{Solução.}

Vamos denotar por $d$ o número de dias e como o Lucro (L) é dado pelo valor da Venda (V) menos o Custo (C), temos que:

$$
V(d)=(18-0,05 d) \cdot(300+1,5) \cdot 200
$$

e

$$
C(d)=380000+2 d \cdot 200 .
$$

Portanto

$$
\begin{aligned}
L=V-C & =(18-0,05 d) \cdot(300+1,5 d) \cdot 200-380000+2 d \cdot 200 \\
& =-15 d^{2}+2000 d+700000
\end{aligned}
$$


Da teoria, sabemos que os pontos críticos são os candidatos a serem os pontos de máximo e/ou mínimo, logo calculando a derivada da função lucro, temos:

$$
L^{\prime}(d)=-30 d+2000
$$

como os pontos críticos, são obtidos quando a derivada é zero ou não existe, analisaremos apenas o que ocorre com $L^{\prime}(d)=0$, já que a derivada de $L$ sempre existe estudaremos apenas essa situação, logo

$$
L^{\prime}(d)=-30 d+2000=0 \Rightarrow d=67 .
$$

Para determinarmos que esse valor representa os dias que representarão lucro máximo para o fazendeiro, usaremos o critério da derivada segunda, primeiramente, note que

$$
L^{\prime \prime}(d)=-30 .
$$

Analisando em $d=67$, temos que

$$
L^{\prime \prime}(67)=-30<0 .
$$

Portanto $d=67$ dias representam a quantidade de dias, onde o fazendeiro obterá o lucro máximo.

Problema 5.9. Um retângulo é inscrito num triângulo de catetos medindo $9 \mathrm{~cm}$ e $12 \mathrm{~cm}$. Encontrar as dimensões do retângulo com maior área, supondo que a sua posição é dada na figura a seguir.

\section{Solução.}

Considere que o retângulo proposto no problema possua os lados com medidas $x$ e $y$ como representado na figura a seguir.

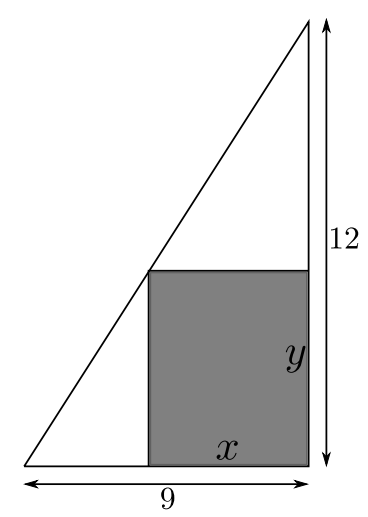

Figura 5.4: Área

Por semelhança de triângulos, temos que:

$$
\frac{12}{9}=\frac{12-y}{x} \Rightarrow 4 x=36-3 y \Rightarrow y=12-\frac{4 x}{3} .
$$

Agora como estamos buscando a área de um retângulo, temos que

$$
A=x \cdot y=x\left(12-\frac{4 x}{3}\right)=12 x-\frac{4 x^{2}}{3} .
$$


Da teoria, sabemos que os pontos críticos são os candidatos a serem os pontos de máximo ou mínimo, logo calculando a derivada da função área, temos:

$$
A^{\prime}(x)=12-\frac{8 x}{3}
$$

como os pontos críticos, são obtidos quando a derivada é zero ou não existe, analisaremos apenas o que ocorre com $A^{\prime}(x)=0$, já que a derivada de $A$ sempre existe estudaremos apenas essa situação, logo

$$
A^{\prime}(x)=12-\frac{8 x}{3}=0 \Rightarrow x=4,5
$$

Para determinarmos que esse valor seja máximo usaremos o critério da derivada segunda, primeiramente, note que

$$
A^{\prime \prime}(x)=-\frac{8}{3}
$$

Analisando em $x=4,5$, temos que $A^{\prime \prime}(4,5)=-\frac{8}{3}<0$.

Portando $x=4,5$ é máximo e como $y=12-\frac{4 x}{3}$, temos que $y=6$.

Problema 5.10. Uma forma líquida de penicilina vendida a um preço de $R \$ 200,00$ a unidade. Se o custo total de produção para $x$ unidades for $C(x)=500000+80 x+0,003 x^{2}$ e se a capacidade de produção da firma for, de no máximo, 30000 unidades por mês, quantas unidades de penicilina devem ser fabricadas e vendidas nesse período para que o lucro seja máximo? E qual o valor do lucro máximo?

Solução. Sabemos que a função lucro é dada pela diferença da venda pelo custo, logo

$$
\text { Lucro = Venda - Custo, }
$$

assim:

$$
L(x)=200 x-\left(0,003 x^{2}+80 x+500000\right)=-0,003 x^{2}+120 x-500000 .
$$

Da teoria, sabemos que os pontos críticos são os candidatos a serem os pontos de máximo ou mínimo, logo calculando a derivada da função lucro, temos:

$$
L^{\prime}(x)=-0,006 x+120
$$

como os pontos críticos, são obtidos quando a derivada é zero ou não existe, analisaremos apenas o que ocorre com $L^{\prime}(x)=0$, já que a derivada de $L$ sempre existe estudaremos apenas essa situação, logo

$$
L^{\prime}(x)=-0,006 x+120 \Rightarrow x=20000
$$

Para determinarmos que esse valor seja máximo usaremos o critério da derivada segunda, primeiramente, note que

$$
L^{\prime \prime}(x)=-0,006
$$

Analisando em $x=20000$, temos que

$$
L^{\prime \prime}(20000)=-0,006<0 .
$$

Portanto o lucro máximo será quando for vendida 20000 unidades, gerando um lucro de 700000 reais. 
Problema 5.11. Um pedaço de fio com 10 metros de comprimento é cortado em duas partes. Uma parte é dobrada em formato de um quadrado, ao passo que a outra é dobrada na forma de um triângulo equilátero. Como deve ser cortado o fio de forma que a área total englobada sejá máxima?

\section{Solução.}

\section{0 metros}
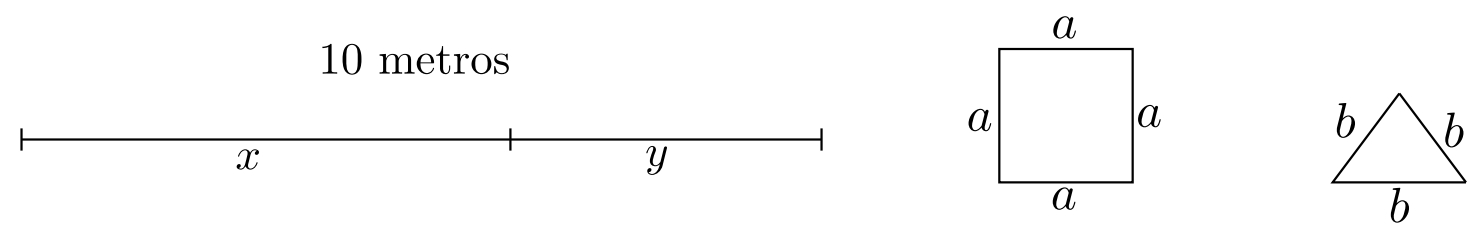

Figura 5.5: Áreas

Supomos que com o comprimento $x$ do segmento, construímos o quadrado de lado $a$, logo temos que

$$
4 a=x .
$$

Por outro lado, supomos que com o comprimento y do segmento dado construímos o triângulo equilátero, logo

$$
3 b=y \text {. }
$$

Portanto, do fato que $4 a=x, 3 b=y$ e $x+y=10$, obtemos:

$$
4 a+3 b=10 \Rightarrow a=\frac{10-3 b}{4} .
$$

Onde temos que a área total, que é a soma da área do quadrado mais a área do triângulo, é dada por:

$$
A=a^{2}+\frac{b^{2} \sqrt{3}}{4} .
$$

Agora como, $a=\frac{10-3 b}{4}$, temos que

$$
A=a^{2}+\frac{b^{2} \sqrt{3}}{2}=\frac{b^{2}(9+4 \sqrt{3})-60 b+100}{16} .
$$

Note que chegamos em uma equação do segundo grau cujo o gráfico tem a concavidade voltada para cima como visto no Problema 3.11. Como neste caso o $x_{v}$ vai nos fornecer um valor mínimo, precisaremos encontrar uma outra maneira de determinar o valor máximo dessa função. Então não seria necessário o cálculo da derivada de $A$, mas o faremos por curiosidade.

Da teoria, sabemos que os pontos críticos são os candidatos a serem os pontos de máximo ou mínimo, logo calculando a derivada da função área, temos:

$$
A^{\prime}(b)=\frac{2(9+4 \sqrt{3}) b-60}{16} .
$$

Como os pontos críticos, são obtidos quando a derivada é zero ou não existe, analisaremos apenas o 
que ocorre com $A^{\prime}(b)=0$, já que a derivada de $A$ sempre existe estudaremos apenas essa situação, logo

$$
A^{\prime}(b)=\frac{2(9+4 \sqrt{3}) b-60}{16}=0 \Rightarrow b=\frac{30}{9+4 \sqrt{3}} .
$$

Para confirmarmos que este é um valor de mínimo, usaremos o critério da derivada segunda. Observe que

$$
A^{\prime \prime}(b)=\frac{2(9+4 \sqrt{3})}{16}
$$

Como $A^{\prime \prime}\left(\frac{30}{9+4 \sqrt{3}}\right)>0$. Portanto este valor representa um ponto de mínimo, o que não estamos procurando.

Seguiremos a mesma linha de raciocínio da resolução do Problema 3.11. A sugestão foi analisarmos o valor da função nos extremos de seu domínio. De maneira análoga, tomando como base a equação (3.1) que está em função de $b$ podemos definir o intervalo de seu domínio como $\left[0, \frac{10}{3}\right]$. Assim, temos:

$$
A(0)=\frac{100}{16}=6,25
$$

e

$$
A(10 / 3) \cong 4,81
$$

Logo, podemos perceber que a secção que deve ser feita no fio original para a obtenção de uma área máxima deve seguir a ideia da construção apenas de uma das figuras propostas (neste caso da construção do quadrado), pois a área será máxima quando o valor de $b=0 \mathrm{~cm}$ ou seja $a=2,5 \mathrm{~cm}$.

Portanto a área máxima é dada pela área do quadrado de lado $2,5 \mathrm{~cm}$ que vale $6,25 \mathrm{~cm}^{2}$.

Um ponto interessante deste capítulo é que ele abre a possibilidade do aluno comparar duas resoluções distintas para o mesmo problema. Aquele estudante que tiver curiosidade de estudar a fundo as soluções propostas para um mesmo enunciado no Capítulo 3 e no Capítulo 5 adquire uma maturidade no assunto que poderá aguçar sua percepção e facilitar seu aprendizado de assuntos correlatos. 


\section{A Derivada na Prática}

Este último capítulo é destinado à resolução de problemas que envolvem Máximos e Mínimos e que aparentemente poderiam ser resolvido apenas com o conhecimento obtido até o Ensino Médio, mas que ao serem analisados com mais cuidado descobre-se que é necessário algo mais.

Quando nos deparamos com equações do terceiro grau, até a universidade nos limitamos ao conhecimento de no máximo identificar suas raízes, não mais que isso. Principalmente pelos pontos de máximos e mínimos não serem necessariamente simétricos com relação as suas raízes, o que nos impossibilita até de estabelecer uma relação entre eles.

Utilizamos a derivada como ferramenta para resolver os exercícios propostos a seguir, mas é importante destacar que não é única a forma de resolução. Todo o trabalho foi construído para consolidar a importância da derivada e este capítulo veio para afirmar a importância desse processo.

Problema 6.1. Uma caixa aberta deve ser feita com uma folha de papelão medindo $8 \mathrm{~cm}$ de largura por $15 \mathrm{~cm}$ de comprimento, cortando-se quadrados iguais dos 4 cantos e dobrando-se os lados. Qual é o tamanho dos quadrados cortados para a obtenção de uma caixa com o volume máximo?

Solução. Sabemos que o volume de um prisma é dado pela área da base vezes a altura, logo temos

$$
V(x)=(8-2 x) \cdot(15-2 x) \cdot x=4 x^{3}-46 x^{2}+120 x,
$$

onde aqui $x$ denota o comprimento do lado dos quadrados que foram cortados.

15

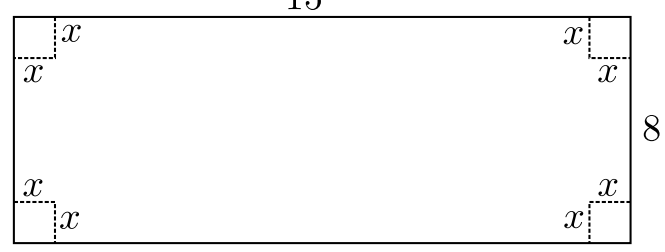

Figura 6.1: Máximos e Mínimos

Da teoria, sabemos que os pontos críticos são os candidatos a serem os pontos de máximo e/ou mínimo, 
logo calculando a derivada da função volume, temos:

$$
V^{\prime}(x)=12 x^{2}-92 x+120
$$

como os pontos críticos, são obtidos quando a derivada é zero ou não existe, analisaremos o que ocorre com $V^{\prime}(x)=0$, já que a derivada de $V$ sempre existe estudaremos apenas essa situação, logo

$$
V^{\prime}(x)=12 x^{2}-92 x+120=0 \Rightarrow x_{1}=6 \text { e } x_{2}=\frac{10}{6} .
$$

Para determinarmos quais desses valores é máximo usaremos o critério da derivada segunda, primeiramente, note que

$$
V^{\prime \prime}(x)=24 x-92 .
$$

Analisando os pontos $x_{1}=6$ e $x_{2}=\frac{10}{6}$, temos:

$$
\begin{gathered}
V^{\prime \prime}(6)=24 \cdot(6)-92=52>0 \Rightarrow x=6 \text { é um ponto de mínimo. Por outro lado temos, } \\
V^{\prime \prime}\left(\frac{10}{6}\right)=24 \cdot\left(\frac{10}{6}\right)-92=-52<0 \Rightarrow x=\frac{10}{6} \text { é um ponto de máximo. }
\end{gathered}
$$

Portanto os quadrados retirados deverão ter lados medindo $x=\frac{10}{6}$.

Problema 6.2. Um tipógrafo quer imprimir boletins com $512 \mathrm{~cm}^{2}$ de texto impresso, margens superior e inferior de $6 \mathrm{~cm}$ e margens laterais de $3 \mathrm{~cm}$ cada uma. Quais as dimensões da folha para minimizar o gasto de papel?

Solução. Notamos primeiramente que a região delimitada para a impressão é um retângulo e que na figura denotaremos por lados $x$ e $y$. Como a área desse documento é de $512 \mathrm{~cm}^{2}$, temos que

$$
A(x, y)=x \cdot y=512 \Rightarrow y=\frac{512}{x} .
$$

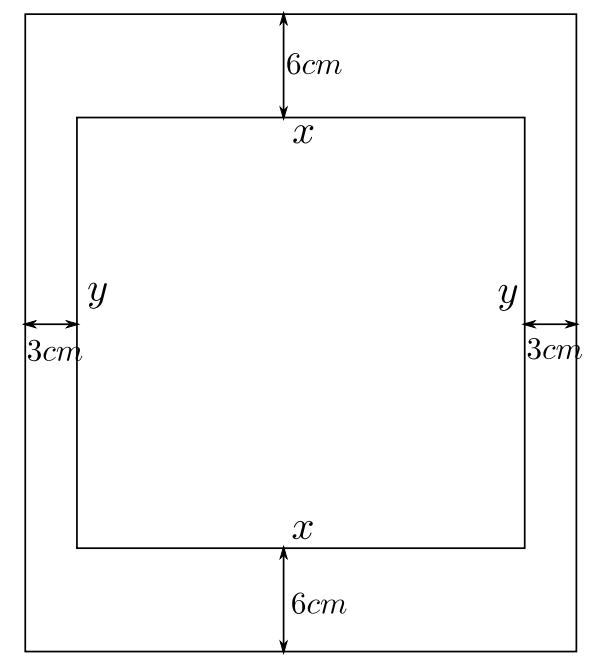

Figura 6.2: Folha 
Por outro lado a folha com margens e laterais tem área dada por:

$$
A=(y+3)(x+6)=\left(\frac{512}{x}+12\right)(x+6)=\left(\frac{512+12 x}{x}\right)(x+6)=\frac{3072}{x}+12 x+584 .
$$

Sabemos que os pontos críticos são os candidatos a serem os pontos de máximo ou mínimo, logo calculando a derivada da função área, temos:

$$
A^{\prime}(x)=\frac{-3072}{x^{2}}+12
$$

Note que $A^{\prime}(x)$ não existe quando $x=0$, contudo, esse ponto não é um ponto crítico, pois $0 \notin D(A)$. Logo, analisaremos os pontos onde $A^{\prime}(x)=0$, assim:

$$
A^{\prime}(x)=\frac{-3072}{x^{2}}+12=0 \Rightarrow 3072=12 x^{2} \Rightarrow 256=x^{2} \Rightarrow x_{1}=-16 \quad \text { e } \quad x_{2}=16 .
$$

Para determinarmos quais desses valores é máximo usaremos o critério da derivada segunda, primeiramente, note que

$$
A^{\prime \prime}(x)=\left(\frac{-3072}{x^{2}}+12\right)^{\prime}=2 \cdot(30712) \cdot x^{-3}=\frac{6144}{x^{3}} .
$$

Logo,

$$
A^{\prime \prime}(16)=\frac{6144}{16^{3}}=1,5>0 \Rightarrow x=16 \text { é um ponto de mínimo. }
$$

Portanto as dimensões da folha horizontalmente é:

$$
16 \mathrm{~cm}+3 \mathrm{~cm}+3 \mathrm{~cm}=22 \mathrm{~cm}
$$

e verticalmente, primeiramente observamos que $y=\frac{512}{x}=y=\frac{512}{16}=32$. Dessa forma, a dimensão da folha verticalmente é:

$$
32 \mathrm{~cm}+6 \mathrm{~cm}+6 \mathrm{~cm}=44 \mathrm{~cm} .
$$

Problema 6.3. Um recipiente em forma de paralelepipedo com base quadrada deve ter um volume de $2250 \mathrm{~cm}^{3}$. O material para a base e a tampa do recipiente custa $R \$ 2,00$ por $\mathrm{cm}^{2}$ e o dos lados $R \$ 3,00$ por $\mathrm{cm}^{2}$. Quais as dimensões do recipiente de menor custo?

Solução. Sabemos que o volume de um paralelepípedo é dado pela área da base vezes a altura, logo temos

$$
V(x)=x \cdot x \cdot y,
$$

e como o volume é de $2250 \mathrm{~cm}^{3}$, temos que

$$
V=x^{2} \cdot y=2250 \Rightarrow y=\frac{2250}{x^{2}} .
$$

Notamos agora que o custo do recipiente é dado por:

$$
\begin{aligned}
C(x) & =(\text { custo da base e tampa }) \cdot[2 \cdot(\text { área da base })]+\text { custo } \cdot[4 \cdot(\text { área da face lateral })] \\
& =2[2 \cdot(\text { área da base })]+3 \cdot[4 \cdot(\text { área da face lateral })] \\
& =2 \cdot 2 x^{2}+3 \cdot 4 \cdot x \cdot y \\
& =4 x^{2}+\frac{2700}{x}
\end{aligned}
$$




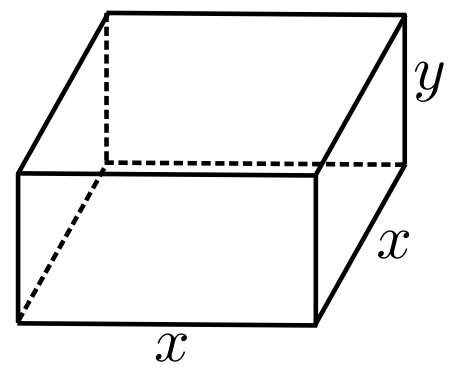

Figura 6.3: Máximos e Mínimos

Como os pontos críticos são os candidatos a serem os pontos de máximo e/ou mínimo, logo calculando a derivada da função custo, assim:

$$
C^{\prime}(x)=8 x-\frac{2700}{x^{2}} .
$$

Note que $C^{\prime}(x)$ não existe quando $x=0$, contudo, esse ponto não é um ponto crítico, pois $0 \notin D(C)$. Logo, analisaremos os pontos onde $C^{\prime}(x)=0$, assim:

$$
C^{\prime}(x)=8 x-\frac{2700}{x^{2}}=0 \Rightarrow x^{3}=\frac{2700}{8} \Rightarrow x=15 \mathrm{~cm} .
$$

Para verificarmos se esse ponto é de mínimo usaremos a derivada segunda, assim

$$
C^{\prime \prime}(x)=8+2 \cdot(2700) x^{-3}=8+\frac{5400}{x^{3}}=9,6>0 \Rightarrow x=15 \text { é mínimo. }
$$

Portanto as dimensões são:

$$
x=15 \mathrm{~cm} \quad \text { e } \quad y=\frac{2250}{x^{2}}=y=\frac{2250}{15^{2}}=10 \mathrm{~cm}
$$

Problema 6.4. Uma lata cilindrica fechada tem capacidade de 1 litro. Mostre que a lata de área mínima é obtida quando a altura do cilindro for igual ao diâmetro da base.

\section{Solução.}

Consideramos uma lada cilíndrica, denotaremos por $r$ o raio da base e por $h$ a sua altura.

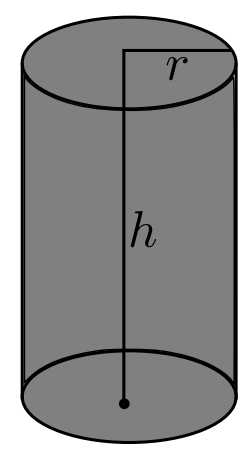

Figura 6.4: Lata 
Sabemos que o volume desse recipiente é dado por:

$$
V=(\text { área da base }) \cdot(\text { altura })=\left(\pi \cdot r^{2}\right) \cdot(h) \text {. }
$$

Agora por hipótese, temos que seu volume é igual a 1, logo temos

$$
V=\pi r^{2} h=1 \Rightarrow h=\frac{1}{\pi r^{2}} .
$$

Quando estamos querendo determinar a área notamos primeiramente que

$$
A=(\text { área lateral }) \cdot(2 \cdot(\text { área da base }))
$$

Logo,

$$
A(r)=2 \pi r h+2 \pi r^{2} \Rightarrow A=2 \pi r\left(\frac{1}{\pi r^{2}}\right)+2 \pi r^{2} \Rightarrow A=\frac{2}{r}+2 \pi r^{2} .
$$

Agora como os pontos críticos são os candidatos a serem os pontos de máximo e/ou mínimo, logo calculando a derivada da função área temos:

$$
A^{\prime}=\left(\frac{2}{r}+2 \pi r^{2}\right)^{\prime}=\left(2 \cdot r^{-1}+2 \pi r^{2}\right)^{\prime}=\frac{-2}{r^{2}}+4 \pi r
$$

Note que $A^{\prime}(r)$ não existe quando $r=0$, contudo, esse ponto não é um ponto crítico, pois $0 \notin D(A)$. Logo, analisaremos apenas os pontos onde $A^{\prime}(r)=0$, assim:

$$
A^{\prime}(r)=\frac{-2}{r^{2}}+4 \pi r=0 \Rightarrow \frac{1}{2 \pi r^{2}}=r \Rightarrow h=2 r \Rightarrow h=d .
$$

Desse modo o problema estará prova se conseguirmos mostrar que $\frac{h}{2}=r$ é mínimo. De fato, para isso usaremos o critério da derivada segunda, para garantirmos que $\frac{h}{2}=r$ é mínimo, assim

$$
A^{\prime \prime}(r)=\left(\frac{-2}{r^{2}}+4 \pi r\right)^{\prime}=\left(-2 . r^{-2}+4 \pi r\right)^{\prime}=\frac{4}{r^{3}}+4 \pi r .
$$

Logo, temos que

$$
A^{\prime \prime}\left(\frac{h}{2}\right)=\frac{4}{(h / 2)^{3}}+4 \pi\left(\frac{h}{2}\right)>0
$$

Portanto de fato, $\frac{h}{2}=r$ é mínimo, isto é, $h=2 r=d$.

Problema 6.5. Uma folha de papel para um cartaz tem $2 \mathrm{~m}^{2}$ de área. As margens no topo e na base são de $25 \mathrm{~cm}$ e nas laterais $15 \mathrm{~cm}$. Quais as dimensões da folha para que a área limitada pelas margens seja máxima?

\section{Solução.}

Para resolvermos esse problema, denotaremos por $x$ e $y$ respectivamente o comprimento das laterais da folha. Podemos pensar a princípio que a folha seja num formato retangular, logo sua área é dada por:

$$
A=x \cdot y
$$




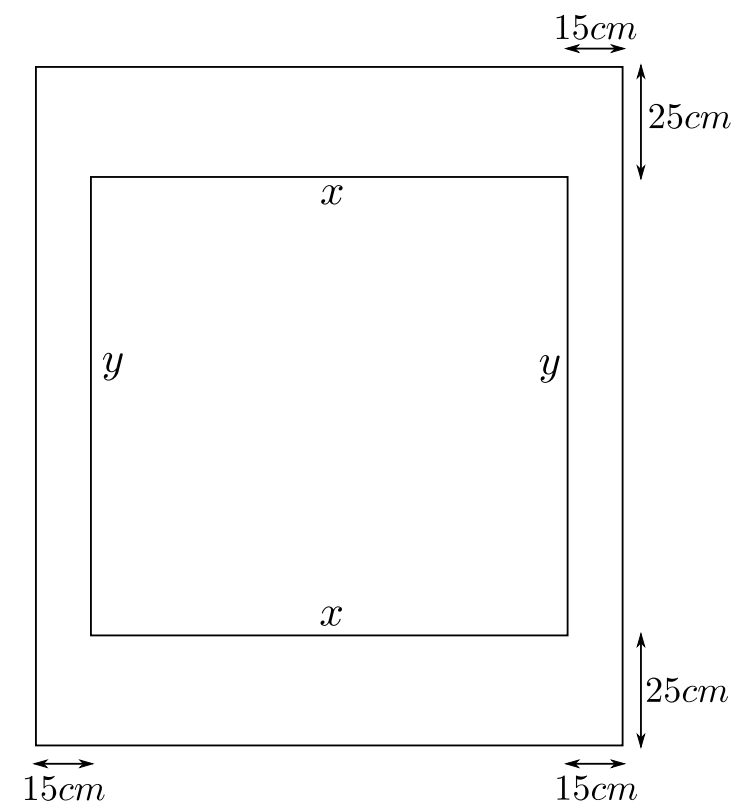

Figura 6.5: Folha

Contudo, por hipótese temos que a área é $20000 \mathrm{~cm}^{2}$, logo

$$
A=x \cdot y=20000 \Rightarrow y=\frac{20000}{x} .
$$

Por outro, a área limitada é dada por:

$$
A=(x-50)(y-30) \Rightarrow A=(x-50)\left(\frac{20000}{x}-30\right) \Rightarrow A=-30 x+21500-\frac{1000000}{x} .
$$

Sabemos que os pontos críticos são os candidatos a serem os pontos de máximo e/ou mínimo, logo calculando a derivada da função área, temos:

$$
\begin{aligned}
A^{\prime} & =\left(-30 x+21500-\frac{1000000}{x}\right)^{\prime} \\
& =-30+\frac{1000000}{x^{2}} .
\end{aligned}
$$

Note que $A^{\prime}(x)$ não existe quando $x=0$, contudo, esse ponto não é um ponto crítico, pois $0 \notin D(A)$. Logo, analisaremos os pontos onde $A^{\prime}(x)=0$, assim:

$$
A^{\prime}(x)=-30+\frac{1000000}{x^{2}}=0 \Rightarrow \frac{100000}{3}=x^{2} \Rightarrow x \simeq 182,5 \mathrm{~cm}
$$

Agora como $y=\frac{20000}{x} \Rightarrow y=\frac{20000}{183} \simeq 109 \mathrm{~cm}$.

Falta apenas verificarmos se essas dimensões são máximas, para isso usaremos o o critério da derivada segunda, assim

$$
A^{\prime \prime}(x)=\frac{-2000000}{x^{3}}
$$


$\operatorname{assim} A^{\prime \prime}(182,5)<0$, portanto, $x \simeq 182,5 \mathrm{~cm}$ é máximo.

Problema 6.6. Ache o raio e a altura de um cilindro circular reto com o maior volume, o qual pode ser inscrito em um cone reto com $10 \mathrm{~cm}$ de altura e $6 \mathrm{~cm}$ de raio.

Solução. A partir do enunciado, podemos representar geometricamente o problema, de acordo com a figura a seguir

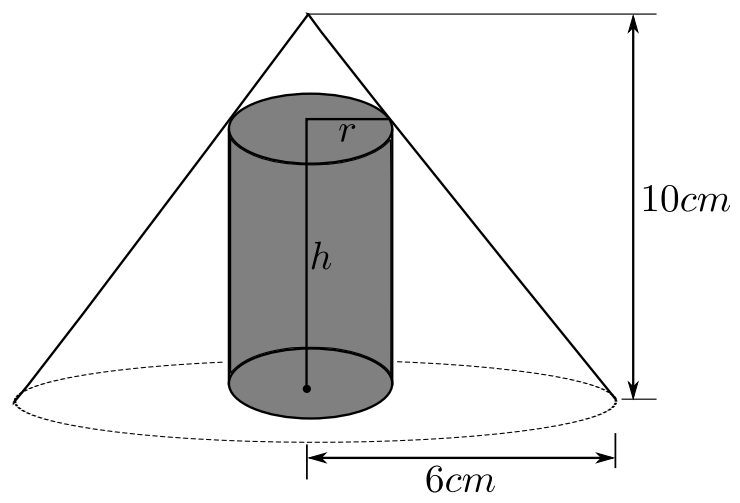

Figura 6.6: Volume

Pela figura usando semelhança de triângulos temos que

$$
\frac{10}{6}=\frac{10-h}{r} \Rightarrow 5 r=30-3 h \Rightarrow r=6-0,6 h \text {. }
$$

Por outro lado, se tratando de um cilindro circular, consideramos como $r$ o raio da base e $h$ sua altura, dessa forma o volume fica:

$$
V=\pi r^{2} h=\pi(6-0,6 h)^{2} h=0,36 h^{3} \pi-7,2 h^{2} \pi+36 h \pi .
$$

Sabemos que os pontos críticos são os candidatos a serem os pontos de máximo e/ou mínimo, logo calculando a derivada da função volume, logo temos:

$$
V^{\prime}(h)=\left(0,36 h^{3} \pi-7,2 h^{2} \pi+36 h \pi\right)^{\prime}=1,08 \pi h^{2}-14,4 h \pi+36 \pi .
$$

Analisaremos os pontos onde $V^{\prime}(h)=0$, assim:

$$
V^{\prime}(h)=1,08 \pi h^{2}-14,4 h \pi+36 \pi=0 \Rightarrow h_{1}=10 \quad \text { e } h_{2}=\frac{10}{3} .
$$

Agora para determinarmos a maior altura, usaremos o critério da derivada segunda, logo

$$
V^{\prime \prime}(h)=2,16 \pi h-14,4 \pi,
$$

assim: $V^{\prime \prime}(10)=20,16 \pi>0$ e $V^{\prime \prime}\left(\frac{10}{3}\right)=7,2-14,4=-7,2<0$. Portanto a altura máximo possível é $h=\frac{10}{3} \mathrm{~cm}$ e $\operatorname{assim} r=6-0,6 h=6-0,6 \cdot\left(\frac{10}{3}\right)=4 \mathrm{~cm}$. 
Problema 6.7. Dois terrenos retangulares, com dimensões $x$ e y e um lado comum $x$, como mostra a figura, devem ser murados. Cada terreno tem uma área de $400 \mathrm{~m}^{2}$. Determinar as dimensões de cada terreno para que o comprimento do muro seja o menor possível.

\section{Solução.}

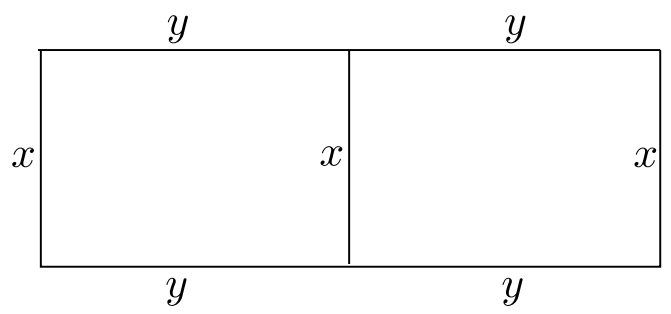

Figura 6.7: Terreno

Como os terrenos são retangulares de lados $x$ e $y$ temos que sua área é dada por:

$$
A=x \cdot y=400 \Rightarrow y=\frac{400}{x} \text {. }
$$

E o comprimento é dado por:

$$
C=4 y+3 x \Rightarrow C=4 \cdot\left(\frac{400}{x}\right)+3 x \Rightarrow C=\frac{1600}{x}+3 x .
$$

Sabemos que os pontos críticos são os candidatos a serem os pontos de máximo e/ou mínimo, logo calculando a derivada da função comprimento, logo temos:

$$
C^{\prime}(x)=\left(\frac{1600}{x}+3 x\right)^{\prime}=-\frac{1600}{x^{2}}+3
$$

Note que $C^{\prime}(x)$ não existe quando $x=0$, contudo, esse ponto não é um ponto crítico, pois $0 \notin D(C)$. Logo, analisaremos os pontos onde $C^{\prime}(x)=0$, assim:

$$
C^{\prime}(x)=-\frac{1600}{x^{2}}+3=0 \Rightarrow \frac{1600}{3}=x^{2} \Rightarrow x=\frac{40 \sqrt{3}}{3} .
$$

Agora como $y=\frac{400}{x}$, então $y=\frac{400}{(40 \sqrt{3}) / 3}=10 \sqrt{3}$.

Contudo, falta apenas comprovarmos que esses valores são de mínimo, para isso, usaremos o critério da derivada segunda

$$
C^{\prime \prime}(x)=\frac{3200}{x^{3}}
$$

$\log _{0} C^{\prime \prime}\left(\frac{40 \sqrt{3}}{3}\right)=\frac{3200}{((40 \sqrt{3}) / 3)^{3}}>0$.

Portanto $x=\frac{40 \sqrt{3}}{3}$ é mínimo. 
Problema 6.8. Certa fábrica produz embalagens retangulares de papelão. Um de seus compradores exige que as caixas tenham $1 \mathrm{~m}$ de comprimento e volume de $2 \mathrm{~m}^{3}$. Quais as dimensões de cada caixa para que o fabricante use a menor quantidade de papelão?

\section{Solução.}

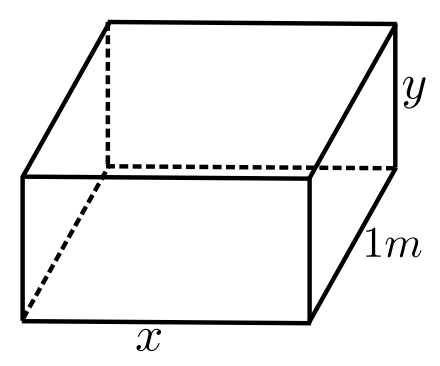

Figura 6.8: Embalagem

Como na figura, temos uma caixa que é um paralelepípedo, cuja dimensões denotaremos por $x, y$ e $1 m$, logo seu volume é dado por:

$$
V=x \cdot y \cdot 1
$$

por hipótese temos que o volume é igual a $2 m^{3}$, logo temos:

$$
V=x \cdot y \cdot 1=2 \Rightarrow y=\frac{2}{x} .
$$

Agora, como as faces são retângulos a área da embalagem fica:

$$
A=2 x \cdot y+2 x+2 y=2 x\left(\frac{2}{x}\right)+2 x+2 \cdot\left(\frac{2}{x}\right)=4+2 x+\frac{4}{x} .
$$

Sabemos que os pontos críticos são os candidatos a serem os pontos de máximo ou mínimo, logo calculando a derivada da função área, temos:

$$
A^{\prime}(x)=2-\frac{4}{x^{2}}
$$

Note que $A^{\prime}(x)$ não existe quando $x=0$.

Contudo, esse ponto não é ponto crítico, pois $0 \notin D(A)$. Logo, analisaremos apenas os pontos onde $A^{\prime}(x)=0$, assim:

$$
A^{\prime}(x)=2-\frac{4}{x^{2}}=0 \Rightarrow 2=\frac{4}{x^{2}} \quad x=\sqrt{2} .
$$

E como $y=\frac{2}{x} \Rightarrow y=\sqrt{2}$. Agora para verificarmos se esses valores são de mínimo, usaremos o critério da derivada segunda, logo:

$$
A^{\prime \prime}(x)=\frac{8}{x^{3}}
$$

Logo, $A^{\prime \prime}(\sqrt{2})=\frac{8}{(\sqrt{2})^{3}}>0$.

Portanto $x=\sqrt{2}$ e $y=\sqrt{2}$ são as dimensões mínimas. 
Problema 6.9. Uma fábrica produz $x$ milhares de unidades mensais de um determinado artigo. Se o custo da produção é dado por $C(x)=2 x^{3}+6 x^{2}+18 x+60$, e o valor obtido na venda é dado por $V(x)=$ $60 x-12 x^{2}$, determinar o número ótimo de unidades mensais que maximiza o lucro $L(x)=V(x)-C(x)$.

Solução. Sabemos que a função lucro é dada pela diferença da venda pelo custo, logo

$$
\text { Lucro }=\text { Venda }- \text { Custo, }
$$

assim:

$$
L(x)=60 x-12 x^{2}-\left(2 x^{3}+6 x^{2}+18 x+60\right)=-2 x^{3}-18 x^{2}+42 x-60 .
$$

Da teoria, sabemos que os pontos críticos são os candidatos a serem os pontos de máximo e/ou mínimo, logo calculando a derivada da função lucro, temos:

$$
L^{\prime}(x)=-6 x^{2}-36 x+42 .
$$

Analisaremos agora o que ocorre com $L^{\prime}(x)=0$, já que a derivada de $L$ sempre existe estudaremos apenas essa situação, logo

$$
L^{\prime}(x)=-6 x^{2}-36 x+42=0 \Rightarrow x_{0}=-7 \text { e } x_{1}=1
$$

como o valor de $x$ representa unidades em milhares, não faz sentido analisarmos o valor $x_{0}=-7$, deste modo, vamos verificar se $x_{1}=1$, para comprovarmos que as mil unidades geram um lucro máximo, usaremos o critério da derivada segunda, logo

$$
L^{\prime \prime}(x)=-12 x-36 \Rightarrow L^{\prime \prime}(1)=-48<0 .
$$

Portando, $x=1$ milhar representa a quantidade de unidades que geram o lucro máximo.

Problema 6.10. Suponha que o número de bactérias em uma cultura no instante $t$ é dada por $N(t)=$ $5000\left(25+t e^{-t / 20}\right)$. Ache o maior número de bactérias durante o intervalo de tempo $0 \leq t \leq 100$.

Solução. Temos que o número de bactérias é dado por

$$
N(t)=5000\left(25+t e^{-t / 20}\right)=125000+\frac{5000 t}{e^{t / 20}} .
$$

Sabemos que os pontos críticos são os candidatos a serem os pontos de máximo e/ou mínimo, logo calculando a derivada da função números de bactérias, temos:

$$
N^{\prime}(t)=\frac{5000\left(e^{t / 20}-t \cdot e^{t / 20} \cdot \frac{1}{20}\right)}{e^{t / 10}} .
$$

Analisaremos agora o que ocorre com $N^{\prime}(x)=0$, já que a derivada de $N$ sempre existe estudaremos apenas essa situação, logo

$$
N^{\prime}(t)=\frac{5000\left(e^{t / 20}-t \cdot e^{t / 20} \cdot \frac{1}{20}\right)}{e^{t / 10}}=0 \Rightarrow e^{t / 20}=\frac{t e^{t / 20}}{20} \Rightarrow t=20 .
$$

Como $N^{\prime \prime}(20)<0$, temos que em $t=20$ a população é máxima. 
Portanto o maior número de bactérias é no instante $t=20$. Logo o número máximo de bactérias é dada por $N(20)=161.787$ bactérias.

Problema 6.11. Uma centena de animais pertencendo a uma espécie em perigo estão colocados numa reserva de proteção. Depois de $t$ anos a população $p$ desses animais na reserva é dada por $p=100 \frac{t^{2}+5 t+25}{t^{2}+25}$. Após quanto tempo a população é máxima?

Solução. Temos que a população $p$ é dada por

$$
p(t)=100 \frac{t^{2}+5 t+25}{t^{2}+25} .
$$

Sabemos que os pontos críticos são os candidatos a serem os pontos de máximo e/ou mínimo, logo calculando a derivada da função números de bactérias, temos:

$$
p^{\prime}(t)=100\left(\frac{(2 t+5)\left(t^{2}+25\right)-\left(t^{2}+5 t+25\right)(2 t)}{t^{4}+50 t^{2}+625}\right) .
$$

Notamos que o denominador a expressão acima é sempre positivo, logo analisaremos apenas o que ocorre com $p^{\prime}(t)=0$, já que a derivada de $p$ sempre existe estudaremos apenas essa situação, assim

$$
p^{\prime}(t)=100\left(\frac{(2 t+5)\left(t^{2}+25\right)-\left(t^{2}+5 t+25\right)(2 t)}{t^{4}+50 t^{2}+625}\right)=0 \Rightarrow 5 t^{2}-125=0 \Rightarrow t_{0}=-5 \text { e } t_{1}=5 .
$$

Como o valor de $t$ representa anos não faz sentindo valores negativos, logo temos verificar se $t=5$ representa a população máxima, para isso, usaremos o critério da derivada segunda, logo

$$
p^{\prime \prime}(t)=\frac{100 t\left(t^{2}-75\right)}{\left(t^{2}+25\right)^{3}} .
$$

Como $p^{\prime \prime}(5)<0$, temos que em $t=5$ a população é máxima. 


\section{Considerações Finais}

No decorrer do trabalho foram desenvolvidos conceitos, exemplos e aplicações com o objetivo de facilitar tanto o entendimento daqueles que forem estudar o assunto abordado aqui quanto atrai-los para uma visão prática da utilização da derivada. É comum a indagação dos alunos sobre a aplicação dos conteúdos estudados, e é gratificante perceber que uma das aplicações da derivada foi bem trabalhada e reforçada durante esta dissertação.

O assunto de máximos e mínimos tem uma apresentação recorrente na vida dos nossos alunos. Ele se apresenta não só em anos diferentes desde o Ensino Fundamental até o Ensino Superior, mas também em disciplinas diferentes como na Matemática, Física, Química e Economia, por exemplo. As aplicações aqui trazidas tornaram atrativo esse estudo, atingindo um dos principais objetivos desta obra. Por ser um conteúdo recorrente e de currículo obrigatório, que possa ser agradável.

A comparação das resoluções dos mesmos exercícios nos permite perceber que a derivada é uma ferramenta flexível e que nos permitiria aprofundar em outros conteúdos se fosse ensinada mais cedo na vida acadêmica dos nossos estudantes. Por outro lado, exige uma maturidade nem sempre encontrada em alunos mais novos. Isso é percebido quando esse assunto comumente é visto pela primeira vez no início de alguns cursos no Ensino Superior.

Então é importante deixar claro que o nosso principal foco neste trabalho não é a implementação de uma teoria no ensino médio ou a classificação de um método como mais fácil ou eficiente que outro, mas a nossa preocupação é sim com nosso aluno. A ideia de facilitar seu estudo ou o entendimento de um conteúdo tão importante para alguns cursos do ensino superior foi a principal motivação para o estudo deste tema.

Quando o aluno tem a possibilidade de escolha, ele toma suas decisões com mais consciência e utiliza o método que mais prefere, tendo também ciência de que cada um deles permite a resolução de situações diferentes. Agora a escolha fica a critério de cada um.

Pode-se notar que, apesar da derivada ser muito útil até mesmo para resolver exercícios do ensino básico, ela precisa de um embasamento teórico e de uma maturidade construída no decorrer dos anos. Espera-se que esse trabalho possa ter ajudado alguns estudantes a entender melhor esse artifício e magnífico e a aplicá-lo com mais facilidade nos exercícios ou em eventuais problemas encontrados em suas vidas profissionais. 


\section{Referências Bibliográficas}

[1] H. Anton, I. Bivens e S. Davis, Cálculo., Bookman, 8. ed. (2007), Porto Alegre.

[2] E. Swokowski, Cálculo com Geometria Analítica., Makron Books, Vol. 1, 2ª Edição, São Paulo.

[3] http://www.oblogdomestre.com.br/2013/01/como-calcular-e-demonstrar-as.html (visto em $09 / 02 / 2015)$.

[4] http://ecalculo.if.usp.br/funcoes/flilimitada/flimitada.htm (visto em 09/02/2015).

[5] http://www.im.ufrj.br/dmm/projeto/projetoc/precalculo/sala/conteudo/capitulos/cap61s2.html (visto em $09 / 02 / 2015$ ).

[6] http://miltonborba.org/Calculo_I/exercicios_Max-Min.pdf (visto em 09/02/2015).

[7] https://www.youtube.com/watch? $v=C Q x b 5 Z X e Y 3 E$ (visto em 09/02/2015).

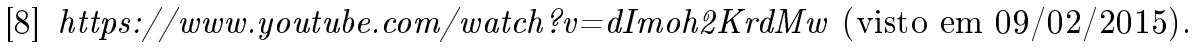

[9] http://portal.mec.gov.br/seb/arquivos/pdf/EnsMed/expensmat-icap2.pdf (visto em 07/04/2015).

[10] http://pnld.moderna.com.br/2012/03/28/a-falsa-formula-de-bhaskara/ (visto em 07/04/2015). 